\title{
Globalization and Self-Organization in the Knowledge-Based Society
}

\author{
Christian Fuchs
}

Institute for Design and Technology Assessment, Vienna University of Technology

Favoritenstr.9-11, 1040 Vienna, Austria; christian@igw.tuwien.ac.at

\begin{abstract}
In this paper I suggest that a theory of selforganization can be used as a consistent background theory for explaining the dynamics and logics of globalization. Globalization is not confined to the human realm, it is an attribute of all complex, self-organizing systems. Globalization in a synchronous sense means a micro-macro-link where bottom-up-emergence of new qualities in the self-reproduction of complex systems takes place, it is accompanied by a macromicro-link of top-down-localization. A dynamic interaction between a global and a local level (glocalization) results in the permanent overall self-reproduction of the system. Globalization in a diachronic sense means the emergence of a new, higher level of self-organization during a phase of instability and heavy fluctuations by order through fluctuation. Globalization is shaped by a dialectic of change and continuity: in the hierarchy that stems from emergent evolution there are both general aspects of globalization and aspects that are specific for each organizational level. Applying this general notion of globalization to society means that human globalization is both a general process that can be found in all societies and a specific process with emergent qualities in concrete phases of societal development. Globalization processes in modern society are based on structural antagonisms that result in uneven developments in the technosphere, the ecosphere, the
\end{abstract}

economy, polity, and culture. The transition to Postfordist, informational capitalism has been a consequence of the development of the structural antagonisms of Fordism and has been accompanied by a new phase of globalization that has transformed the subsystems of society and has resulted in new antagonism that are an expression of general antagonisms that shape modern societies. Hence we find antagonistic tendencies of contemporary globalization in all subsystems of society that result in both risks and opportunities. Human beings have the ability to actively shape society in such a way that an alternative sustainable form of globalization can be achieved.

Keywords: globalization, self-organization, society, knowledgebased society, informational capitalism, antagonism

Acknowledgement: This paper is based on research done within the framework of the project 'Human Strategies in Complexity: Philosophical Foundations for a Theory of Evolutionary Systems' (http://www.self-organization.org) funded by INTAS (\#0298) and supported by the Austrian Federal Ministry of Education, Science and Culture.

\section{Introduction ${ }^{1}$}

In this paper I argue that globalization is an attribute of all complex, self-organizing systems and I point out major aspects of the globalization of the knowledge-based society. First, I will give an introduction to important methodological, epistemological, and ontological questions concerning theorizing globalization (section 2). I especially will consider existing literature that deals with the relationship of globalization and self-organization and will show that it doesn't treat the topic in a sufficiently consistent and well-grounded manner. I will then consider the relationship of self-organization and globalization in more abstract terms

${ }^{1}$ This paper is a theoretical expansion of ideas first developed together with Wolfgang Hofkirchner in a series of papers: Fuchs/Hofkirchner (2001, 2002a, 2002b). 
that apply for all complex systems in nature and society (section 3). Hence I will suggest that globalization is a process that doesn't only take place in society, but also in nature. Based on this foundation it will be possible to describe the globalization of society in terms that apply to all forms of society (section 4). This will involve both a synchronous and a diachronic form of globalization. For considering globalization as an attribute of social self-organization, some foundations of a theory of social self-organization will be pointed out. The next step will be a discussion of globalization in modern, capitalist society (section 5 ). For doing so, general several antagonisms of modernity will be outlined. Based on these assumptions, the antagonistic relationship of globalization and knowledge-based society will be explained (section 6). I will end with a conclusion about agency in the global society (section 7).

The structure of the sections 5 and 6 is based on assumptions about the structure of society. Society is made up by several interconnected, but relatively autonomous self-organizing subsystems (Fuchs 2002c, Fuchs/Hofkirchner/Klauninger 2002). The basic systems are the technosphere, the ecosphere, and the sociosphere. In the technosphere the human being makes use of tools as a means for achieving defined goals by transforming nature. In the ecosphere the human being transforms nature in order to organize natural resources in such a way that it can utilize these resources for its needs and goals. In the sociosphere the human being enters social relationships in order to make sense of the world, to give meaning to actions and existence, and to form individual and collective identities. The three realms - the technological, the ecological, and the social - are interconnected in the sense that in each situation in a social system human beings make use of tools, change their environment, and enter social relationships. The sociosphere can be further subdivided into three subsystems: the economy, polity, and culture (fig. 1). In the economic system the human beings make use of tools and natural resources in order to produce, distribute, allocate, and consume use-values that satisfy human needs. In the political system the human beings establish power structures in order to achieve collective decisions. In the cultural system the human being produces a set of norms and values that define living conditions and life-styles. Hence society consists of five interconnected self-organizing subsystems/levels: the ecological, the technological, the economic, the political, and the cultural realm.

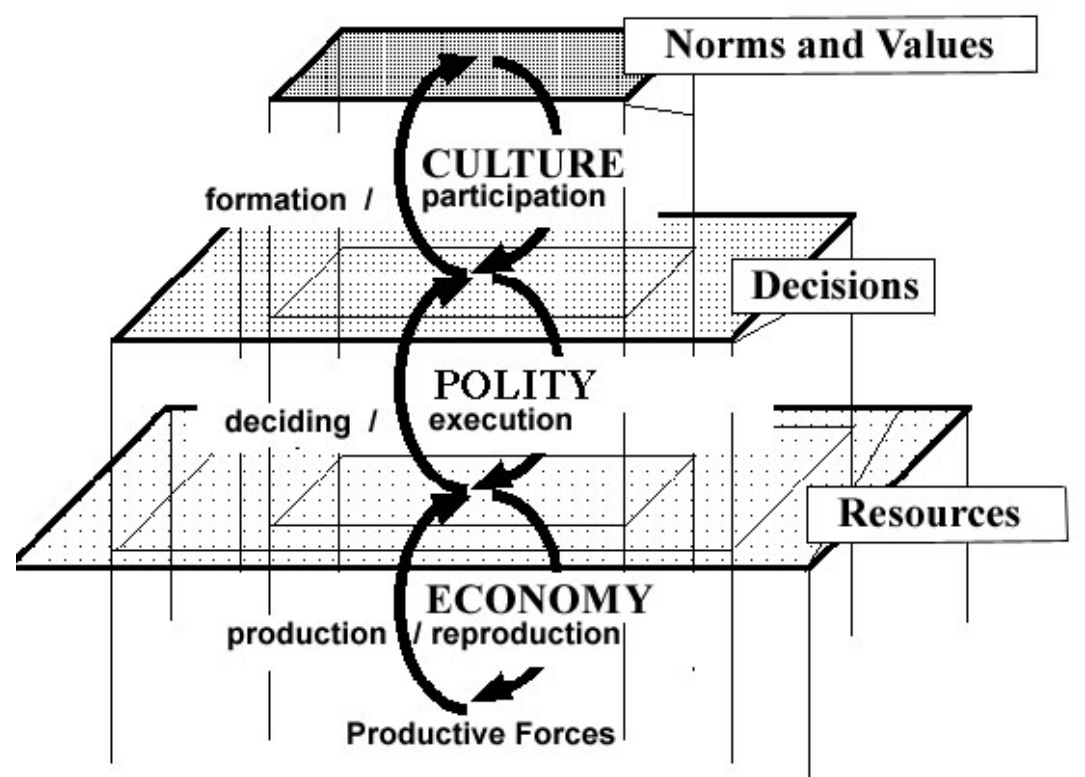

Figure 1: The self-organization of the three interconnected subsystems of the sociosphere

The structure of section 5 and section 6 is based on the distinction of these five dimensions of society. In section 5 I will discuss the globalization of each dimension in modern society, in section 6 I will discuss the globalization of each dimension in the knowledge-based society. If one takes a closer look at the structure of this paper, one will see that methodologically I ascend from the abstract to the concrete, I will start with a general systemic description of globalization in self-organizing systems, and will end with a model of the globalization of the knowledge-based society. 
Concerning the interconnections of different realms of society, Susantha Goonatilake $(1997,1998$, 2002) argues that the "three lineages of information - the genetic, the cultural and the artefactual - will increasingly merge their constituent information contents through advances in biotechnology and information technology" (ibid.: 715). He argues that historically first the genetic lineage, then the cultural, and finally the artefactual lineage, the latter in the form of computers, have emerged. I think that the three realms have been connected since the beginning of society because in each society we find the natural environment, human beings, and tools. The physical or natural information space is the oldest one, the living one has been produced as a result of the self-organization of matter, the social realm has been one result of the self-organization of living matter. Hence the historical sequence is physical, biological, social systems, the latter consists of human beings entering communicative relationships and in these relationships making use of tools in order to consciously and purposefully produce use values and change nature in a way that satisfies human needs. But Goonatilake is right in stressing that in the knowledgebased society, the genetic, the social, and the technological realm and their informational content increasingly merge as can be seen in the case of genetic engineering, the Humane Genome project, cyberspace, Virtual Reality. The interconnection and merging of all three realms as a dynamic unity indeed is a major dynamical force of globalization and hence a "future sociology must incorporate dynamics of all three realms" (Goonatilake 1997: 724).

\section{Epistemological and Ontological Aspects of Theorizing Globalization}

There is much talk about globalization in the public, the media, and politics. For some globalization seems to be the ultimate remedy for the global problems we are facing today, for others it is a catchword for describing a phase of increased capitalistic exploitation. Globalization is a polarizing subject-matter, we find both radical optimists and radical pessimists in this discourse. The radical optimists argue that globalization is a new form of societal development that can only guarantee general wealth when the state retreats from social policy, the radical pessimists use the term globalization as a synonym for capitalism and argue that globalization should be reverted. Both positions are one-sided and don't take the complexity of the emergence of a global information society into account. Globalization discourse is symptomatic for the increased complexity of society, the emergence of new discourses is characteristic for phases of rapid social change.

There is a lack of understanding of what globalization actually is, whether it is something new or something old, how its dynamics unfold, whether there is just one form or there are different alternative forms of globalization, and what its causal relationships are. A general theory of globalization seems to be necessary in order to answer these questions. This paper tries to introduce some foundations for such a theory and suggests that a general theory of globalization shall be based on a general theory of selforganization.

One important methodological issue about globalization concerns change and continuity. The hyperglobalizers argue that globalization is a radical novel phenomenon and that the emerging global society marks a discontinuous and radical break with prior forms of society. E.g. Martin Shaw (1999b) says that globality is a revolutionary transformation that is centred on fundamental political transformations, global changes would be fundamental, wide-ranging and deep-seated. Kenichi Ohmae (1995) argues that "what we are witnessing is the cumulative effect of fundamental changes in the currents of economic activity around the globe", this would result in a decline and end of the nation state. Such approaches don't take into account that there are old phenomena of societal globalization such as world religions, empires such as the Roman or the British one or the empire of Han China; the world market, large population movements such as during slavery; colonialism, or the system of submarine 
cables established in the middle of the $19^{\text {th }}$ century that formed the first global system of communication'. Sceptics argue that globalization is a myth, that there are no fundamental novel qualities of society and that there is a continuity of an old social system. The sceptics say e.g. that what is called globalization today is just "a more extensive version of a much longer historical process" (Nicholson 1999: 31), a continuous historical expansion. The most well know globalization sceptics are Paul Hirst and Graham Thompson (1999). They argue that globalization is a myth because transnational companies would be rare, most would be based nationally and would trade multinationally; foreign direct investment (FDI) would be highly concentrated among the advanced industrial economies, the Third World would remain marginal both in investment and trade; trade, investment and financial flows wouldn't be global, but concentrated in the Triad of Europe, Japan and North America.

Globalization is not an even process that affects and benefits all regions and groups to the same extent, it is highly uneven and segmented. Globalization "implies neither homogenisation nor equity" (Keohane/Nye 2000: 76). One of my main arguments in this paper is that globalization is indeed a tendency that can be found in all social systems and that hence it is nothing completely new, however we are today witnessing a new phase of globalization that results in new qualities of social systems. In order to speak of the existence of contemporary globalization, it is not necessary that all regions and groups are included or benefit from the current developments, the decisive factor is that their social situation and their lives are affected by these developments. The emergence of transnationalism e.g. doesn't mean that all large companies are transformed into transnational corporations (TNCs), but that a new quality, a new tendency of capital accumulation is added that transforms the old situation. Besides TNCs there exist e.g. in the retail market "mainly regional MNEs [multinational enterprises] and their focus is local, home-triad market-oriented" (Rugman/Girod 2003: 24). However, this doesn't imply that transnationalism as a new form of economic globalization is a myth ${ }^{3}$, it only shows that new tendencies don't completely eliminate old ones.

Events in one part of the world today frequently shape social relationships in another far remote part of the world, there is a global scope of interdependence of social relationships. Today we find a massive increase of extensity, intensity, speed, and impacts of flows of resources, capital, commodities, information, technologies, people, lifestyles, and values, this quantitative increase has resulted in new qualities of societal development such as: global neoliberalism, a real-time interactive communication system that changes all areas of social life, a flexible regime of accumulation based on lean production and outsourcing, participatory management, strategic alliances and innovation networks, the network enterprise, competition states, the emergence of global governance that is based on complex relationships of nation states and private political actors such as NGOs and TNCs, the triadization of world trade and capital export, global mass media (such as the Internet and CNN), a new dimension of international conflicts (9/11, the two wars against Iraq, the "war against terror", ethnic postcolonial and post-Soviet conflicts such as in Rwanda and former Yugoslavia, global problems that threaten the further existence of humankind, the shift from industrial society to global informational capitalism (i.e. the phenomenon and the important consequences of global flows of information) and along with it a bunch of new issues such as e-government, e-learning, electronic surveillance, etc. Hirst and Thompson consider (the non-existence of) globalization in quantitative terms, however it is not so relevant to compare the current phase of social development quantitatively with the phase of imperialistic development at the end of the $19^{\text {th }}$ and the beginning of the $20^{\text {th }}$ century, it is rather decisive to compare the new Postfordist mode of capitalistic development with the post-war Fordist mode. If one does so, one will indeed find important quantitative changes that have resulted in new qualities of society. There is indeed a tendency to conceive globalization only in quantitative terms, e.g. Robert O. Keohane and Josep S. Nye Jr. (2000) argue in line

\footnotetext{
${ }^{2}$ In 1864 a submarine cable was laid between Karachi and the Persian Gulf, in 1866 the first transatlantic submarine cable was laid (it ran from Ireland to Newfoundland).

${ }^{3}$ In e.g. the car industry, the electronics industry, or the textiles and clothing industries indeed a great deal of transnational production can be found.
} 
with Held et al. (1999) that contemporary globalization is characterised by a larger thickness, i.e. intensity and extensity of interdependence ${ }^{4}$ : there are more flows that affect the lives more people to a larger extent. I argue that an equally important aspect is how these lives have been changed qualitatively. Hirst and Thompson (1999) say e.g. that "the startling feature is that trade to GDP ratios were consistently higher in 1913 than they were in 1973 (with the slight exception of Germany where they were near enough equal)" and that the expansion of the volume of world trade has since the 1970ies not been larger than in the period from 1870-1913. I will show later in this paper statistically that both world trade and capital export have in Postfordism increased in comparison to the Fordist era, that capital export mainly originates from OECD countries, that in the last decades Latin America and Asia have gained importance as targets of FDI, that the majority of imports and exports take place in North America and Europe, and that Asia has played an increasing important role in world trade during the last 50 years (due to Japan and the Southeast Asian countries), whereas Latin America and Africa have increasingly become more unimportant in world trade. These are both important quantitative and qualitative changes.

Another main problem besides the emphasis on long-term quantitative changes in Hirst and Thompson's approach is that they consider globalization reductionistically as merely an economic process. I am arguing that a third kind of globalization theory is needed that considers a dialectic of change and continuity: there are general long-term patterns and tendencies of globalization that can be found in society (and indeed as I will argue in all self-organizing systems), but there are also qualities of globalization that are characteristic only for certain phases of systemic development. So globalization can be pictured as the unity of many long-term and short-term uneven processes that results in a step-like hierarchical emergent evolution where there are general patterns of globalization and localization as well as emergent qualities of globalization that arise as new order through fluctuation in phases of instability and constitute a new level and phase of development that has both novel qualities and is a continuation of older tendencies. One can say that globalization processes sublate ("aufheben") themselves, develop in an uneven and asynchronous way and at each moment show both patterns of change and continuity.

The problem of globalization theory is that frequently one can find in it an "inversion of explanans and explanandum" (Rosenberg 2000), globalization is not considered as the explanandum that must be clarified within the framework of a more general theory, but it is seen as something that explains the world and the latter's changes. Many globalization theories are "not terribly interested in discovering abstract principles of the observed realities" (Friedman 2000: 640). In order to avoid this mistake, I suggest that globalization is an attribute of self-organizing systems and that a theory of self-organization can serve as an adequate background theory for explaining globalization.

Explaining globalization is necessary for a foundation of a new worldview that allows the solution of the global problems. Wolfgang Hofkirchner (1994) argues that there are global problems that affect the whole humankind as an object and can only be solved by the whole humankind as subject. A new world order that can solve these planetary problems would need a new world picture as a foundation. Theories of selforganization would be suited for such a foundation because development would be their central aspect and a further step in development would be needed for solving the global problems. This further step would have to be an act of free self-determination of humankind and the creation of a noosphere where there is participation and awareness of all and the human being can develop into a homo creator in a creative universe.

The theory of self-organization has lead to a change of scientific paradigms: from the Newtonian paradigm to the approaches of complexity. There is a shift from predictability to non-predictability, from

\footnotetext{
4 "Globalism is a state of the world involving networks of interdependece at multi-continental distances. [...] Globalization is the process by which globalizm becomes increasingly thick. [...] Thickness means that different relationships of interdependence intersect more deeply at more points" (Keohane/Nye 2000: 75+77+79).
} 
order and stability to instability, chaos and dynamics; from certainty and determination to risk, ambiguity and uncertainty; from the control and steering to the self-organization of systems, from linearity to complexity and multidimensional causality; from reductionism to emergentism, from being to becoming and from fragmentation to interdisciplinarity. Self-organization theories seem to be particularly suited as a methodological foundation for a general theory of globalization because they have a strong emphasis on complexity, non-linearity, multidimensionality, ambiguity, and uncertainty, and societal globalization is inherently coupled with increased complexity and risks.

There are on the one hand theories of globalization that explain the phenomenon in a reductionistic way and argue that one subsystem of society and its logic cause the increased globalization of overall society. An economistic version of globalization-reductionism can be found in world systems theory, a politicistic version in the theory of international relations, a culturalistic version in cultural studies. On the other hand there a multidimensional analyses that argue that there is a plurality of forces and logics of globalization. Two prominent representatives of such theories are Ulrich Beck and Anthony Giddens. Beck (1997) sees globalization as the transnational networking of actors, there would be an economic, an ecological, a cultural, a political, and a civil dimension of globalization. Giddens (1990) argues that globalization is the central aspect of modernisation and that there are four aspect of globalization: the capitalist world economy, a worldwide system of nation states, the world military order, and the international division of labour. Such approaches are right in stressing multiple dimensions and the complexity of globalization, but frequently they result in relativistic multifactor analyses that can't show how the dimensions of globalization are interconnected, violate the philosophically theorem of foundation, can't adequately ground their theories, and are rather dualistic. Such multifactor analyses argue against reductionism and linearity that globalization is a "multi-dimensional process" (Khondker 2000: 17), a "differentiated and multifaceted process" (Held/McGrew/Goldblatt/Perraton 1999: 27), or that there is a pluralistic global field (Robertson 1992). Göran Therborn (2001) proposes a multidimensional and multifaceted theory of globalization and argues that there are four dimensions of globalization, an economic, a socio-political, a cultural, and an ecological one. Each one "tends to be driven by a dynamic of its own with little or no sideglances at the others" (Therborn 2001: 449). Due to the "multidimensionality of globalization" he suggests that one should better speak of globalizations than of globalization. Globalization doesn't mean the globalization of autonomous functionally differentiated systems that have an increasingly worldwide character, it means an increasing networked and interrelated character of social systems in such a way that they have overlapping logics and closely influence each other over spatial and temporal distances. There must be a common ground of different logics of globalization, I suggest that all complex systems require a permanent interaction between a more local and a more global level for their reproduction and that such systems from time to time enter discontinuous phases where heavy fluctuations result in the emergence of new, higher order, i.e. new, more global system-types. In this respect evolution from the smallest particles to the most complex societies can be considered as emergent evolution that involves the stretching of a systemic hierarchy and the globalization of organizational levels. I suggest that in society globalization is a process that is due to the self-conscious agency of human actors that has intended and unintended consequences and that at certain points requires the creation of more global levels in order to solve existing problems. Historically society has acquired an ever more global character, but especially in modern society the speed, intensity and extensity of globalization is massively increasing. Globalization is a general process in self-organizing systems, in human systems it can be consciously designed, although it has not only expected, but also unexpected results. Hence globalization is also a general process of humankind, but there are different forms of globalization. It is not possible to revert globalization, but to revert certain forms of globalization that don't fulfil humane goals and to find alternative forms of societal globalization. In the broad sense of the emergence of higher levels, globalization can be found in all complex systems, there are both general and specific aspects of globalization, i.e. in each system type there is besides a general logic also a specific logic of globalization. Hence in society all subsystems are shaped by general aspects of human globalization, but each subsystem also has its own relative autonomous logic of globalization. For explaining globalization 
consistently, it is insufficient to argue either in a reductionistic or a relativistic manner, a dialectic of generality and specificity should be applied. Within a general theory of self-organization, the notion of emergent evolution can be applied in such a way that globalization can be conceived as both a general and a specific process with general as well as emergent, system-specific qualities. In short I am arguing that it is wrong to say that theories of globalization are either "monocausal" or "multicausal" (Held/McGrew/Goldblatt/Perraton 1999: 12) because there are many different uneven tendencies of globalization caused by different forces, but this difference does have a common ground. A dialectical theory of globalization tries to resolve this dichotomy.

Although globalization is a complex and multidimensional phenomenon, it can be the case that one subsystem of a global system is more influential than others and has a dominant position in the system. In the global information society, the economy has such a dominant character, the structural coupling between the economy and other subsystems of global society has an increasingly dense character, i.e. economic logic permeates other subsystems to an increasing extent (Fuchs 2003b). This doesn't mean that the economy is a determining system, but that it is a dominant system (ibid.). Reductionist and relativistic analyses can't take consistently into account the emergence of such a dominant logic. Hence Beck's argument that Wallerstein's theory of globalization is "monocausal and economic" (Beck 1997: 66) and Giddens' argument that Wallerstein "continues to see only one dominant institutional nexus (capitalism) as responsible for modern transformations" (Giddens 1990: 69) don't take into account that a certain subsystem of society can indeed acquire a dominant, but not determinant position and that such uneven relationships can nonetheless be explained within a theory that accounts for the multidimensionality and complexity of globalization as well as for the relative autonomy of social systems.

I agree with many Marxist analyses of globalization that the economy is a particularly important system involved in globalization that deserves special attention, that what is called globalization today results in increased polarization and fragility of society, that one must challenge "there is no alternative"-positions on globalization that argue that people can't do anything about the global problems and simply have to adapt to and cope with the new global complexity and the problems it has produced, and that agency is a very important factor for establishing an alternative, democratic form of contemporary globalization. However, in many such analyses there are some assumptions that I don't share:

- Globalization is a purely economic process: "In a sense one can say that such terms as globalization are simply codes for the retreat from Marxist notions like imperialism and a substitution of cultural and political issues for what is actually at stake in the changes taking place in the world - changes that are, above all, in the social relations of production" (Ebert 1999).

- Globalization is caused by capitalism and hence is a synonym for the expansion of class-based exploitation: "Globalization, I argue, is a struggle over the structured inequality in the world economy. [...] Globalization begins with the commodification of labour power itself. [...] Globalization is the process by which capitalists get access to cheap labour and maintain their competitive rate of profit. [...] Globalization is [...] the internationalisation of class structures" (Ebert 1999). "[Globalization is] a natural outcome of capitalist development. It is not the start of a new society, as alleged. It is a creature of capitalist society, bearing both the ingenuity and inner contradictions of capitalism" (Zeitlin 2001: 467).

- There is nothing new about the changes we are witnessing today, there is only a continuation of capitalism, novel aspects of globalization are myths that serve dominant economic interests. What is called "globalization" today is conceived as a quantitative intensification of class relationships that doesn't have new qualities. E.g.: "The world's political economy is not more globalized than it was a hundred or a hundred and fifty years ago. [...] It's capitalism, not globalization. [...] The system is the same, its logic is the same, and the need for workers of the world to unite has never been greater" (Tabb 1997). Globalization is "capitalism's continuing imperialism grown bigger and stronger, enabled by a versatile new technology and weakened political opposition to expand geographically and exploit 
more human labour and natural resources over most of the globe" (Zeitlin 2001: 469). Globalization "is another word for the reach of American imperialism, the power of financial markets, the spread of capitalist social relations, the intensification of exploitation and a vast growth in social inequality" (Panitch 2001).

Such assumptions can't explain older, pre-capitalistic forms of globalization and they are based on undialectical conceptions of the relationship of change/continuity and quantity/quality. A dialecticalmaterialistic account of globalization must consider the latter as a set of processes that develop in such a way that in specific historic phases of development new tendencies emerge that transform older tendencies that nonetheless continue to exist. Globalization develops dialectically in such a way that new levels of organization emerge, old levels are eliminated and old tendencies are preserved. Hence in globalization one can find all three meanings of sublation (Aufhebung) that Hegel has outlined: uplifting, elimination, and preservation. Saying that globalization equals capitalism results in static, non-dialectical theories. Globalization operates on various levels, an intensification on one level results in new qualities on higher levels, hence we today find long-term, mid-term and short-term processes of globalization that interact complexly, contemporary globalization is on the one hand capitalistic and is an intensification of capitalist relationships, but this quantitative increase has resulted in new qualities, a new mode of capitalistic development that has emergent qualities and can at the same time be seen as a preservation of the overall capitalistic structure of society. One should also give attention to the fact that capitalistic globalization is the antagonistic continuation of a more general trend of human globalization that has both specific and general qualities. In order to avoid the reductionism and determinism of economistic accounts of globalization and the relativism of pluralistic multifactor analyses, I suggest with Pierre Bourdieu a more general notion of the economic as all sort of pure economic, political, cultural, and symbolic processes of production and (in modern society) accumulation (cf. Fuchs 2003a). There is a "whole universe of economies" (Bourdieu 1990: 51) that differ in the composition of capital that is employed in specific fields. Contemporary globalization results from the antagonistic logics of accumulation of (purely) economic capital, political capital, and cultural capital. The subsystems of society have a relative autonomy which is not to deny that the logic of accumulating money and commodities has a dominant (but not determining) character in modern society that under neoliberal conditions has resulted in tight structural couplings and an increased penetration of all subsystems with (purely) economic logic. Contemporary antagonistic globalization is a result of the general logic of accumulation and heteronomy.

Self-organization theories put forward the idea that causes and effects can't be mapped linearly in complex systems: similar causes can have different effects and different causes similar effects; small changes of causes can have large effects whereas large changes can also only result in small effects. Hence conceptualizing globalization as an aspect of self-organizing systems enables us to assume that in a globalizing world there are complex, non-linear causal relationships that are stretching across large spatio-temporal distances. In highly globalized systems, interactions in one system can have large effects on systems that are located far remotely, effects can stretch across large distances and be intensified or dampened by mediating systems, global interactions are to a certain extent unpredictable due to the complex relationships of the elements and subsystems of highly globalized systems. The more global a system, the more likely it will have a high complexity and a high level of networking among its elements. Human globalization doesn't have clear-cut, determined effects because social systems are complex, selforganizing systems, globalization processes have a high degree of ambiguity. I suggest that in modern society this ambiguity is due to the antagonistic character of social systems, the accumulation of economic, political, and cultural capital (to use the terminology of Pierre Bourdieu, cf. Fuchs 2003a) results in uneven, conflicting patterns of societal development. Hence I will describe the globalization processes of modern society throughout this paper as antagonistic processes and tendencies.

Almost all theories of globalization argue that globalization is a social phenomenon, whereas I would like to suggest that it is a general aspect of all complex systems. Although a general theory of self- 
organization seems particularly suitable for explaining globalization, there are only a few scientific works that have thus far considered the relationship of globalization and self-organization. These works all have an eclecticist character.

James N. Rosenau (2003) argues that as systems and their environments become ever more complex, feedback loops proliferate and nonlinear dynamics intensify. Contemporary globalization would be due to technological, organizational and economic revolutions that cause an increased fragmentation of society. Rosenau seems to be impressed by his new discovery of self-organization theory and lists many aspects of it. His main argument is that globalization results in an increasingly complex world where effects intensify in nonlinear ways. "With the advent of a bifurcation of global structures and a vigorous multicentric world of diverse collectivities that is adding substantially to the density of actors on the global stage, it might seems as if the world is headed for increasing unrest and instability. The ever-widening interdependence of publics, economies, societies, and politics generated by a microelectronic revolution that has collapsed time and space would also seem to have rendered global structures vulnerable to instabilities in one part of the world spreading quickly to other parts" (Rosenau 2003: 217f). This argument is an important one and can best be explained within the framework of a general theory of social selforganization, however Rosenau doesn't attempt to explain how self-organization and globalization are exactly interrelated and how the second can be considered as an attribute of the first.

John Urry (2003) argues in his book "Global Complexity" that the global is complex and systemic and "comprises a set of emergent systems possessing properties and patterns that are often far from equilibrium" (Urry 2003: 7). The increased networked character of society would result in openness and unpredictability. Globalization wouldn't be reducible to a single process and it wouldn't have a linear trajectory. Social space would be characterised today by fluids that flow across different borders, use diverse networks, combine together with each other, and are not solid or stable. Networks would amplify small inputs, global fluids would be unpredictable global flows that have uneven, emergent and unpredictable shapes. "Global fluids travel along these various scapes, but they may escape, rather like white blood corpuscles, through the 'walls' into surrounding matter and effect unpredictable consequences upon that matter. Fluids move according to certain novel shapes and temporalities as they break free from the linear, clock time of existing scapes - but they cannot go back, they cannot return, because of the irreversibility of time. [...] They roam the globe, possessing the power of rapid movement, across over and under many apparent regions, disappearing and the reappearing, transmutating their form, cropping up like the islands of an archipelago, unexpectedly and chaotically" (ibid.: 60+73). The most important global fluids would be travelling peoples, the Internet, information, world money, global brands or logos, automobility, environmental and health hazards, the world's oceans, and social movements. Global emergence would mean that "emergent effects are often produced by 'small causes' and these get relayed through the diverse and overlapping global networks and fluids that interact physically, and especially informationally, under, over and across the earth's surface, stretching over hugely different temporal scales" (ibid.: 94). In search for a terminology that can adequately describe the complex, networked, to a certain extent decentralized and unpredictable character of globalizing society, Urry has come across self-organization theory and realized that self-organizing systems are essentially complex, interconnected, and unpredictable in character. However, he starts from a theory of globalization and uses the terminology of self-organization theory metaphorically to emphasise certain developments, he doesn't adequately integrate the notions of self-organization and globalization, self-organization is considered an attribute of globalization, whereas I would suggest to start from a theory of self-organization and to consider globalization as an attribute of self-organization. Urry doesn't consistently explain the dynamic of social self-organization that results in globalization, a precise notion of social self-organization is missing.

Niklas Luhmann has argued that the elements of a social system are not human actors, but selfreferential communications that are not limited in scope. Hence there would only be one society, the world 
society (Luhmann 1997a; 1997b: 145-171). This would especially be true in a world of global media and global communication technologies that transcend all borders. There wouldn't be a global system of regional societies, but only a single world society. He doesn't adequately take into account that although today we find a single global economic system and global technological networks, there is no single global political and cultural system. There certainly is a global communication society and there are a lot of global communication flows today in all subsystems of society, but one should not deny that there is also much communication at national, regional, and local levels, the nation state has not disappeared, it is still important and a major unit of social and political self-organization. There is not only one society, the world society, rather there is the world society as global level of organization that is made up by the emergent results of communications between different transnational actors and national societies. Luhmann opposes globalization theories (Giddens, Robertson) that stress the importance of national societies in global processes (Luhmann 1997b: 158ff) Conceiving social self-organization as detached from human actors results in functionalistic relativism and dualism that doesn't acknowledge the capacity of human actors to intervene into and consciously shape complex social systems although there is a great deal of uncertainty and unpredictability of social actions (Fuchs 2003a, 2003f). Luhmann (1997) rightly sees that exclusion and global neglect are major social problems today, but he doesn't offer any possible solutions for this problem, it seems like this is for him a necessary side-effect of the autopoiesis of late capitalism. He argues that modern society is centreless and out of control, hence not all kinds of concern could be included (ibid.). "The world society has reached a higher level of complexity with higher structural contingencies, more unexpected and unpredictable changes (some people call this 'chaos') and, above all, more interlinked dependencies and interdependencies. This means that causal constructions, (calculations, plannings) are no longer possible from a central and therefore 'objective' point of view. [...] [This] destroys the ontological and the logical assumptions of central guidance. We have to live with a polycentric, polycontextural society" (ibid.). Luhmann argues that in such a situation science can only describe situations, but not as act as ethical science and propose problem solutions. He concludes that "we shall have to face unresolvable indeterminacies" (ibid.). A functionalistic theory that bans agency and conscious participatory system design from its vocabulary leaves us with the dissatisfying assessment that there are problems, but no solutions.

A society is a network of social systems that by interacting can maintain some unity, cohesion, and continuity across time-space and within certain borders. In a society, relations between social systems are organized as regularized practices and reproduced in such a way that the society as a system can reproduce itself within certain borders. In case of the world society this border is only limited in space-time by the extent to which humans settle in spaces and transform nature into social space. I suggest to see the world society as one level of social analysis, it covers those social relationships that have global extension such as the world market, global socio-technological networks, international political relationships such as in warfare or the United Nations, etc. Mainly the economy and technology today have a truly global scope, whereas politics and culture are mainly organized within the confines of nation states that form distinct units of social reproduction with citizenship clearly delimiting borders. Hence I suggest to speak of nation states also as societies and distinct levels of social analysis. But not all cultural and political relationships are confined to the borders of nation states, there are also global cultural flows and global political relationships. Nation states are important actors in world polity, world polity is a system of relationships between nation states that also involves transnational political institutions (the latter indeed have an increasing importance). Globalization analysis should show how the global, the national, the regional, the local, and the individual are coupled and interact. In global informational capitalism we are witnessing an increasing importance of the global level, but this doesn't mean that the other levels (such as the nation state) are dissolved, they are transformed in complex and uneven manner. Hence I suggest that in the social world we find both a global society and national societies, nation states are important actors in the world society, but certainly not the only actors as can be seen by the increasing importance of transnational economic, political, military, and cultural collective actors. It is short-sighted to argue like Niklas Luhmann that there is only one society, the world society, because this doesn't take into 
account the importance and relative functional autonomy of nation states as self-organizing networks of self-organizing social systems, networks that are themselves nodes within the self-organizing social network we call global society.

In a more specific, economic context globalization and self-organization is explored in the papers of Voets/Biggiero (2000) and Rycroft (2003). Voets/Biggiero (2000: 73f) argue that in "a broad sense, globalization is the self-organizing process of constructing a world socio-economic community, with increasing degrees of interconnection between members. In a narrow sense we argue that globalization is the process of increasing the openness of local environments to the world community: that is, a process of growing interconnection between local contexts". They argue that business networks that make use of decentralised, transnational forms of production involve a growing degree of self-organization. Rycroft (2003) points out that innovation networks of firms are self-organizing in the sense that they make use of distributed knowledge in order to achieve economic aims, are constantly learning through collaboration, and make productive use of "noise" and failure. "Because process and product innovation involves solving problems, self-organization is about a continual search for knowledge and procedures that will contribute to problem solving. [...] Keeping pace with the complexity of technological progress requires that networks repeatedly learn about, integrate, and apply a wide variety of knowledge and know-how from a wide variety of locations around the globe. [...] No single organization engaged in the innovation of complex technology, not even the largest and most sophisticated MNC is likely to succeed if it embarks on a 'go it alone strategy"' (Rycroft 2003: 4+11). I strongly agree with Voets and Biggiero that the increasingly networked character of firms and the economy puts forward the idea of worker participation in decision making, financial results, and ownership, I also agree with these authors that the network economy should be described in terms of self-organization and that innovation networks are good examples for synergetical processes. However, the concepts of social self-organization employed in both papers are very vague, the exact relationship between self-organization and globalization remains unclear, selforganization is mainly used metaphorically, not as an integrated notion that explains the dynamic reproduction and globalization of social systems.

Taken together these works show that there are good reasons to argue that a theory of globalization shall be based on a general theory of self-organization, but they don't show consistently how globalization can be explained as a central attribute of the dynamic of self-organizing system, how globalization is shaped by general and specific logics of self-organization and how uneven, stratified patterns of societal globalization emerge from antagonistic forms of social self-organization. The aim of this paper is to outline some foundations of a theory of self-organization that can explain these aspects of globalization processes. As a foundation for doing so, I will now outline a general model of globalization in complex, self-organizing systems that can be applied to all systems in nature and society.

\section{Globalization as a General Quality of Self-Organization}

A system is a totality that is comprised of elementary unity that are structurally related and that construct a border which delimits the system from its environment. One can describe a system by distinguishing between an elementary micro level and a structural macro level. The micro level is local in the sense that it is made up of single units, whereas the macro level is more global in the sense that the structural relationships transcend the singularity of the parts.

Self-organized development means a double reflexive, circular process where the parts interact synergetically and produce new, emergent qualities on the macro level that can't be reduced to the micro level (the whole is more than the sum of its parts) and enable and constrain further activities of the parts. The bottom-up micro-macro-causation is a process of upward globalization in the sense that singularities produce more general, higher qualities by interaction. The macro level is permanently re-constituted in a 
bottom-up process, bottom-up emergence means the productive sublation of the micro-level in a globalization process. The top-down-macro-micro-causation is a process of downward-localization in the sense that there is feedback from the global structures to the behaviour of the parts. The micro level is permanently re-constituted in a top-down process, top-down emergence means the productive sublation of the macro level in a localization process. Global structures are adapted and localized to the micro level. Fig. 2 shows the double-process that relates micro-level and macro-level by globalization and localization and forms a self-organizing loop.

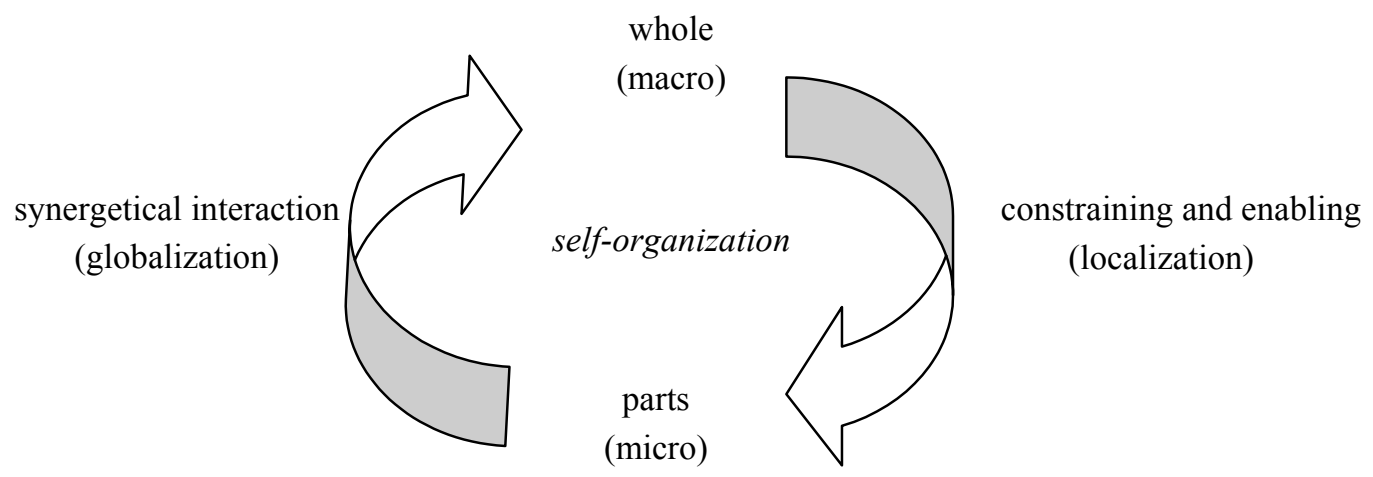

Figure 2: The dialectic of globalization and localization in self-organizing systems

Globalization is a general process characteristic of all complex, self-organizing systems. From time to time systems leave the phase of synchronic reproductive self-organization loops (self-reproduction) and enter phases of diachronic self-organization where a new system type or level emerges from instabilities and disorder. The result of diachronic self-organization (order through fluctuation, order from noise) is a hierarchy of systems where upper systems are more complex and global, they are characterized by emergent qualities that can't be found on lower, more local levels. Each system is a local elementary part of a more global whole as well as a global whole made up of more local parts. This dialectic of globality and locality is the main characteristic of the material hierarchy that is typical for the self-organization of the universe.

Globalization in a self-organizing system takes place in an informational process that involves cognition, communication, and co-operation (for a discussion of these three aspects of information production see Hofkirchner 2002a). When two systems interact (see fig. 3), they enter an objective relationship, i.e. a (mutual) causal relationship is established. A portion of subjective, systemic information ("cognition") is communicated from system A to system B (and vice versa, "communication"). This causes structural changes in the other system. If there is an informational relationship between the two systems, it is determined that there will be causal interactions and structural effects. The structure of the systems (structural, subjective information) changes, but we don't know to which extent this will actually be the case, which new subjective information will emerge, which information (structures) will be changed etc. There are degrees of autonomy and freedom (=chance). If structural changes in system $B$ take place and are initiated by system $A$, this means an objectification of subjective information of $A$ in $B$ from the point of view of $A$. From the point of view of $B$ it means subjectification of objective information from the environment. In a communication process, this also takes place the other way round. As a result of communication it cannot only be the case that an objectification of information in some of the involved systems takes place, it can also be the case that due to the synergies between the systems new qualities (information) emerge in their shared environment ("co-operation"). Structural, subjective information of the involved systems is co-ordinated, synergies arise and hence something new is produced commonly in a self-organization process. The new structure or system that arises is an objectification of subjective information of the involved systems. Information in self-organizing systems has cognitive (subjective), communicative (new subjective information (=structures) emerges in systems due to interaction) and cooperative aspects (interaction results in synergies that cause the emergence of new, objectified 
information in the shared environment of the involved systems). Co-operation is the general process of interaction between units that results in a globalization of local behaviour, i.e. productive relationships result in the emergence of new qualities.

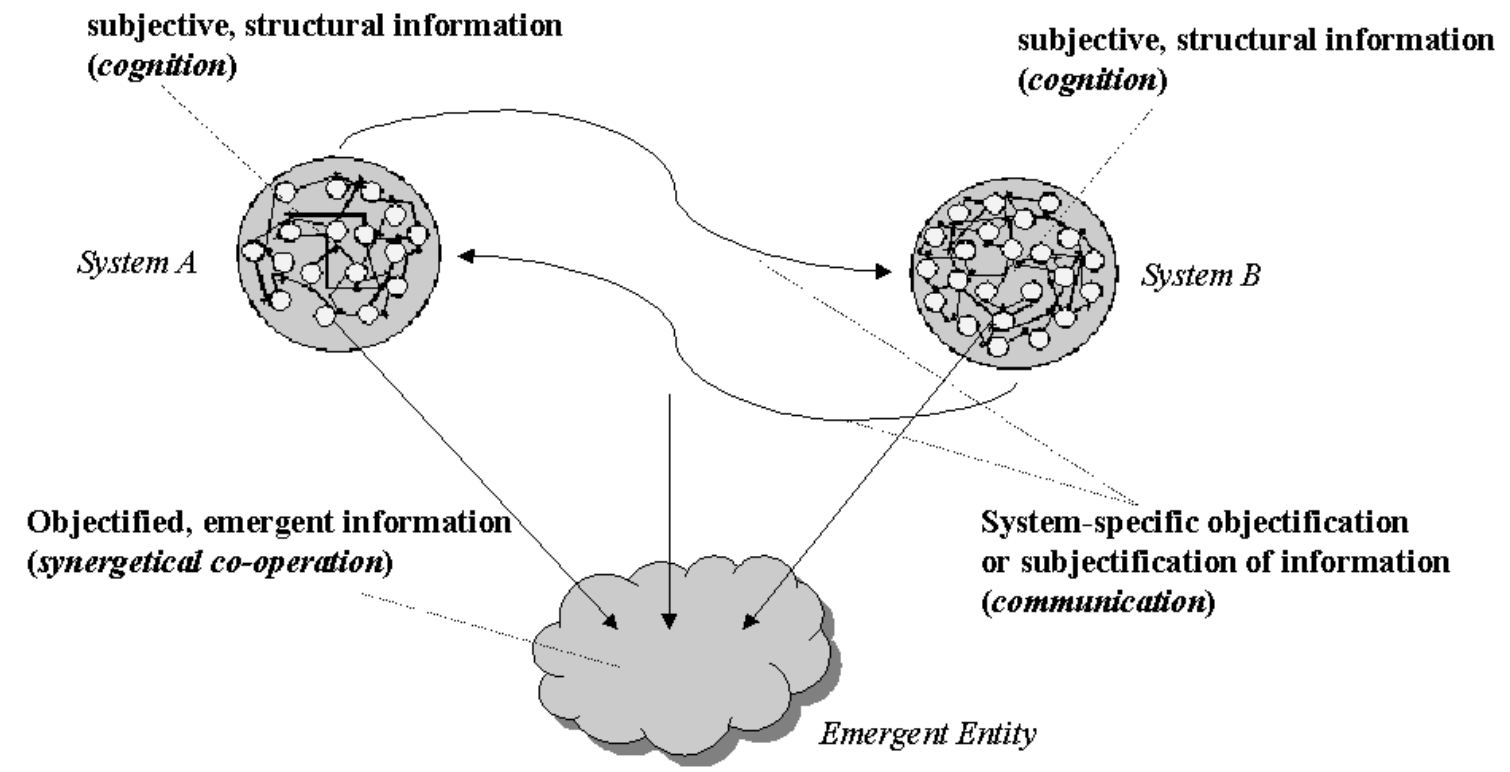

Figure 3: A general model of the three aspects of information-generation (cognition, communication and co-operation) in selforganizing systems

Based on this general model of globalization in self-organizing systems, I will now show how the relationship of globalization and self-organization can be conceived in social systems.

\section{Globalization and Social Self-Organization}

Globalization is mainly a sociological topic, but there is much disagreement on the question since when society is characterized by massive phases of globalization. Immanuel Wallerstein argues that the capitalistic world-system is a global system ever since its emergence in the $16^{\text {th }}$ century, Anthony Giddens argues that globalization has been increasingly taken place since the establishment of modern society in the $19^{\text {th }}$ century, Roland Robertson argues that globalization is a very long term process, extending back through thousands of years and characterised by a phase of extreme rapidity and extensiveness from 1870-1920, for John Tomlinson globalization is a very recent characteristic of society since the 1960s. In contrast to these approaches, I argue that globalization is not only a social process, but one that takes places in all complex (i.e. also natural) systems as process of bottom-up-emergence. All social relationships are based on bottom-up-social-emergence and hence involve various forms of globalization. Whenever a social system faces large problems that it can't cope with on existing spatio-temporal levels, it enlarges its borders spatio-temporally, i.e. new levels of social organization are created. In recent years we have been witnessing a massive increase of global problems as well as a massive increase of social levels and time-space distantiation of social relationships.

In social self-organization the local level is formed by knowledgeable human (individual and collective) actors, the global level by social structures like natural resources (ecological structures), tools (technological structures), property (economic structures), decision-power (political structures), and definitions (norms, values, ideas, traditions, ideologies; cultural structures). It is a reflexive, mutual, circular loop where human actors in a process of social globalization synergetically produce social structures that enable and constrain further actions and thinking in a process of social localization. Social structures are 
medium of social actions in localization processes and outcome of social actions in globalization processes (fig. 4$)^{5}$.

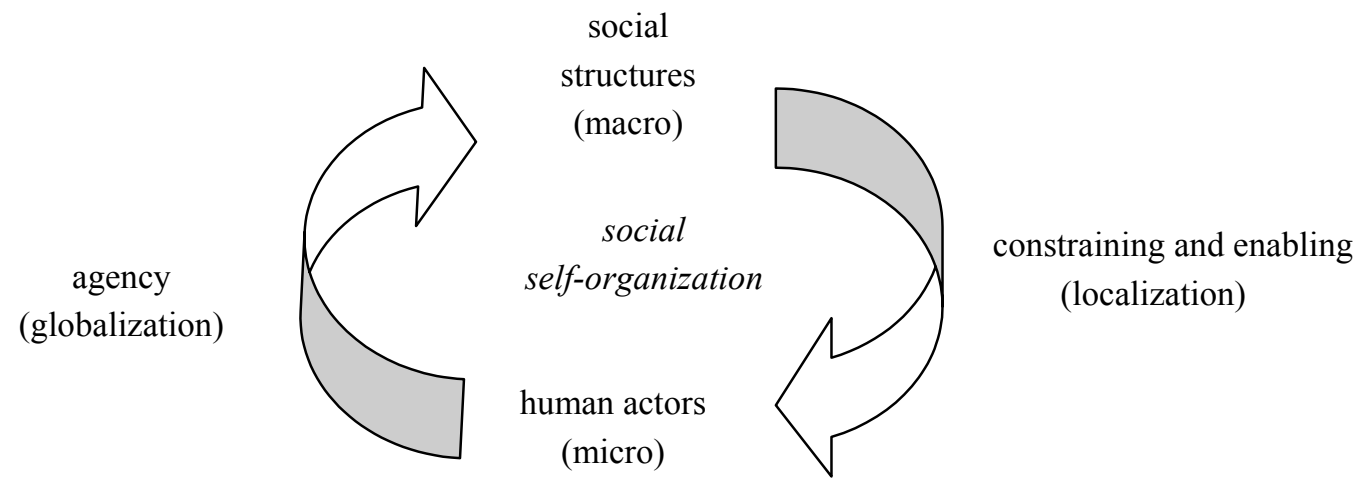

Figure 4: The dialectic of globalization and localization in social self-organization

So one can say that all social relationships are coined by a dialectic of globalization and localization, each time we act socially, we refer to more global structures that transcend our singularity and enable and constrain our behaviour and interactions, social actions produce more global structures. The more global a social structure, the more it is detached from the permanent immediate control of single individuals/groups. The hierarchy of social globality reaches from the individual as starting point to local immediate relationships like family, friendships, or colleagues, to local intermediary structural relationships like local city council, transmediary (national) structural relationships like institutions of the state or national markets, to international structural relationships like international agreements or the European Union, and finally global or transnational structural relationships of worldwide reach like the Internet, the world market or human rights (at least by idea). For most of us the more local levels of this hierarchy are the environments of immediate permanent physical and social contact, whereas the more global levels are the environments of indirect contact that most mainly observe and come in contact with by the mass media. Certain actors like transnational corporations, NGOs, computer users, etc. frequently switch in a flexible way from one level to others.

Globalization can generally be defined as the stretching of social relationships in space-time, a globalizing social system enlarges its border in space-time, as a result social relationships can be maintained across larger temporal and spatial distances. Self-organizing social systems have the ability to create new realities that have a more global reach than previous realities, they can enlarge their borders. Anthony Giddens similarly defines globalization as "intensification of worldwide social relations which link distant localities in such a way that local happenings are shaped by events occuring many miles away and vice versa" (Giddens 1990: 64). Globalization is based on processes of disembedding, i.e. the production of time-space distanciation of social relationships. Processes of disembedding are accompanied by processes of reembedding that adapt the disembedded social relationships to local (temporal and spatial) conditions. Globalization involves the stretching of practices and actions that constitute self-organizing social systems in time-space, it is based on action at a distance, globalization results in an increase of the intensity, extensity, reach and velocity of social relationships, i.e. there is a faster and wider flow of more artefacts, people and symbols over networks across space-time. Disembedding and reembedding are interconnected processes that are an expression of the dialectic of the global and the local. The global is based on the interaction of localities, the global is adapted to local circumstances. Roland Robertson (1994) speaks in this context of "glocalization". "From my standpoint the concept of globalization has involved the simultaneity and the inter-penetration of what are conventionally called the global and the

\footnotetext{
${ }^{5}$ For a discussion of foundations of a theory of social self-organization see Fuchs (2003a, b, e, f, g)
} 
local, or - in more general vein - the universal and the particular. [...] globalization - in the broadest sense, the compression of the world - has involved and increasingly involves the creation and the incorporation of locality, a process which itself largely shapes, in turn, the compression of the world as a whole" (Robertson 1994). "Our suggestion is that there are built-in brakes on globalization, namely those inherent in the unavoidable necessity of adaptation to (or production of) particular circumstances. Hence, the proposition that globalization is self-limiting" (Robertson/White 2003b: 17).

Taking a look at influential definitions of globalization from scientists like Giddens, Held/McGrew, and Robertson shows that their definitions concentrate on quite similar aspects. "Globalization may be thought of initially as the widening, deepening and speeding up of worldwide interconnectedness in all aspects of contemporary social life. [...] Globalization can be taken to refer to those spatio-temporal processes of change which underpin a transformation in the organization of human affairs by linking together and expanding human activity across regions and continents. [...] [lt implies] a stretching of social, political and economic activities across frontiers such that events, decisions and activities in one region of the world can come to have significance for individuals and communities in distant regions of the globe. In this sense, it embodies transregional interconnectedness, the widening reach of networks of social activity and power, and the possibility of action at a distance" (Held/McGrew/Goldblatt/Perraton 1999: 2+15). "Globalization as a concept refers both to the compression of the world and the intensification of consciousness of the world as a whole" (Robertson 1992: 8). These definitions show that the central aspects of globalization are interconnection, intensification, time-space-distanciation, deterritorialisation/supraterritoriality ${ }^{6}$ of relationships; time-space-compression, action at a distance, and accelerating interdependence. Theories of globalization that see globalization as a general process seem to agree that these phenomena apply to all realms of society. I would like to add that they apply not only for society, but can be found in all self-organizing systems, i.e. all complex systems in nature and society. Globalization is a general process in the sense that emergence can result in an increase of interconnections, distanciation, compression and acceleration of the relationships between complex systems and elements of a complex system.

Also in the second sense, globalization is a general process of humankind. During the history of society the organization of social relationships has become more global in temporal and spatial scope. "Throughout recorded history, a trend can be observed toward the enlargement of the geographical scope of human communities; it has been one aspect of the increasing scale of social organization" (Modelski 1972). This tendency involves the increase of the networked character of human actions, the increase of the number of actors and complexity of society due to the latter's enlargement and the increase of complexity of social relationships. All social action is a kind of problem-solving that is based on the human beings' striving for achieving defined goals by entering social relationships and appropriating nature. In the material production of reality, human beings sooner or later encounter problems that are due to the limited local availability of resources, intelligence, solutions, and capacities and that they can't solve on local levels. Hence they create new emergent levels of reality that are more complex and more global in reach. This new level will be the spatio-temporal foundation of action for some time, but practices within this system will sooner or later also reach certain limits. Social globalization in a synchronous sense takes place permanently in the sense that there are mutual productive, synergetical relationships between actors and structures that involve a double-process of globalization (micro-macro-link) and localization (macro-micro-link). In a diachronic sense social globalization refers to phases of crisis and heavy

\footnotetext{
${ }^{6}$ Jan Aart Scholte (1999) argues in a very interesting article that contemporary globalization means "a proliferation of social connections which are at least partly - and often quite substantially - detached from territorial space. [...] Such phenomena cannot be situated at a fixed and limited territorial location. They operate largely without regard to territorial distance. [...] Globality (as supraterritoriality) describes circumstances where territorial space is substantially transcended. Phenomena like Coca-Cola and faxes are 'global' in this sense because they can extend anywhere in the world at the same time and can unite locations anywhere in effectively no time " (Scholte 1999: 12). As examples he mentions telephone networks, electronic finance, multilateral institutions, the depletion of the atmospheric ozone, global transactions, satellite TV, social movements, the Internet, transborder companies, globally marketed products, global tourism, etc.
} 
fluctuations that are due to conflicting patterns of development and escalating problems that can't be solved on existing levels of organization, as a result new order arises through fluctuation (Ilya Prigogine's principle of order through fluctuation), a new, more global level of organization, a new type of social system is created and the old system is incorporated into the new organization. Globalization in this sense means the diachronic, discontinuous emergence of new levels of self-organization. There is both a synchronous and a diachronic type of globalization, the synchronous one takes place permanently and results in emergence on existing levels, from time to time the system can't cope with its own complexity and the emergence of a new level of self-organization takes place discontinuously.

Göran Therborn $(2000,2001)$ suggests that globalization takes place in historical waves that have multiple dimensions and consist of periods of intensive globalization followed by periods of deglobalization. This idea seems to be related to the concept of economical long waves and it shares certain deterministic assumptions with it ${ }^{7}$. There is no good reason to assume that there is a social law that results in sequences of globalization and de-globalization because the social world is one of human agency and hence one of conditioned chance where the future is relatively open and depends on human practices and struggles. Hence it is not determined if a phase of intensive globalization will be followed by another phase of globalization, a phase of stabile reproduction without the creation or destruction of levels, or by a phase of de-globalization. The phase of rapid economic development ranging from approx. 1870 until the First World War that was described by many as the phase of imperialism was a phase of economic globalization in the sense of capital export and world trade, it was followed by the Fordist phase of development that after the Great Depression was based on economic de-globalization with a primacy of protected, relatively self-sustaining national markets. Here globalization was followed by de-globalization. Concerning technological networks, the submarine cable networks used for telegraphy constituted a form of globalization of communication, with the rise of telephone, radio, TV, and finally fibre-optic cable networks used for Internet communication further phases of the globalization of communication followed. Hence here globalization wasn't followed by de-globalization, but by further globalization. The two examples show that a phase of globalization can be followed by both de-globalization or another phase of globalization.

There are certain mechanisms of knowledge storage in society that allow time-space distanciation of social relationships. In non-literate societies the only "container" storing information were human memory, tradition and myths. Writing and notation have allowed a certain time-space distanciation of social relationships. Other forms of storing information that have followed and have caused further time-space distanciation are cities, lists, time-tables, money, money capital, nation-states, communication and transportation technologies in general and especially the rapid-transit transportation and electronic communication technologies (including electromagnetic telegraph, telephone and computer mediated communication). Tribal societies were high presence societies, their self-organization took mainly place on local levels without much time-space distanciation. The rise of more complex structural forms on the one hand was a medium of the globalization of social self-organization, on the other hand it is also an outcome of societies need of stretching its border if certain problems can't be solved within an existing locale. Based on the duality of structure (cf. Fuchs 2003f), the self-organization of society generates and differentiates knowledge which can be stored and controlled across time and space by making use of certain structures. During the history of mankind these storage capacities and mechanisms have been improved and allowed an increase of time-space distanciation. During the last decades, information storage and usage has become a major factor in all aspects of modern life. Information and information technologies today are not only major economic factors, they have also gained massive importance in political life, science, culture, administration, art, education, health and media. Therefore we can also speak of the dominant mode of reproduction and self-organization of the modern world as the informational mode of capitalist development.

\footnotetext{
${ }^{7}$ For a characterization of long-wave theory as reductionist and deterministic see Fuchs (2002a)
} 
Globalization can be found in specific forms in the five subsystems of society. These are: the technosphere, the ecosphere, the economy, polity, and culture. In the technosphere the human being produces and uses tools that shall help him in achieving defined goals, in the ecosphere the human being appropriates natural resources and exchanges matter and energy with nature in order to survive, in the economy the human being produces property in order to satisfy his needs, in the political system the human being establishes and makes use of power structures in order to decide how his living conditions shall be designed, and in culture the human being constitutes definitions (norms, values, traditions, ideologies) in order to shape his living conditions and life-style properly. Globalization can be defined in respect to each of these subsystems of society.

\begin{tabular}{|l|l|}
\hline \multicolumn{1}{|c|}{ subsystem of society } & globalization as... \\
\hline technosphere & spatio-temporal enlargement of socio-technological systems \\
\hline ecosphere & spatio-temporal enlargement of socio-ecological systems \\
\hline economy & $\begin{array}{l}\text { spatio-temporal enlargement of economic structures and practices of } \\
\text { production, distribution and consumption }\end{array}$ \\
\hline political system & $\begin{array}{l}\text { spatio-temporal enlargement of power- and decision structures and } \\
\text { political practices }\end{array}$ \\
\hline culture & spatio-temporal enlargement of normative structures and practices \\
\hline \multicolumn{1}{|l}{ Table 1: Forms of globalization }
\end{tabular}

In modern society these processes of globalization are based on a logic of accumulation of natural resources, tools, money capital, power, and hegemony. In comparison to premodernity the intensity, velocity, extensity, and impacts of globalization are much larger in modern society. The self-organization of the subsystems of modern society can be described as processes of antagonistic self-enlargement that produces dichotomies (between nature and culture, have and have-nots, economic classes, the more powerful and the less powerful, the knowing and the unknowing, the educated and the uneducated, men and women, young and old, rich and poor, etc.) that result in material and intellectual inequality. Due to this inherent logic of accumulation, modern society has transformed structures into (ecological, technological, economic, political, and cultural) capital that yields (material and symbolic) profit by being accumulated (see Fuchs 2003a, b). Hence modern society is a capitalistic society not solely in an economic, but a multidimensional sense of the word. The main problem that modern society tries to solve is how to accumulate ever more capital. Whenever an existing regime/mode of accumulation that shapes the self-organization of the subsystems reaches its inherent limits and enters crisis, new strategies and areas of accumulation are needed in order to revert to ordered processes of accumulation. Hence globalization is in modern society inherently driven by the logic of capital accumulation that results in the appropriation and production of new spaces and systems of accumulation.

In modern society, self-organization is controlled by certain classes, the social structures are alien powers opposed to the human being which enslave him instead of being controlled by him. Alienated or estranged structures are forces imposed on the individuals as an interest "alien" to them that are independent of them. Due to this lack of self-determination and self-control, one can speak of alienation or estrangement, modern social structures are estranged social structures. In modern society the dialectic of structures and actors that is basic for all social systems and their capacity to organize themselves becomes an antagonism which relates the two categories in materially colliding ways that produce separated interests and unequal distributions.

Based on these basic assumptions about the relationship of globalization and social self-organization, I will now outline the antagonistic globalization of the five dimensions of modern society. 


\section{The Antagonisms of the Global Modern Age}

The antagonism between structures and actors results in a clash of estrangement and selfdetermination that is characteristic for all subsystems of modern society. In respect to the increasing global character of modern society, several antagonisms can be found

\begin{tabular}{|l|l|l|}
\hline subsystem & faces on the way towards globality an antagonism between... \\
\hline technosphere & global alliance technology & global megamachine \\
\hline ecosphere & global sustainability & global degradation \\
\hline economy & global wealth & global empire \\
\hline polity & global participation & global control \\
\hline culture & global wisdom & global imperialism \\
\hline
\end{tabular}

Table 2: Antagonisms of the Global Modern Age

The basic conflict is that many people can't cope with the increased complexity of the world because their lives are increasingly shaped by global alienated structures that are out of their reach and that they can't participate in. They are not provided with much help for better understanding and participating in these structures, but are rather left alone and all on themselves. The increased feeling of powerlessness and alienation has resulted in identity conflicts and along with it in an aggravation of nationalism, racism, fundamentalism, ethnical conflicts, etc. Globalization is an ambivalent process that produces both new opportunities and risks in all subsystems of society. These conflicts can be described as antagonisms.

\begin{tabular}{|c|c|c|}
\hline \multirow{2}{*}{$\begin{array}{l}\text { subsystem } \\
\text { technosphere }\end{array}$} & \multicolumn{2}{|c|}{$\begin{array}{l}\text { on the way to the global modern society the individual faces } \\
\text { antagonisms between...that challenge its identity }\end{array}$} \\
\hline & individual & global technology \\
\hline ecosphere & individual & global ecology \\
\hline economy & individual & global economy \\
\hline polity & individual & global politics \\
\hline culture & individual & global culture \\
\hline
\end{tabular}

\subsection{Technosphere: Global Alliance Technology vs. Global Megamachine}

In modern society, technology is both medium and outcome of capitalistic development. By establishing new technologies, productivity can be increased and hence economic capital organized more efficiently. Technology mediates capital accumulation. Economic capital accumulation requires a permanent increase of productivity and hence there is a need for permanently developing new, more productive technologies. Capital accumulation results in new technologies. Technology as such is a means for achieving defined goals efficiently and simplifying human existence. In modern society it is not a means that serves primarily human ends, but a means that serves only partial economic interests, hence it is a means of domination and control. Technology as such can increase human wealth and co-operation, but as a means of control it is a megamachine that serves as a medium of domination and alienation. In capitalism, technology is not only a means for increasing productivity, but also a means for reducing the turnover time of capital. The turnover time is the total time of production and circulation of capital. The faster capital can be produced and circulated, the higher the speed of accumulation. Technological progress in capitalism is a continuous effort to shorten turnover time.

The history of technological progress is a history of the globalization of society. Especially transportation and communication technologies (railway, telegraph, broadcasting, automobile, TV, aviation, digital computer-based communication technology, and most recently digital network technology and the Internet) have increased the speed of global flows of capital, commodities, power, communication, 
and information. The Earth has been increasingly transformed into a technological network of communication and transport that affects all realms of society. There is both the capacity of network technology and new media to function as global megamachine or as global alliance technology. The first installs a worldwide system of domination, the second increases human wealth and well-being for all. The outcome of this conflict has not yet been decided, it depends on active human practice and struggles. Technology is not an end in itself, technological progress is due to social interests and conflicts.

Already the Romans made use of networks of postal communication, the invention of the printing press in the fifteenth century allowed a new efficient form of the distribution of written communication beyond closed local communities. With the rise of industrialism and modern society technological progress allowed communication to be dissociated from physical transportation (Thompson 1995). Submarine cable networks used for telegraphy were established and constituted the first global system of communication (ibid.). The $20^{\text {th }}$ century has seen an unprecedented increase in intensity, extensity, and velocity of global communication that is closely related to the rise of radio, television, satellite transmission, the microelectronic revolution and digital fibre-optic cable networks/digital data processing.

The transatlantic cable of 1866 reduced the time of transmission of information between London and New York by over a week, the telephone increased the velocity of messages by a few minutes, the Internet reduced it not much at all in comparison to the telephone (Keohane/Nye 2000: 80). This doesn't imply that technological globalization is a myth, but that we should also stress qualitative aspects such as the reduction of the costs of information transport and new qualities of communication such as many-tomany-communication, interactivity, hyperlinking, multimedia, conversion, simulated virtual realities, the decontextualisation and derealization of communication, implications of computer mediated communicated for the formation of identities, etc.

\subsection{Ecosphere: Global Sustainability vs. Global Degradation}

Nature has prior to human existence been a global system in the sense that it produces processes that have global environmental impacts and massively change the material reality on Earth. Such global ecological processes are e.g. ice ages, natural disasters such as earthquakes, gales, typhoons, hurricanes, floods, volcanic eruptions, continental drift, etc. With the rise of industrialism and capitalism the man-nature-system has been massively transformed because natural resources play an essential role in the accumulation of commodities. The massive increase in material flows of non-renewable resources has resulted in global environmental degradation and a global ecological crisis. The ecosphere is global in the sense that its subsystems are highly mutually coupled, instabilities of some parts can have massive negative influences on the whole global ecosphere and its subsystems.

Environmental degradation takes place on a worldwide scale, all humans feel its effects. E.g. due to the depletion of the ozone layer global warming increases massively, this results in a massive transformation of the seasons, resulting e.g. in periods of extreme heat followed directly by periods of extreme coldness. In Austria we had $25^{\circ} \mathrm{C}$ in early April 2003 and snow one week later, in early June 2003 the temperature rose to $36{ }^{\circ} \mathrm{C}$. Global ecological problems are e.g. ozone depletion, loss of bio-diversity, climate change and global warming, depletion of natural resources, deforestation, desertification, water pollution, acid rain, nuclear catastrophe, greenhouse effect, hazardous wastes, soil exhaustion, etc. The recent deregulation of markets has resulted in a further increase of environmental degradation (Borghesi/Vercelli 2003). Whereas in premodern times the speed of environmental changes was very slow, modernization has resulted in a massive, human-caused artificial speed-up of these changes that nature can't cope with.

The ecological crisis is characteristic for an age of massively increased risks (Beck 1992, 1999a, 1999b), modern society today is a global risk society. On the one hand there are risks immanent in nature, 
on the other hand there are socially produced ecological risks (Giddens 1999). Most of the problems that constitute the ecological crisis are produced risks.

The global-local link can also be observed in the ecological crisis. The global ecological problems have local specificity and consequences, local environmental degradation can have more global impacts (e.g. oil tanker catastrophes, Chernobyl). Due to the fact that environmental risks affect all people worldwide, increased awareness and "ecological consciousness" can be observed globally. Many of the new social movements stem from the environmental sector. The need for a global sustainable society that doesn't produce the risk of destroying the foundation of existence of future generations and where nature is preserved in order not to endanger the foundation of the existence of humankind has to a certain extent been realised. This increased awareness is due to the increased destruction of the ecosphere, characteristic of it is e.g. the rapid growth of international environmental treaties (Frank 1997) and international environmental organizations (Held/McGrew/Goldblatt/Perraton 1999: 388). Interestingly the number of such treaties has sharply declined in the 1990ies, this might be a manifestation of neoliberal ecological policies. The increased awareness poses the possibility for realising a global sustainable society, but this promise is scattered by the continued industrial advancement of ecological degradation (e.g. approx. $25 \%$ of the worldwide emitted carbon dioxide is produced in the USA, but President Bush has refused to sign the Kyoto treatment which would legally bind industrialised nations to reduce worldwide emissions of greenhouse gases). We are witnessing an antagonism between global ecological sustainability and global ecological degradation. Environmental globalization involves both the emergence of global ecological risks that threaten all people and the survival of humankind and the formation of global ecological consciousness. The risk society "shows a tendency toward the objective unification of those affected into global danger situations. In any case, friend and foe, east and west, above and below, city and countryside, black and white, south and north are exposed to the levelling pressure of intensifying civilization risks" (Beck 1999a: 269). Ecological risks affect all, but are unevenly spread in the sense that well-off social strata and regions can afford to reduce their exposure to threats. All are affected by global risks, but some can better escape them.

\subsection{Economy: Global Wealth vs. Global Empire}

Increased global economic productivity puts forward another antagonism. Due to the high development of the economic forces there would be the possibility for establishing global wealth and a world without hard work, starvation, a society with a maximum of free time (i.e. a leisure society). Technology is an important factor in this respect. But actually the global increase of productivity and wealth has only profited economic interests and a small elite, not all of humankind. There is increased total wealth, but also an increase of global inequality, unemployment, and poverty. The total fortune of the three richest men is larger than the total GNP of the 48 poorest countries. The income gap between the richest fifth of the world population and the poorest fifth has increased from 1990 to 1997 from $60: 1$ to $74: 1$. 1,2 billion people must survive with less than one dollar per day, 2,8 billion with less than 2 dollars per day (all data: UNDP 2002).

Capitalism is due to the world market an inherently global economic system. Already Karl Marx and Friedrich Engels described this global character of modern society. "The bourgeoisie has, through its exploitation of the world market, given a cosmopolitan character to production and consumption in every country. [...] All old-established national industries have been destroyed or are daily being destroyed. They are dislodged by new industries, whose introduction becomes a life and death question for all civilized nations, by industries that no longer work up indigenous raw material, but raw material drawn from the remotest zones; industries whose products are consumed, not only at home, but in every quarter of the globe. [...] In place of the old local and national seclusion and self-sufficiency, we have intercourse in every direction, universal inter-dependence of nations" (Marx/Engels 1848: 466f). Marx spoke about "the entanglement of all peoples in the net of the world-market" and "the international character of the capitalistic regime" (Marx 1867: 790). The world-market would be the basis of capitalistic production and 
the "immanent necessity of this mode of production to produce on an ever-enlarged scale tends to extend the world-market continually" (Marx 1894: 346). The development of the productive forces would "put world-historical, empirically universal individuals in place of local ones" (Marx/Engels 1845/46: 36) and would establish a "universal intercourse between men". The global character of capitalism would have produced a universal dependence and history as world history. It would have "produced world history for the first time, insofar as it made all civilised nations and every individual member of them dependent for the satisfaction of their wants on the whole world, thus destroying the former natural exclusiveness of separate nations" (Marx/Engels 1845/46: 60). Marx stressed the relationship of economic globalization and technological progress: "Whereas on the one hand the improvement of the means of transportation and communication brought about by the progress of capitalist production reduces the time of circulation of particular quantities of commodities, the same progress and the opportunities created by the development of transport and communication facilities make it imperative, conversely, to work for ever more remote markets, in a word - for the world-market" (Marx 1885: 254) Means of transport and communication would be "the weapons for conquering foreign markets" (Marx 1867: 475).

Immanuel Wallerstein (1974a) has continued this tradition and has stressed that capitalism is a world system $^{8}$ in the sense that it requires a global division of labour and a world market for achieving profit. The political structure of the capitalistic world system would be based on a hierarchical, segmented division between central states, semi-peripheral states and peripheral states. There would be unequal exchange in the capitalistic world system that results in the appropriation of surplus value of the whole economy by core areas.

Marx saw that globalization is a process immanent in capitalism, but he didn't see that globalization always means glocalization due to the fact that territorial expansion of capital reflects and adapts to local conditions. Gilles Deleuze and Félix Guattari (1977) have described this relationship as a dialectic of deterritorialization and reterritorialization. "It may be all but impossible to distinguish deterritorialization from reterritorialization [...] they are [...] like opposite faces of one and the same process" (Deleuze/Guattari 1977: 333). They argue that capitalism is a schizophrenic system, in order to function it would collapse existing structures and territories, but on the other hand it would be in need for restructuring and regrouping structures and territories. The emergence of capitalism would have resulted in a massive deterriorialization of all realms of social life. Primitive accumulation would have resulted in the deterritorialization of private owners and peasants, resulting in the emergence of "double free" wage labour. Deterritorialization here means expropriation, but also territorial shifts in terms of the shift of the centres of production from the countryside to urban areas and from agriculture to industrial factories. Capitalism would have been the result of the meeting of the flow of decoded money (transformation of money into capital) and that of deterritorialized labour. Reterritorialization would also mean the reappearence of old forms in new forms. E.g. the despotic state would continue to reappear in its repressive form in the modern state. Capitalism means on the one hand a permanent revolution of the technological productive forces, but on the other hand and mutually coupled to the development of these forces it means economic crisis. The tendency of the rates of profit to fall (TRPF) that was described by Marx, Deleuze and Guattari argue, means the tendency that capitalism reaches certain inner limits and must try to overcome this limit by deterritorializing production. But by overcoming this limit it again sets a new inner limit that will be reached during the further development of the productive forces, hence there will again be crisis, deterritorialization, reterritorialization, etc. Capitalism deterritorializes and reterritorializes its own inner limit, in this respect deterritorialization has to do with the territorial expansion of capital. Decoding Deleuze's and Guattari's postmodern jargon shows that their theory reveals that

\footnotetext{
8 "It was only with the emergence of the modern world-economy in sixteenth-century Europe that we saw the full development and economic predominance of market trade. This was the system called capitalism. Capitalism and a world-economy (that is, a single division of labor but multiple polities and cultures) are obverse sides of the same coin. One does not cause the other. [...] Capitalism was from the beginning an affair of the world-economy and not of nation-states. It is a misreading of the situation to claim that it is only in the twentieth century that capitalism has become 'world-wide"' (Wallerstein 1974b)
} 
capitalism is essentially based on glocalization, capitalism destroys, creates, and transforms territories by expanding flows of capital, commodities, labour, technology, and information Deterrioralized flows and the deterrioralized capitalistic socius result in the global dimension of capitalism that is intrinsic linked to displacement and reappearance of the local. Deleuze and Guattari anticipated developments that have more than 20 years later been described by Manuel Castells and others as the emergence of the network society. They give attention to dynamic processes and have established a theory of dynamic, productive flows that are cut off by localizing static tendencies just to produce new dynamic flows. They describe this dialectical relationship of statics and dynamics in terms of body without organs and desiring machine. The continuity of the capitalist process would be given by this unity of schism and flow, the movement of displacement would be an essential aspect of the deterriorialization of capitalism (ibid.: 296f). The state would be a localizing force that reterritoralizes the dynamic economic flows, it must "invent specific codes for flows that are increasingly deterritorialized" (ibid.: 280). "The more the capitalist machine deterritorializes, decoding and axiomatizing flows in order to extract surplus value from them, the more its anciary apparatuses such as government bureaucracies and the forces of law and order, do their utmost to reterritorialize, absorbing in the process a larger and larger share of surplus value" (ibid.: 45). Deleuze and Guattari say that capitalist deterriorialization stretches from centre to periphery and hence they also give attention to the uneven development and effects of globalization.

There is much talk about globalization today, the term is most often used in the sense of economic globalization. But if capitalism has always been a world system, is there actually something new about economic globalization? The push of economic globalization characteristic for Postfordism doesn't simply mean a large increase of world trade, the annual growth of world trade was $6 \%$ in the years 1948-1960, $8 \%$ in the years $1960-73,4.5 \%$ in the years $1973-79$ and $4 \%$ in the years 1980-88 (Hopkins et al. 1998: 71). However, if one takes a look at trade-GDP percentages for developed countries, one will find that trade as a proportion of world GDP (measured in constant prices) has been higher since the early 1970s than in any previous era (Exports-GDP: 1913 11,2\%, 1950 8,3\% 1973 18\% 1985 23,1\%; Imports-GDP: 1880-1900 12,4\%, $1901-1913$ 13,3\%, $1948-1958$ 10,1\%, $1959-1972 \quad 15,4 \%, \quad 1973-198721,7 \%$; Held/McGrew/Goldblatt/Perraton 1999: 169f).

There was a rapid growth of foreign direct investment in the last three decades, annual global FDI outflow increased from 197014141 Mio. US\$, to 53674 Mio. US\$ in 1980, to 233315 Mio. US\$ in 1990 , and to 1379493 Mio. US\$ in 2000; global FDI outflow increased from 197012586 Mio. US\$, to 54945 Mio. US\$ in 1980, to 202782 Mio. US\$ in 1990, and to 1491934 Mio. US\$ in 2000 (Source: UNCTAD Online Handbook of Statistics, http://www.unctad.org/) (see also tab. 4). This quantitative growth is not too surprising because capital accumulation means increasing capital flows and stocks. More interesting are the qualitative changes that can be seen by taking a look at the global distribution of FDI. Fig. 5 shows that the growth of global investment inflows has mainly affected Western Europe, North America, and the Asia/Pacific-region (and to a certain extent Latin America). Africa and Central/Eastern Europe seem to be not very interesting targets of capital export. In Asia the change is due to the rapid increase of capital investment in Southeast Asia (especially China, Hong Kong, Indonesia, Southern Korea, Malaysia, Singapore, Thailand), in Latin America the change is due to the rapid increase of capital investment in Argentine, Bermuda, Brazil, Cayman Islands, and Mexico. Fig. 6 shows that the major foreign investors stem from Western Europe and North America. A third important actor concerning capital export is Japan, its foreign direct investments have in 2001 been larger than the total of all Asian/Pacific-states taken together. In $200193,5 \%$ of all FDI outflows came from developed countries, 5,9\% from developing countries, and $0,6 \%$ from Central/Eastern Europe; $45,7 \%$ of global foreign investment was directed at Western Europe, 20,7\% at North America, 2,3\% at Africa, 11,6\% at Latin America/Caribbean, 13,9\% at the Asia/Pacific region (92,2\% of it at the East, South and Southeast Asian region), and $3,7 \%$ at Central/East Europe, and 2,1\% at other developed countries (ibid.). Tab. 5 shows in relative terms that the majority of FDI is located within OECD countries and that in the last decades Latin America and Asia have gained importance as targets of FDI. 
FDI inflows and outflows have rapidly increased during the last 15 years. The growth rates are given in table 4.

\begin{tabular}{|l|l|l|l|}
\hline & $1986-1990$ & $1991-1995$ & $1996-2000$ \\
\hline $\begin{array}{l}\text { FDI inflow } \\
\text { annual } \\
\text { growth }\end{array}$ & $23.6 \%$ & $20.0 \%$ & $40.1 \%$ \\
\hline $\begin{array}{l}\text { FDI outflow } \\
\text { annual } \\
\text { growth }\end{array}$ & $24.3 \%$ & $15.8 \%$ & $36.7 \%$ \\
\hline
\end{tabular}

Table 4: Annual growth rates of global FDI inflow and outflow, 1986-2000, Source: UNCTAD (2002), p. 4

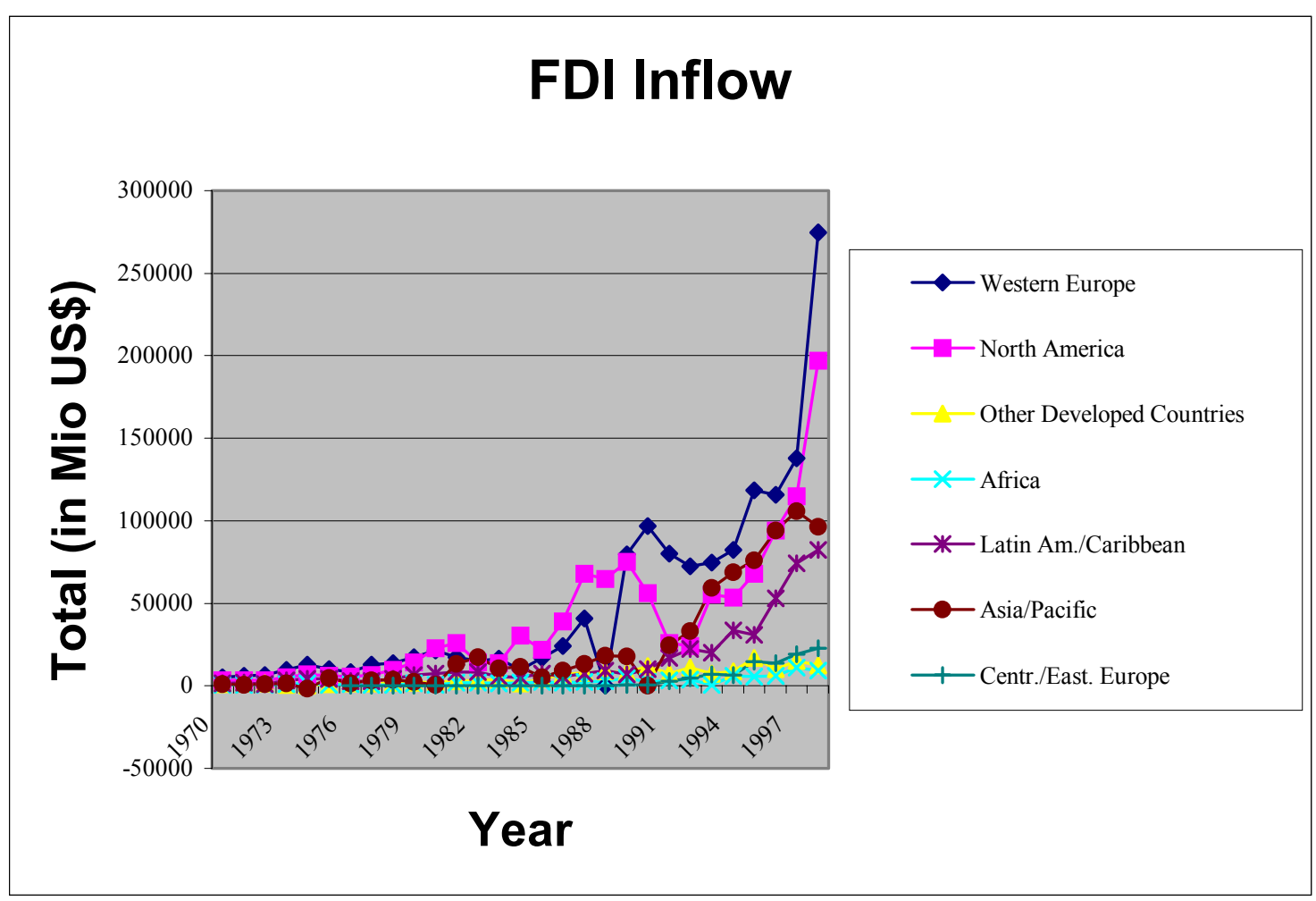

Figure 5: Distribution of Global FDI Inflows (Data Source: UNCTAD Online Handbook of Statistics, http://www.unctad.org/, the countries summed up as "other developed countries" are: Australia, Israel, Japan, New Zealand) 


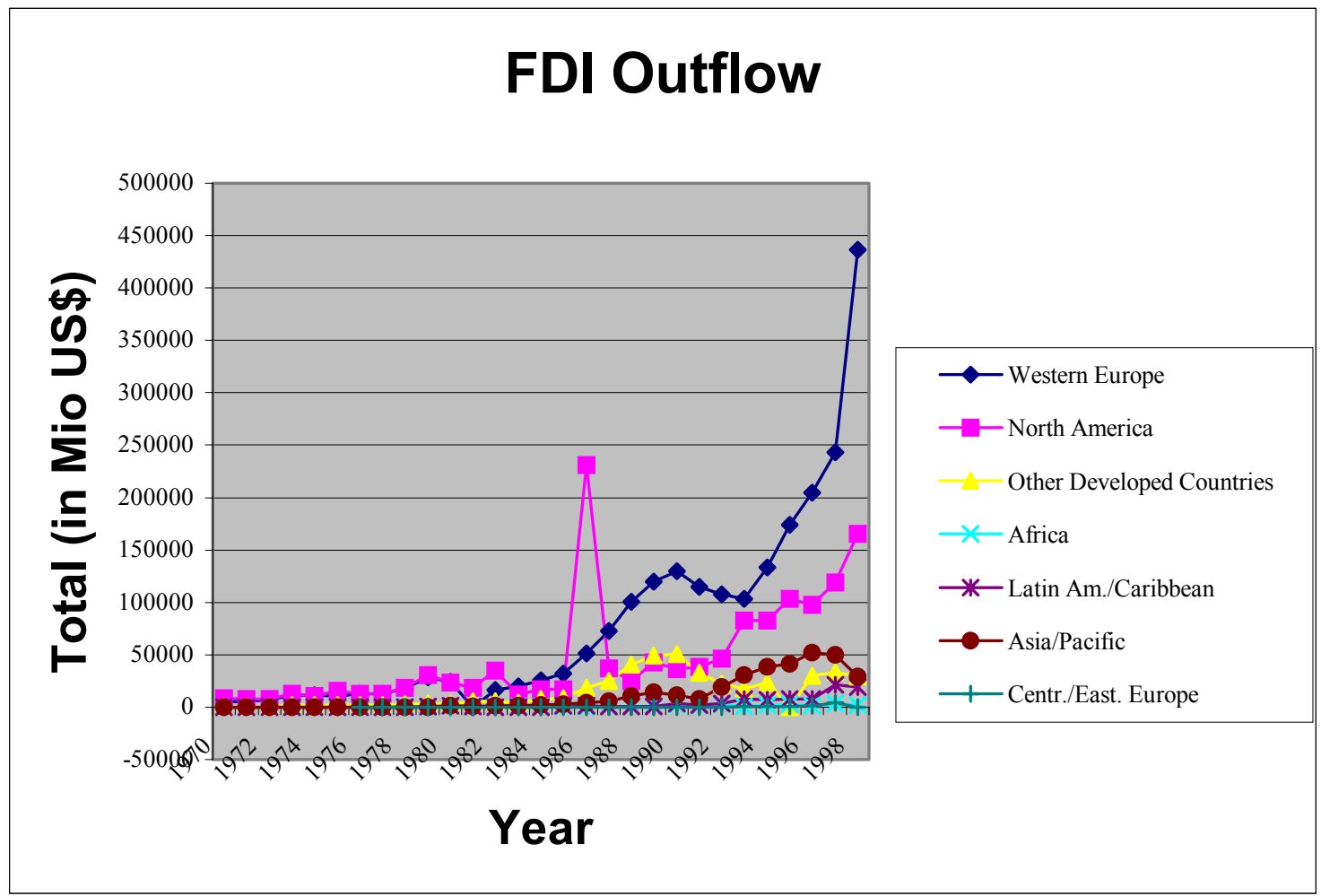

Figure 6: Distribution of Global FDI Outflows (Data Source: UNCTAD Online Handbook of Statistics, http://www.unctad.org/; the countries summed up as "other developed countries" are: Australia, Israel, Japan, New Zealand).

Table I.2. Distribution of world FDI inflows, 1986-2001

(Percentage)

\begin{tabular}{|c|c|c|c|c|c|}
\hline Region & $1986-1990$ & 1991-1992 & $1993-1998$ & $1999-2000^{\text {a }}$ & 2001 \\
\hline Developed countries & 82.4 & 66.5 & 61.2 & 80.0 & 68.4 \\
\hline Western Europe & 38.4 & 46.0 & 33.7 & 51.9 & 45.7 \\
\hline European Union & 36.2 & 45.3 & 32.1 & 50.2 & 43.9 \\
\hline Japan & 0.2 & 1.2 & 0.3 & 0.8 & 0.8 \\
\hline United States & 34.6 & 12.7 & 21.7 & 22.6 & 16.9 \\
\hline Developing countries & 17.5 & 31.2 & 35.3 & 17.9 & 27.9 \\
\hline Africa & 1.8 & 2.2 & 1.8 & 0.8 & 2.3 \\
\hline Latin America and the Caribbean & 5.0 & 11.7 & 12.3 & 7.9 & 11.6 \\
\hline Asia and the Pacific & 10.6 & 17.4 & 21.2 & 9.2 & 13.9 \\
\hline Central and Eastern Europe & 0.1 & 2.2 & 3.5 & 2.0 & 3.7 \\
\hline \multicolumn{6}{|l|}{ Memorandum } \\
\hline Least developed countries & 0.4 & 1.1 & 0.6 & 0.4 & 0.5 \\
\hline
\end{tabular}

Source: UNCTAD, FDI/TNC database.

a Years characterized by exceptionally high cross-border M\&A activity.

Note: The shaded years are FDI trough periods, while non-shaded years are FDI growth periods.

Table 5: Distribution of world FDI inflows, 1986-2001, in relative terms. Source: UNCTAD 20002, p. 7.

FDI instock as percentage of GDP increased on a global scale from $6 \%$ in 1980 , to $9 \%$ in 1990 , and $20 \%$ in 2000 , in the developed countries the increase was from $19805 \%$ to $19908 \%$ and $200017 \%$, in Africa the increase was from 1980 9\% to $199011 \%$ and 2000 26\%, in Latin America/Caribbean from 1980 6\% to $199010 \%$ and $200031 \%$, in Asia/Pacific from 1980 13\%, 1990 15\%, and $200032 \%$ (UNCTAD Online Handbook of Statistics). FDI outstock as percentage of GDP increased on a global scale from $5 \%$ in 1980 to $8 \%$ in 1990 and to $20 \%$ in 2000 , in developed countries this increase was from $19806 \%$ to $199010 \%$ and $200022 \%$, in developing countries the increase was rather modest from $19801 \%$ to 1990 $3 \%$ and $200012 \%$ (there was a more rapid increase from 1998 onwards due to more foreign investment 
from South, East and South-East Asian countries, mainly China, South Korea, Malaysia, Singapore, and Taiwan) (ibid.). This shows that the economies of African, Latin American, and Asian countries are increasingly more dependent on foreign capital, whereas this is not the case in Western industrialized countries and Japan. An increasing share of GDP is made up by FDI in Western countries, whereas this is not the case in developing countries. This means that developing countries are highly dependent on Western capital and that this dependence has increased during the last 30 years.

Globalization sceptics such as Hirst and Thompson (1999) argue that there is no such thing as globalization because the majority of FDI flows would remain within OECD countries. The argument is true, but as statistical data show total FDI flows have massively increased during the last decades, outflows mainly stem from OECD countries, but concerning inflows Asia and Latin America are today much more important than some decades ago. Hence there are both quantitative and qualitative changes of capital export. Another sceptic argument is that in OECD countries like France, Germany or the UK FDI as percentage of home country GDP is today lower than at the beginning of the $20^{\text {th }}$ century. This is true, but doesn't mean that globalization is a myth. Capitalism is a dynamic system, there might be phases of more or less intensive trade and investment. The classical era of imperialistic development at the end of the $19^{\text {th }}$ century and the beginning of the $20^{\text {th }}$ century was characterised by massive outward capital investments of Western countries, the era of Fordism that followed was characterised by relatively selfsustaining national economies in comparison to the era of imperialism. If one compares the Fordist mode of capitalistic development with the post-Fordist mode one will indeed find a massive quantitative increase of capital export and new qualities of global production (like joint ventures, strategic alliances, participative management, diffused and outsourced forms of global production). It is true that globalization is an old phenomenon (indeed a phenomenon that can be found in all self-organizing systems), but today we are witnessing new qualities of economic (and other forms of) globalization.

Considering world trade statistically (tab. 6), one sees that the export share (in world exports) has decreased during the last 50 years in North America, Latin America, Central/Eastern Europe, and Africa, whereas it has increased in Western Europe and Asia; the import share (in world import) has decreased during the last 50 years in Latin America, Central/Eastern Europe, Africa, increased in North America, Asia, and remained constant in Western Europe. The majority of imports and exports takes place in North America and Europe, Asia has played an increasing important role in world trade during the last 50 years (due to Japan and the Southeast Asian countries), Latin America and Africa have increasingly become more unimportant in world trade.

The absolute majority of world trade takes place within North America and Western Europe, Japan and Southeast Asia also play an important role in world trade. The vast majority of FDI outflows stems from Western Europe and North America, also the majority of FDI inflows go to these two regions, but concerning inflows Southeast Asia and Latin America are of increasing importance. The share of worldwide foreign direct investment inflow into the developing countries has decreased from $20,9 \%$ in the period $1970-1974$ to $11.7 \%$ in 1988 , whereas it has increased from $78,9 \%$ to $88,3 \%$ in the Western industrial countries (Hopkins et al. 1998: 73). Christopher Chase-Dunn (2001) has shown that the rate of investment globalization (total foreign investment/total GDP) has increased since 1985, but that the ratio has in 1992 not been higher than in $1913^{\circ}$. These data show that Postfordist economic globalization doesn't mean increased investment in the Third World or only quantitative increase in foreign capital investment or world trade. Postfordist economic globalization means the creation of new basic conditions for the valorization processes of capital in the form of the deregulation, dismantling and removing of the

\footnotetext{
${ }^{9}$ The investment globalization ratio has in 1992 as well as in 1913 been at approx. 0.09, the trade globalization ratio (sum of the value of global exports/sum of all national GDPs) has in 1913 been at approx. 0.09 and in 1992 at approx. 0.13) (Chase-Dunn 2001). The trade globalization ratio has during the 20th century progressively increased except in two phases of slump, whereas the investment globalization ratio has only massively increased during the last 20 years (ibid.).
} 
institutional barriers for these processes as well as the internationalization of capital in the sense of a polarization and concentration of world trade and capital export and foreign direct investments. This concentration can be described as a triadization (concentration within the three large economic regions Europe, United States and Southeast Asia/Japan), concerning capital export, but not world trade, also Latin America is of some importance. The Third World, especially Africa, is increasingly uninteresting for Western economic interests and is simply neglected and excluded. The newly industrializing Asian countries are the primary focus of Western capital export outside of the OECD.

$\begin{array}{lllllll}1948 & 1953 & 1963 & 1973 & 1983 & 1993 & 200\end{array}$

\begin{tabular}{|c|c|c|c|c|c|c|c|}
\hline \multirow{4}{*}{ World } & \multicolumn{7}{|c|}{ Exports } \\
\hline & \multicolumn{7}{|c|}{ Value } \\
\hline & 58,0 & 84,0 & 157,0 & 579,0 & 1835,0 & 3671,0 & 5984,0 \\
\hline & \multicolumn{7}{|c|}{ Share } \\
\hline World & 100,0 & 100,0 & 100,0 & 100,0 & 100,0 & 100,0 & 100,0 \\
\hline North America & 27,3 & 24,2 & 19,3 & 16,9 & 15,4 & 16,6 & 16,6 \\
\hline Latin America & 12,3 & 10,5 & 7,0 & 4,7 & 5,8 & 4,4 & 5,8 \\
\hline Mexico & 1,0 & 0,7 & 0,6 & 0,4 & 1,4 & 1,4 & 2,6 \\
\hline Brazil & 2,0 & 1,8 & 0,9 & 1,1 & 1,2 & 1,1 & 1,0 \\
\hline Argentina & 2,8 & 1,3 & 0,9 & 0,6 & 0,4 & 0,4 & 0,4 \\
\hline Western Europe & 31,5 & 34,9 & 41,4 & 45,4 & 38,9 & 44,0 & 41,5 \\
\hline C./E. Europe/Baltic States/CIS a & 6,0 & 8,1 & 11,0 & 9,1 & 9,5 & 2,9 & 4,8 \\
\hline Africa & 7,3 & 6,5 & 5,7 & 4,8 & 4,4 & 2,5 & 2,4 \\
\hline South Africa $b$ & 2,0 & 1,7 & 1,5 & 1,0 & 1,0 & 0,7 & 0,5 \\
\hline Middle East & 2,0 & 2,7 & 3,2 & 4,1 & 6,8 & 3,4 & 4,0 \\
\hline Asia & 13,6 & 13,1 & 12,4 & 14,9 & 19,1 & 26,1 & 25,0 \\
\hline Japan & 0,4 & 1,5 & 3,5 & 6,4 & 8,0 & 9,9 & 6,7 \\
\hline China & 0,9 & 1,2 & 1,3 & 1,0 & 1,2 & 2,5 & 4,4 \\
\hline India & 2,2 & 1,3 & 1,0 & 0,5 & 0,5 & 0,6 & 0,7 \\
\hline Australia and New Zealand & 3,7 & 3,2 & 2,4 & 2,1 & 1,4 & 1,5 & 1,3 \\
\hline Six East Asian traders & 3,0 & 2,7 & 2,4 & 3,4 & 5,8 & 9,6 & 9,5 \\
\hline \multicolumn{8}{|l|}{ Memorandum item: } \\
\hline \multirow[t]{3}{*}{ GATT/WTO Members c } & 60,4 & 68,7 & 72,8 & 81,8 & 76,0 & 89,5 & 92,5 \\
\hline & \multicolumn{7}{|c|}{ Imports } \\
\hline & \multicolumn{7}{|c|}{ Value } \\
\hline \multirow[t]{2}{*}{ World } & 66,0 & 84,0 & 163,0 & 589,0 & 1881,0 & 3770,0 & 6270,0 \\
\hline & \multicolumn{7}{|c|}{ Share } \\
\hline World & 100,0 & 100,0 & 100,0 & 100,0 & 100,0 & 100,0 & 100,0 \\
\hline North America & 19,8 & 19,7 & 15,5 & 16,7 & 17,8 & 19,8 & 22,5 \\
\hline Latin America & 10,6 & 9,3 & 6,8 & 5,1 & 4,5 & 5,2 & 6,1 \\
\hline Mexico & 0,8 & 1,0 & 0,8 & 0,6 & 0,7 & 1,8 & 2,8 \\
\hline Brazil & 1,7 & 1,6 & 0,9 & 1,2 & 0,9 & 0,7 & 0,9 \\
\hline Argentina & 2,4 & 0,9 & 0,6 & 0,4 & 0,2 & 0,4 & 0,3 \\
\hline Western Europe & 40,4 & 39,4 & 45,4 & 47,4 & 40,0 & 43,1 & 40,3 \\
\hline C./E. Europe/Baltic States/CIS a & 5,8 & 7,6 & 10,3 & 8,9 & 8,4 & 2,9 & 4,3 \\
\hline Africa & 7,6 & 7,0 & 5,5 & 4,0 & 4,6 & 2,6 & 2,2 \\
\hline South Africa $b$ & 2,2 & 1,5 & 1,1 & 0,9 & 0,8 & 0,5 & 0,5 \\
\hline
\end{tabular}




$\begin{array}{lrrrrrrr}\text { Middle East } & 1,7 & 2,0 & 2,3 & 2,8 & 6,3 & 3,4 & 2,9 \\ \text { Asia } & 14,2 & 15,1 & 14,2 & 15,1 & 18,5 & 23,4 & 21,9 \\ \text { Japan } & 1,0 & 2,9 & 4,1 & 6,5 & 6,7 & 6,4 & 5,6 \\ \text { China } & 1,1 & 1,7 & 0,9 & 0,9 & 1,1 & 2,8 & 3,9 \\ \text { India } & 3,1 & 1,4 & 1,5 & 0,5 & 0,7 & 0,6 & 0,8 \\ \text { Australia and New Zealand } & 2,6 & 2,4 & 2,3 & 1,6 & 1,4 & 1,5 & 1,2 \\ \text { Six East Asian traders } & 3,0 & 3,4 & 3,1 & 3,7 & 6,1 & 9,9 & 8,5 \\ \text { Memorandum item: } & & & & & & & \\ \text { GATT/WTO Members c } & 52,9 & 66,0 & 74,2 & 89,1 & 83,9 & 89,1 & 93,1\end{array}$

Table 6: World merchandise trade by region and selected economy, 1948, 1953, 1963, 1973, 1983, 1993 and 2001 (Billions dollars and percentage), Source: WTO (2002)

Economic globalization is today shaped by the rise of transnational corporations (TNCs). The restructuring of corporations (decentralization, flexibilization, outsourcing, lean management, flattening of hierarchies, just-in-time-production, etc.) is aiming at increasing profits by cutting costs. The model for this is the Japanese Lean-Production-system of Toyota, hence one also quite often speaks of Toyotism. The goals of the existing forms of automation and computerisation are the decrease of labour costs in order to increase profits. Transnational corporations (TNC) are an important aspect of the Postfordist economy. Their number has increased from 7,000 in 1970 to an estimated 53,600 in 1998 (French 2000). Transnationalism is different from the export strategy and multinationalism. In a corporation that employs an export strategy a foreign branch of the corporation distributes the corporation's commodities in a specific country and is controlled by the centre of the corporation that resides in one country. Multinational corporations are based on the idea that all establishments should be relatively autonomous and should try to autonomously control certain local, regional and national markets. Transnational corporations break the production process down into small units and make use of outsourcing and sub-contracting in order to produce each unit in a part of that world where the conditions of production are attractive. Transnational corporations have a globally distributed and networked character, they produce and market different and diversified products and services all over the world on local, regional, national and international markets. TNCs account for around two-thirds of world trade and a quarter of world output (Held/McGrew/Goldblatt/Perraton 1999: 236, 272).

Tab. 7 shows the top 25 TNCs (ranked by amount of foreign assets), 5 of them have as home economy the USA, 4 Germany, 3 UK and France, 2 Japan, Spain, and Switzerland, 1 the Netherlands, Italy, Honk Kong, and Australia. TNCs are almost exclusively Western corporations.

The global cities-approach argues that the largest cities (New York, London, Tokyo, Paris, Frankfurt, Zurich, Amsterdam, Los Angeles, Sydney, São Paulo, Mexico City, Hong Kong) are the headquarters of capitalism, they would be the primary geographical nodes of global informational capitalism (cf. e.g. Castells 1989, Sassen 1991, 1995, Yeoh 1999). "The more globally the economy becomes, the higher the agglomeration of central functions in a relatively few sites, that is, the global cities" (Sassen 1991: 5). Global cities gather the most important economic and political actors of world society, they are a location of the most important infrastructures and in them one can find a concentration of corporate headquarters, service industries, international financial services, telecommunication facilities, etc. Saskia Sassen (1991) argues that there is a concentration of command-and-control functions of capitalism in a few global cities. Global cities "concentrate the infrastructure and the servicing that produce a capability for global control" (Sassen 1995: 63). A certain percentage of workers in these cities are knowledge-based workers, but these cities reflect geographies of segmentation, they are also the locus of a new low-wage and unemployed underclass. Both the richest classes and very poor classes can be found in these cities, the hierarchically segmented social space is reflected in a segmented urban space where one can find 
protected rich areas besides ghettos. Extreme affluence and extreme poverty exist side by side in these cities, but they are increasingly territorially separated by military means. The poor are excluded from access to the centres of affluence, hence Mike Davis speaks of rich areas in global cities like Los Angeles as "high-tech castles" (Davis 1990: 248). Global cities gather both cosmopolitan yuppies and excluded, impoverished individuals, winners and losers of modernization. The segmenting logic of modernization manifests itself in an urban dualism of affluence and poverty (Castells 1989: 224). "A new urban dualism is emerging from the opposition between the space of flows and the space of places: the space of flows that links places at a distance on the basis of their market value, their social selection, and their infrastructural superiority; the space of places that isolates people in their neighborhoods as a result of their diminished chances to access a better locality (because of price barriers), as well as the globality (because of lack of adequate connectivity)" (Castells 2001: 240f).

\begin{tabular}{|l|l|l|l|l|l|}
\hline Rank & Corporation & $\begin{array}{l}\text { Home } \\
\text { Economy }\end{array}$ & Industry & $\begin{array}{l}\text { Foreign Assets } \\
\text { (Mio US\$) }\end{array}$ & $\begin{array}{l}\text { Total Assets } \\
\text { (Mio US\$) }\end{array}$ \\
\hline 1 & Vodafone Group & UK & Telecomm. & 221238 & 222326 \\
\hline 2 & General Electric & USA & $\begin{array}{l}\text { Electrical \& electronic } \\
\text { equipment }\end{array}$ & 159188 & 437006 \\
\hline 3 & Esson Mobil Corporation & USA & Petroleum & 101728 & 149000 \\
\hline 4 & Vivendi Universal & F & Diversified & 93260 & 141935 \\
\hline 5 & General Motors & USA & Motor vehicles & 75150 & 303100 \\
\hline 6 & Royal Dutch/Shell & UK/NL & Petroleum & 74807 & 122498 \\
\hline 7 & BP & UK & Petroleum & 57471 & 75173 \\
\hline 8 & Toyota Motor & Japan & Motor verhicles & 55974 & 154091 \\
\hline 9 & Telefonica & Spain & Telecomm. & 55968 & 87084 \\
\hline 10 & Fiat Spa & Italy & Motor vehicles & 52803 & 95755 \\
\hline 11 & IBM & USA & $\begin{array}{l}\text { Electrical \& electronic } \\
\text { equipment }\end{array}$ & 43139 & 88349 \\
\hline 12 & VW & Germany & Motor verhicles & 42725 & 75922 \\
\hline 13 & Chevron Texaco & USA & Petroleum & 42576 & 77621 \\
\hline 14 & Hutchinson Whampoa & Hong Kong, & Diversified & 41881 & 56610 \\
\hline China & France & Electricity, gas, water & 38521 & 43460 \\
\hline 15 & Suez & Germany/USA & Motor vehicles & 36108 & 187087 \\
\hline 16 & DaimlerChrysler & Australia & Media & 35289 & 39279 \\
\hline 17 & News Corporation & Switzerland & Food \& beverages & 33119 & 39954 \\
\hline 18 & Nestlé & France & Petroleum & 31944 & 81700 \\
\hline 19 & Total Fina Elf & Spain & Petroleum & 31184 & 487763 \\
\hline 20 & Repsol YPF & Germany & Motor vehicles & 30214 & 45910 \\
\hline 21 & BMW & Japan & $\begin{array}{l}\text { Electrical \& electronic } \\
\text { equipment }\end{array}$ & 29100 & 68129 \\
\hline 22 & Sony & Germany & Electricity, gas, water & 27885 & 114951 \\
\hline 23 & E.On & Switzerland & $\begin{array}{l}\text { Machinery \& } \\
\text { equipment }\end{array}$ & 26000 & 30962 \\
\hline 24 & ABB & Netherlands & $\begin{array}{l}\text { Electrical \& electronic } \\
\text { equipment }\end{array}$ & 25980 & 35885 \\
\hline 25 & Philips Electronics & & & \\
\hline & & & Ta & & \\
\hline
\end{tabular}

Table 7: The world's top 25 non-financial TNCs, ranked by foreign assets, 2000 Source: UNCTAD (2002)

Zygmunt Bauman (1998) argues in this context that contemporary globalization has resulted into a polarisation between the globalized rich and the localized poor. The globals would be cosmopolitan, extraterritorial elites that traverse space easily and in a self-determined way, they would live in time, space wouldn't matter for them, since spanning every distance would be instantaneous. The locals would be fixed in space and locality (the "locally tied"), they would live in space that ties down time and keeps it beyond their control. The globals would travel at will and be welcomed everywhere, the locals would frequently travel illegally, would not be welcomed, and would be threatened by arrest and deportation. Mobility would be a central aspect of today's society as well as the most powerful and most stratifying factor, globals and locals would be characterized by different degrees of mobility in the sense of freedom 
to choose where to be. "Being local in a globalized world is a sign of social deprivation and degradation. [...] One difference between those 'high up' and those 'low down' is that the first may leaver the second behind - but not vice versa. Contemporary cities are sites of an 'apartheid à rebourse': those who can afford it, abandon the filth and squalor of the regions that those who cannot afford the move are stuck to. [...] The tourists travel because they want to; the vagabonds because they have no other bearable choice. The vagabonds are, one may say, involuntary tourists" (Bauman 1998: 2+86+93). There would be forceful localization and enclaves of the globalized elite, the communication between the two classes would almost break down. Bauman characterises the current mode of societal development as liquid modernity, "in 'liquid' modernity, it is the most elusive, those free to move without notice, who rule" (Bauman 1999: 120).

Economic globalization in its current form doesn't put forward a global leisure society along with global wealth, it has resulted in the constitution of a worldwide system of domination that is strictly shaped by economic interests. Toni Negri and Michael Hardt call this decentralised, flexible, networked global capitalistic system Empire: "In contrast to imperialism, Empire establishes no territorial center of power and does not rely on fixed boundaries or barriers. It is a decentered and deterritorializing apparatus of rule that progressively incorporates the entire global realm within its open, expanding frontiers. Empire manages hybrid identities, flexible hierarchies, and plural exchanges through modulating networks of command. [...] The concept of Empire is characterized fundamentally by a lack of boundaries: Empire's rule has no limits. First and foremost, then, the concept of Empire posits a regime that effectively encompasses the spatial totality, or really that rules over the entire "civilized" world. No territorial boundaries limit its reign" (Negri/Hardt 2000). Empire would be a global system of capitalistic rule, it would be based on a crisis of the sovereignty of nation states, the deregulation of international markets, an intervening global police force, as well as mobility, decentralisation, flexibilization, and the network character of capital and production.

A truly global world society requires global wealth and social security for all, the material preconditions for such a world already exist, the outcome antagonism between global wealth and global Empire depends on human practice.

\subsection{Polity: Global Participation vs. Global Control}

Political globalization today means the emergence of transnational political organizations that go beyond the nation state. These are on the one hand global political and military confederations of dominating political and economic groups and states (e.g. G8, UNO, World Security Council, NATO, Worldbank, IMF, WTO, OECD, WHO), on the other hand global social networks that are part of civil society. International non-governmental organizations (NGOs) show that world domestic policy is not just simply the aggregate of national foreign policies, it is the globalization of official decision-making institutions and of civil society which transforms itself into a global network of organizations and informal connections. NGOs increasingly address global political issues such as global poverty, the global ecological crisis, global peace and disarmament, global estrangement, and global exploitation; they demand global solutions for global problems. The number of international NGOs has rapidly increased during the last 30 years, it has more than doubled from 9521 in 1978 to 20063 in 1989, and again more than doubled from 1989 until 1999 to 43958 (fig. 7). 


\section{Number of International NGOs}

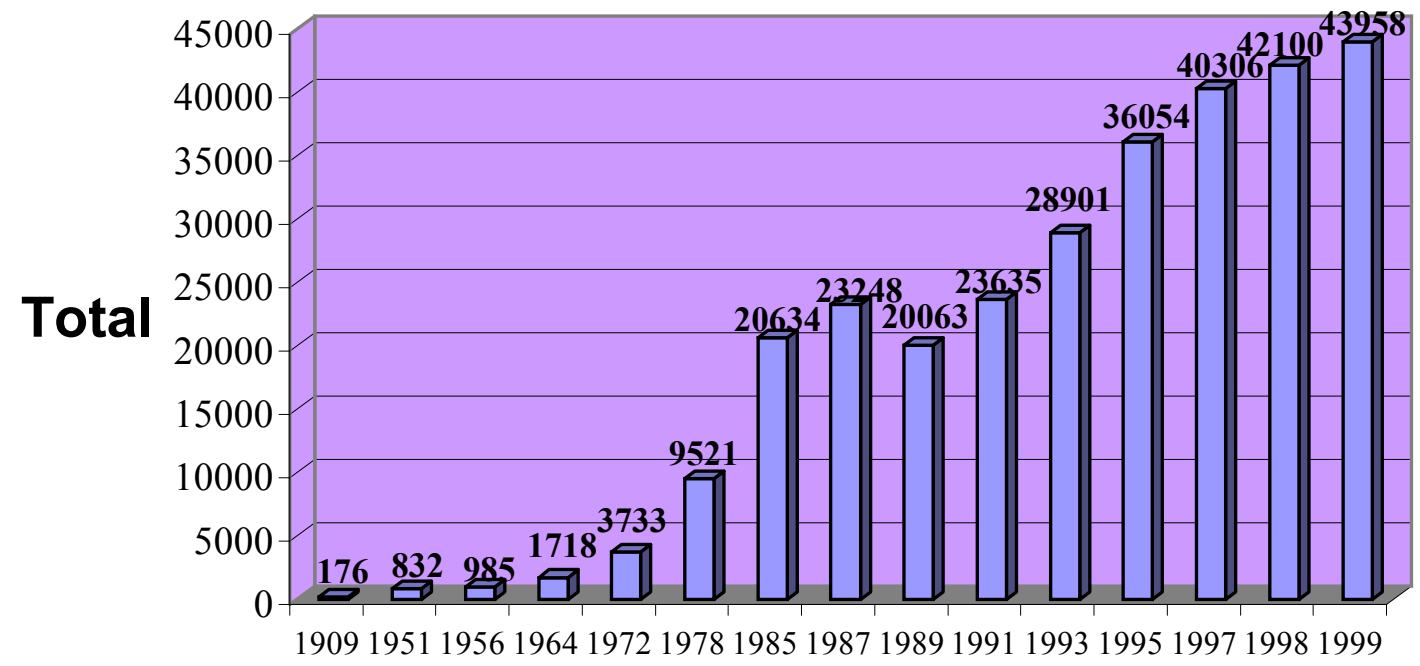

Year

Figure 7: The growth of the number of international NGOs (Data Source: Union of International Associations Online Statistics, http://www.uia.org/statistics/pub.php)

On the other hand we today also witness a form of official global politics that can be described as the global hegemony of neoliberalism. The policy of state regulation is shifting from Keynesianism to neoliberalism. Neoliberal policies aim at creating a framework for the economy that makes it possible to raise profits by minimising the costs of investment, reducing social security, and preaching self-help and self-responsibility of the individual for his/her problems and of the capability of the market to regulate itself without human intervention. This results in de-regulation, precarious job relationships, the dismantling of the welfare state, deterioration of labour and social policies, lowering of taxes on capital, flexible labour times, privatisation of formerly public services and industries, liberalisation of international trade policies, rise of new free trade associations (EU, NAFTA, APEC, AFTA, MERCOSUR etc.).

Aspects of neoliberalism include: the withdrawal of the state from all areas of social life, destruction of the welfare state and collective responsibility; preaching of self-help, self-responsibility of the individual for his/her problems and of the capability of the market to regulate itself without human intervention; growth, productivity and competition are presented as the only goals of human actions; old ultraliberal ideas are presented as modern and progressive (in fact they constitute a conservative restauration); homogenization of the money and finance markets under the dominance of a few nations; this ideology makes use of a kind of new Social Darwinism that puts across the message that only the strong and remarkable survive in society and on the market; establishment and institutionalisation of a permanent insecurity of wage and living conditions ("flexploitation") and of an individualization of work contracts; state-assistance and -subsidies for large corporations; neoliberal ideologies claim that the economy is independent from society, that the market is the best means of organizing production and distribution efficiently and equitably and that globalization requires the minimisation of state spending especially for social security; these developments are presented as something inescapable, self-evident and without alternatives. The neoliberal state creates the legal framework for flexible wages and flexible working times. Collective bargaining systems are increasingly superseded by systems at a sectoral, regional or company level. The state tries to facilitate capital investment and technological progress by subsidies, R\&D programmes, funds and institutional support. The transition to the information society has produced new areas of regulation such as data protection, data security, intellectual property rights, e-commerce, 
cybercrime. The state increasingly tries to activate entrepreneurial thinking of the individual by creating new forms of self-dependence and self-employment, reducing unemployment benefits and welfare, tightening eligibility criteria, installing sanctions and coercive activation programmes ("workfare", "welfare to work"). Pensions are increasingly cut and the retirement age lifted, private pension funds are encouraged. Universities are considered as enterprises and co-operation between universities and corporations is encouraged. Regulation is increasingly important on and shifted to the supranational, regional and local level and networks/links between cities, regions and federal states are established (also on a cross-border-basis). Certain state functions are shifted to civil society (neo-corporatism). Public enterprises and services are increasingly privatised and commercialised. Welfare is shifted from the private to the corporate level.

TNCs have become important political actors and the state has transformed itself into a competitive nation state (Cerny 1995, 1997, Hirsch 1995, 2002, Jessop 2002): Corporations invest capital where they find the best conditions of production, "movement of production" has become a threatening formula that is implicitly used by corporations to influence politics. "Globalization leads to a growing disjunction between the democratic, constitutional, and social aspirations of people - which continue to be shaped by and understood through the framework of the territorial state - and the increasingly problematic potential for collective action through state political processes. [...] But rather than the state being directly responsible for market outcomes that guarantee the welfare of its citizens, the main focus of this competition state in the world - partly analogous to the experience of state governments in the United States - is the proactive promotion of economic activities, whether at home or abroad, that will make firms and sectors located within the territory of the state competitive in international markets. The state itself becomes an agent for the commodification of the collective, situated in a wider, market-dominated playing field" (Cerny 1995). Habermas argues that "under the conditions of global competition, national governments, incapable of macro-steering to influence the cycles of their increasingly de-nationalized "popular economies", have to limit themselves to improving the relative attractiveness of their local position, i.e. local conditions for capital valuation" and that there is a "race to the bottom", a "cost-cutting deregulatory race that reduces the capacities for social-political action and damages social standards" (Habermas 2001).

There is a competition for good conditions of economic investment between nation states and hence nation states are frequently forced to facilitate privatisation, deregulation, deterioration of wages, labour legislation and welfare policies in order to attract the interest of the nomadic, flexible and transnationally operating capital. The nation state is by definition inflexible and fixed in space-time whereas capital is operating globally and is making use of modern technologies in order to decentralise its means of organization. The state attempts to fix an increasingly mobile and flexible capital in its own territorial space by creating incentives. The nation state is not a "weak state", it transforms its functions and answers with measures of re-organization to the increased globalization and complexity of the world. Welfare functions are increasingly shifted to civil society, public institutions are increasingly tossed into economic autopoiesis, self-observation, self-containment and self-description are altered in such a way that the closure of society increases although the openness of the world economy grows. Economic and political autopoiesis are not autonomously organized, it rather seems like the logic of economic autopoeisis permeates society to an increasing extent. "In Empire and its regime of biopower, economic production and political constitution tend increasingly to coincide" (Negri/Hardt 2002: 55). One answer of the nation state to increased complexity and globalization is the increase of the self-observation capacities of society. This results e.g. in law\&order-politics, increased repression towards the unemployed, tight immigration policies, militarization of border defence, upgrade and extension of internal and external defence and promotion of new measures of surveillance. Especially after September $11^{\text {th }}$ many nation states have answered to the increased complexity of the modern world with an increase of self-observation. It seems questionable to me that increased closure of society can be the adequate answer to increased globalization and complexity. 
Neoliberalism means the formation of a rigid globally dominant political system that puts forward alldominating economic interests. Many functions of the welfare state are today shifted to NPOs and NGOs, but they are not simply the "vicarious agents of neoliberalism", their modes of decentralised, networked self-organization show that political globalization can be based on global co-operation, they facilitate new progressive principles of global solidarity and participation. Many of the political NGOs that engage in critique in the new protest movements have an international character, international practices and address international issues. They constitute an alternative political form of globalization. The new social protest movements like the so-called "anti-globalization movement" - that is in fact a movement against neoliberal globalization and for an alternative, sustainable form of globalization - question global neoliberal control and argue in favour of international solidarity and global participation. Participation is an integrated notion that is based on co-operation, self-determination, and inclusion in multiple dimensions. A system can be considered as participatory if power in the system is distributed in such a way that all members and concerned individuals can own the system co-operatively and can produce, decide and live in the system co-operatively (Fuchs 2003e). The antagonism between global control and global participation shapes the political systems today, its outcome depends on human practice.

International NGOs can generally be considered as embodiments of universalism, indvidualism, rational voluntaristic authority, human progress, and world citizenship (Boli/Thomas 1999). Many of the new protest movements have a global character, their strategies reach beyond the nation state, and they represent a global civil society. Their form of organization is based on networking and coalition building. They are neither driven by concerns for the accumulation of capital or power, but are voluntary organizations that pursue progressive goals like global peace, global wealth, global justice, global environmental protection, and global human rights. These movements are multi-generational, multi-class, and multi-issue, they are united by the protest against capitalism as a "common enemy", but have different reasons for engaging in protest as well as different goals and backgrounds. Nonetheless one can say that they generally aim at global participation and radical direct democracy and reflect these goals within their decentralised, heterarchical forms of organization. They make use of new information and communication technologies in order to foster their organization and networks and for planning and co-ordinating practices. They embody the progressive principle of participation and are an expression of the increasing discontent with the existing world system. However, there is a lack of unity and clarity of larger goals, the movements are quite distant from the scientific and theoretical theories on alternative models of sociey (but its also the other way round: these theoretical works frequently are also quite distant from political practice). These new movements will only gain public credibility if they can offer plausible alternatives to the existing form of globalization. The new protest movements can be seen as a fourth generation people's movements ${ }^{10}$ (Venter/Swart 2003), they resist the globalization-from-above of markets and capital through grass-roots globalization-from-below (Falk 1999) and are an expression of the formation of "global consciousness" (Robertson 1992).

Neoliberal policy is a global form of policy because there are international political bodies like the IMF, the Worldbank, and the WTO that are keen on furthering liberalization, deregulation, and privatization all over the world. Concerning trade liberalization there is also an increasing importance of free trade agreements (EU, NAFTA, APEC, AFTA, MERCOSUR etc.). Important principles of the WTO are the most favoured nation principle (negotiated tariff cuts between countries have to be passed on to all other trade partners) and reciprocity in the sense that tariff cuts in one country should also result in tariff cuts among its trading partners. With the GATS (General Agreement on Trade and Services) the WTO is trying to apply these principles of liberalization and privatization also to public services.

\footnotetext{
${ }^{10}$ According to David Korten (1990) first generation NGOs promote local relief and welfare work, second generation NGOs promote local community and project involvement, third generation NGOs promote sustainable systems development, and fourth generation NGOs facilitate people's movements.
} 


\subsection{Culture: Global Wisdom vs. Global Imperialism}

The increasing global character of culture can be experienced in our everyday life. Many of us watch American and French films, eat Chinese, Italian, Mexican, Indian, etc. food, listen to music from all over the world, go to Southern or Caribbean countries to spend their holidays, etc. The increased global character of society results in various forms of contact between different cultures. There are several possibilities of cultural interaction (Hofkirchner 2001, 2002b). First, the reductionist form of unity without plurality: One culture sees and presents itself as the ultimate normative cultural standard that shall be realised globally. Other cultures are considered as lacking behind this standard, and hence are considered as $2^{\text {nd }}$ class or as not worth preserving. With the rise of global consumer culture, this position has sometimes been described as Americanization (Jameson 1998), McDonaldization (Ritzer 1993), CocaColonization (Wagnleitner 1994), Disneyfication (Ayres 2003, Giroux 1995), or cultural imperialism (Jameson 1998, Tomlinson 1991). CNN, Coca Cola, and McDonalds are the main symbols of this development for both those who perceive homogenisation as a threat and those who see it as the epitome of freedom, democracy, and human rights.

Second, there is the form of plurality without unity. This position has two distinctive forms. The first can be described as holistic or projective plurality without unity (fundamentalism). It projects the differences of a specific culture onto other cultures, and possibly onto all other cultures. Other than in the reductionistic position of unity without plurality it argues in favour of a separation of cultures because it considers other cultures as dangerous and a specific culture as higher value that most be protected from foreign influences. Fundamentalism is a separatistic form of plurality without unity. This is a position of cultural relativism that sees all cultural interaction or mixture as dangerous and hence argues in favour of cultural difference. Ajun Appadurai (1990) argues in this context that global flows today occur in and through the growing disjunctures between ethonscapes (global flows of tourists, immigrants, refugees, exiles, guestworkers), technoscapes (global flows of technology), finanscapes (global flows of capital), mediascapes (global flows of information and images) and ideoscapes (global flows of ideologies). Global flows would occur at great speed, scale and volume and would be unpredictable. These unpredictable flows would be considered as threat to national identities and would result in the rise of separatist movements. The global flows would be absorbed into local political and cultural economies where they would be repatriated as heterogenous dialogues of national sovereignty, fundamentalism, ethnocide, riots, mutual cannibalisation. Appadurai argues that globalization produces violent forms of difference and separation.

In its second, dualistic form, plurality without unity is conceived in such a way that all cultures would be a mixture of different cultures, there would be no general standard of unity, only different cultural traditions. The emphasis in this postmodern version of cultural interaction is on the difference of cultures and on the opposition to cultural unity. This postmodern form puts forward concepts such as multiculturalism, cultural diversity, cultural plurality, cultural difference, hybridisation/global mélange (Pieterse 1995), global ecumene (Hannerz 1989), crossover culture, creolization (Friedman 1990, Hannerz 1987), mestization (Masini 1994) or multiple identites. Cultural products like music, films, food, etc. would have an increasingly multi-cultural character.

The first position is insufficient because it doesn't acknowledge the need of local self-determination, it is imperialistic in the sense that it fetishizes the One at the expense of the Many. The second and third position are insufficient because they don't acknowledge the need of cultural interaction and a certain degree of unity and universal rights. It fetishizes locality, difference and the Many at the expense of unity and the One. We could today indeed speak of an antagonism between the One and the Many. Western economic, political, and cultural hegemony is perceived as a threat for identity by less modern or traditional nations and regions, especially in the Islamic world. The Western fetishization of the image of 
unity that is frequently defended and enforced by violent means (Afghanistan, Iraq, etc.) calls forth a fundamentalistic fetishization of difference and separation. Benjamin Barber (1995) has described this antagonism as a conflict between Jihad and McWorld: "The first scenario rooted in race holds out the grim prospect of a retribalisation of large swaths of humankind by war and bloodshed: a threatened balkanisation of nation-states in which culture is pitted against culture, people against people, tribe against tribe, a Jihad in name of a hundred narrowly conceived faiths against every kind of interdependence, every kind of artificial social cooperation and mutuality: against technology, against pop culture, and against integrated markets; against modernity itself as well as the future in which modernity issues. The second paints that future in shimmering pastels, a busy portrait of onrushing economic, technological, and ecological forces that demand integration and uniformity and that mesmerize peoples everywhere with fast music, fast computers, and fast food - MTV, Macintosh, and McDonald's - pressing nations into one homogenous global theme park, one McWorld tied together by communications, information, entertainment, and commerce" (Barber 1995: 4). Jihad and McWorld would be dialectically connected in the sense that they on the one hand are different and oppose each other, but on the other hand need one another and are interdependent.

It is important to see that this cultural antagonism is not due to an intrinsic, essential incompatibility of different cultures that hinders cultural interaction and must put forward a clash of civilizations, but that rather it is a result of the asymmetrical development of the modern world system that produces inequalities, asymmetrical distribution of power and wealth, and multiple lines of domination and exploitation. Samuel P. Huntington (1993) has argued that there are essential cultural differences that must result in cultural clashes: "It is my hypothesis that the fundamental source of conflict in this new world will not be primarily ideological or primarily economic. The great divisions among humankind and the dominating source of conflict will be cultural. [...] The clash of civilizations will dominate global politics. The fault lines between civilizations will be the battle lines of the future" (Huntington 1993: 27). This would be the case because there would be basic historical differences among civilizations concerning the relations between God and man, the individual and the group, the citizen and the state, parents and children, husband and wife, as well as concerning questions of rights, responsibilities, liberty, authority, equality, and hierarchy. Globalization would increase the interactions between peoples of different civilisations and would result in the awareness of differences. There would be a strong dividing fault line between Western and Islamic civilizations, the West would be required to "maintain the economic and military power necessary to protect is interests" (Huntington 1993: 33) in relation to other civilizations. Huntington conceives cultural relationships in terms of competition, hostility, and incompatibility. He disregards that today there is and that historically there has been also a great deal of cultural dialogue. For him the source of conflict are differences in values and belief, he ignores the asymmetrical global distribution wealth, power, and recognition. Cultural conflicts are today in fact not due to essential differences in values that can't be reconciled (universal human rights just like crusades against the faithless can e.g. be both be given reason for by referring to the Bible or the Koran), but due to the material differences and hierarchies produced by worldwide capitalism. For Huntington there can be no cultural dialogue or a world of material and cultural harmony, only a world of different civilizations that is shaped by competition.

This cultural antagonism has been produced by the capitalistic world system and has culminated in the attacks of September $11^{\text {th }}, 2001$ and a new vicious cycle of radicalization and violence. "The World Trade Center was a symbol of America's global hegemony in the economic realm, and the Pentagon is obviously the icon of its military preeminence around the world. [...] there are many around the world, including a number within the Islamic world, who are waging war against McDonaldization and American-style consumerism" (Ritzer 2002). Each side radicalizes its position (fetish of unity or difference), this results in the further radicalization of the other side, etc. The outcome is a highly dangerous and explosive situation that can't be solved by military means, but only by mutual dialogue. A global cultural system exists today, but it is one with unequal opportunities for shaping the emerging global value system. Many groups see their identity challenged by global consumerism and are unsatisfied with the unequal opportunities for 
access and participation in global culture, they experience globalization as discontent and engage in efforts to resolve these feelings of unease. "There is now one pluralistic world culture, not in the sense that there is a global consensus on matters of ultimate value, but in the sense that actors in different parts of the system share at least some conceptions about what the world is like and what is worth striving for" (Lechner 1989). Frank Lechner $(1989,1993)$ argues that this cultural unease results in various movements of world rejection. Fundamentalists, anti-modernists, anti-globalization activists, nationalists, etc. are not simply anti-global movements, they are active parts of the globalization of society and in their actions they permanently refer to the consequences of globalization. They either suggest a global fundamentalist system (guided by religious principles) or cultural separation as solutions, there is both a universalistic and a particularistic form of fundamentalism. Fundamentalism "takes on the tensions produced by the clash between a universalising global culture and particular local conditions. [...] [It] has its origins in real discontents experienced by real people" (Lechner 1993: 340f).

In this respect a third form of cultural interaction seems feasible, namely unity in plurality. This position acknowledges the dialectical relationship of the global and the local, the One and the Many and argues that global dialogue and cultural contact is necessary in order to realise fundamental human values that shall apply for all human beings, but that at the same time there shall be no actor that can absolutely define these values. Hence global values shall be constituted consensually and in herrschaftsfreiem Dialog (non-dominative dialogue, Habermas 1984, 1987). Unity in plurality is a form of cultural interaction where different local values, identities, traditions and patterns are preserved and acknowledged, but where there is also an emphasis on a mixture of culture and the construction of a certain degree of global unity and identity in order to advance global peace and wealth for all.

Hegel has outlined that Identity and Difference and the One and the Many are dialectically connected. A thing would be identical with itself, a reflection-into-self $(A=A)$ (Hegel 1830I: §113). "Essence is mere Identity and reflection in itself only as it is self-relating negativity, and in that way self-repulsion. It contains therefore essentially the characteristic of Difference" (ibid.: §116). A thing is only what it is in difference to other things, it is also reflection-into-other. But a thing is not only identical with itself and different from other things, there is also a unity of a thing and other things on a higher level. Hegel calls this unity the Ground. "The Ground is the unity of identity and difference, the truth of what difference and identity have turned out to be - the reflection-into-self, which is equally a reflection-into-other, and vice-versa" (ibid.: $\S 121)^{11}$. Something is only what it is in its relationship to another, but by the negation of the negation this something incorporates the other into itself. The dialectical movement involves two moments that negate each other, a somewhat and an other. As a result of the negation of the negation, "Something becomes an other; this other is itself somewhat; therefore it likewise becomes an other, and so on ad infinitum" (ibid: §93). Being-for-self or the negation of the negation means that somewhat becomes an other, but this again is a new somewhat that is opposed to an other and as a synthesis results again in an other and therefore it follows that something in its passage into other only joins with itself, it is self-related (ibid.: §95). In becoming there are two moments (Hegel 1812: §176-179): coming-to-be and ceasing-to-be: by sublation, i.e. negation of the negation, being passes over into nothing, it ceases to be, but something new

\footnotetext{
${ }^{11}$ Hegel not only discusses the dialectical relationship of Identity and Difference, but similarly also the dialectic of the One and the Many when he points out the dialectical concept of matter. 11 "The One, as already remarked, just is self-exclusion and explicit putting itself as the Many. Each of the Many however is itself a One, and in virtue of its so behaving, this all rounded repulsion is by one stroke converted into its opposite - Attraction [...]. But the Many are one the same as another: each is One, or even one of the Many; they are consequently one and the same. Or when we study all that Repulsion involves, we see that as a negative attitude of many Ones to one another, it is just as essentially a connective reference of them to each other; and as those to which the One is related in its act of repulsion are ones, it is in them thrown into relation with itself. The repulsion therefore has an equal right to be called Attraction; and the exclusive One, or Being-for-self, suppresses itself. The qualitative character, which in the One or unit has reached the extreme point of its characterisation, has thus passed over into determinateness (quality) suppressed, i.e. into Being as Quantity“ (Hegel 1874: §97f).
} 
shows up, is coming to be. What is sublated (aufgehoben) is on the one hand ceases to be and is put to an end, but on the other hand it is preserved and maintained (ibid.: §185).

The theory of self-organization has several philosophical implications (cf. Fuchs 2003c, d):

1. Self-organizing systems are shaped by a dialectic of determinism and indeterminism, necessity and chance. One can say that it incorporates both a closed causality and an open causality.

2. Emergence means that many Ones that are opposed to and different from many Others synergetically produce a new Whole or Identical One.

3. Self-organizing systems are shaped by a dialectic of globality and locality: There are general principles of self-organization that apply to all types of self-organizing systems, but also specific principles for each special type of system.

One can say that (as Hegel as well as self-organization theory have shown) philosophically the Global and the Local, the One and the Many, Identity and Difference, Unity and Plurality are in essence dialectically connected, Unity in Plurality is a "natural" relationship of complex systems, it is part of their essence. If actuality is different from essence because there is e.g. the domination of a unity without plurality or a plurality without unity, then these are false relationships that shall be transformed into true ones because the actuality of these categories doesn't correspond to their essence.

The universal is not the same as the global and the particular not the same as the local, although important theorists of globalization like Roland Robertson (1992) tend to mix up and use these terms interchangeably. Robertson conceives globalization as a two-fold process of the universalization of particularism and the particularization of universalism and has coined the term glocalization for stressing the interconnectedness of both concepts. As an example he mentions the tendency in consumerist global capitalism for globewide supply, particularistic demand, and the tailoring of products to increasingly specialised regional, societal, ethnics, class and gender markets - so-called "micro-marketing" (Robertson 1992: $100,173,177 f)$

I suggest that the universal has to do with aspects of global culture, i.e. a global applicability of norms, rights and values. This can best be illustrated by the discourse about universal human rights. The idea of the universal applicability got a boost from the Enlightenment and the formation of modern society, universal rights were seen in terms of freedom, equality, and fraternity and were the cultural dimension of the expansion of freedom in the sense of a free market, private ownership and "double free" wage labour. Socialism has established an alternative form of universalism that challenges the global existence of private ownership and class-based society and argues that the universal values put forward by bourgeois democracy have an ideological character that serves the installation of a global system of exploitation. Capitalism wouldn't be a truly universal system in the sense that it is based on universal participation and wealth. Socialism started from an alternative version of universalism, but degraded into an ideology of particularism. A third important aspect of universalism in modern society has been modern science that is based on the search for universal truths that can be proved by standardised methods. The universal describes the ethical dimension of the global, only certain global developments have a universal character. "The global is not a synonym for the universal; global interconnectedness is not experienced by all peoples or communities to the same extent or even in the same way" (Held/McGrew/Goldblatt/Perraton 1999: 28). A global development is universal when all have access to it, can participate in it and benefit from it. Today we find e.g. a global economic system and global technological networks, but these are not universal achievements because they are characterised by unevenness, disparities, segmentations, and stratifications, i.e. only certain groups benefit from the increase of productivity and wealth and the increased speed, intensity and extensity of communication. The unity of universal particularism and particular universalism corresponds to the idea of unity in plurality as humane form of cultural globalization. 


\subsection{Globalization and the Third World}

After outlining basic aspects of the five dimensions of the globalization of modern, capitalist society, it makes sense to make some remarks on globalization and the Third World because developing countries have been particularly experiencing the negative side of modernization and globalization.

The United Nations Human Development Report (UNDP 1999, 2002, 2003) provides data that document the rise of poverty, exclusion, misery, and inequality in many parts of the Third World ${ }^{12}$. During the last 30 years life expectancy increased by 8 years, illiteracy has been cut nearly in half to $25 \%$, in East Asia the number of people surviving on less than $1 \$$ a day was almost halved during the 1990ies. India and China have been successful in lifting many people out of income poverty. These are positive results, but in many other parts of the Third World the living conditions have worsened. 54 countries are poorer now than in 1990. There is a decline in 21 countries in the HDI (measures long and healthy life, education, standard of living). Of the 54 countries with declining income, 20 are from Sub-Saharan Africa, 17 from Eastern Europe and the Commonwealth of Independent States (CIS), 6 from Latin America/Pacific, and 5 from Arab States.

More than 1.2 billion people - one in every five on Earth - survive on less than $1 \$$ a day. During the 1990s the share of people suffering from extreme income poverty fell from 30 to $23 \%$. But the total number just fell by 123 million (growing world population). Excluding China the number increased by 28 million (China has managed to lift 150 million - $12 \%$ of the population - out of poverty during the 1990s). But in Latin America, the Caribbean, the Arab States, Central and Eastern Europe, and Sub-Saharan Africa the number of people surviving on less than $\$ 1$ a day increased. From 1990 to 1999, in SubSaharan Africa the percentage increased from 47,4 to 49,0, in Latin America/the Caribbean it increased from $11,0 \%$ to $11,1 \%$, in Central+Eastern Europe and the CIS from $6,8 \%$ to $20,3 \%$, in the Middle East/North Africa from 2,1\% to 2,2\%. Only in East Asia and the Pacific it has been reduced from 30,5\% to $15,6 \%$.

Over the past two decades income inequality worsened in 33 of 66 developing countries with data. The number of hungry people nearly fell by 20 million in the 1990s, but excluding China it increased, especially in South Asia and Sub-Saharan Africa. One in six of the world's adults is illiterate, $80 \%$ of children in developing countries are enrolled in primary schools, but in South Asia (54\%) and Sub-Saharan Africa (57\%) enrolments are low. Only one of three African children enrolled in primary school completes this education. Illiterates are mainly female. Every year more than 10 million children die of preventable illnesses. More than 500000 women a year die in pregnancy and childbirth, with such deaths 100 times more likely in Sub-Saharan countries than in high-income OECD countries. 39 million of the 42 million people living with HIVIAIDS are located in developing countries. More than 1 billion people in developing countries - one person in five - lack access to safe water, 2,4 billion lack access to improved sanitation.

The richest $5 \%$ of the world's people receive 114 times the income of the world's poorest $5 \%$, the richest $1 \%$ receive as much as the poorest $57 \%$, the 25 million richest Americans have as much income as almost almost 2 billion of the world's poorest people, in 1820 Western Europe's per capita income was 2,9 times Africa's, in 1992 it was 13,2 times. The income gap between the fifth of the world's people living in the richest countries and the fifth in the poorest was 74 to 1 in 1997, up from 60 to 1 in 1990, and 30 to 1 in 1960 (UNDP 2002). The assets of the top three billionaires are more than the combined GNP of all least developed countries and their 600 million people (UNDP 1999). The fifth of the world's people living in the highest-income countries had in the late 1990 s $86 \%$ of world GDP, the bottom fifth just $1 \%$ (UNDP 1999).

\footnotetext{
${ }^{12}$ If not indicated otherwise the data stem from the United Nations Human Development Report 2003 (UNDP 2003).
} 
Globalization is not a universal and wise process because it doesn't benefit all to the same extent and indeed causes problems for and exclusion of many. Globalization involves processes of time-space distanciation in the sense that the lives of people all over the world are increasingly shaped by decisions taken at a distance. Globalization is an uneven process that is experienced differently by different people and benefits different people differently. When we speak about globalization we also have to speak about the fact that modernization has produced the globalization of poverty and inequality. People in the developing countries are especially affected by both phenomena. Hence when we talk about globalization, we also have to talk about globalization and the Third World (cf. e.g. Kiely/Marfleet 1998).

People in developing countries have had to experience the negative side of the globalization of modernity in the form of colonialism. Classical theories of imperialism and underdevelopment have argued that the development of the First World depends on the underdevelopment of the Third World, that through exploitation of surplus value and unequal exchange poverty in the Third World rises and causes the accumulation of capital and wealth in the First World. There is still some truth to these assumptions, but the relationships between developing and developed countries also have to a certain extent changed. TNCs investing in the Third World, wars against developing countries like Iraq, and the debt trap are an expression of the extraction of surplus value from the Third World. Unequal exchange still is a major problem because developing countries lack behind the productivity of Western technology and frequently have less speed of innovation. Hence their exported products are rather labour-intensive, i.e. they have a high value, whereas many Western products have competitive advantages on the world market due to a lower value. This results in the fact that frequently Third World countries have to sell their products on the world market below the products' value or that they can't compete with Western technological advantages. This is an expression of unequal exchange because one hour of Third World labour materialized in products due to structural competition on the world market caused by Western domination will frequently sell at a price that is much lower than the actual reproduction costs of the labour force. In order to solve this problem many Third World countries try to buy expensive Western technology, frequently this doesn't improve their competitiveness, but rather increases their dependency on Western capital. The exploitation of surplus value from the Third World is frequently seen as the essence of globalization, but in fact capital export today is mainly concentrated within the three regions, North America, Europe, and South-East Asia. The Asian tiger countries (Hong Kong, Taiwan, Philippines, Malaysia, Thailand, Singapore, Indonesia, South Korea) attract Western capital, whereas large parts of the Third World - especially countries in Africa and Latin America - are excluded from the global economy. So the mechanisms that produce poverty in the Third World not only include exploitation, exclusion is the main structural force of impoverishment. Economic globalization doesn't mean a massive increase of foreign direct investment in the Third World, but the triadization of capital export and world trade, as well as the rise of the transnational strategy of production. Capital is increasingly concentrating in certain areas of the world, these areas only include certain selected parts of the Third World, capital is moving out of many parts of the Third World, the materialization of these movements of neglect and exclusion means an increase of poverty and social problems.

Colonization has been based on the assumption that Europe represents progress and the developing countries backwardness and primitiveness. Difference has been ideologically used as a ground for continuous exploitation and murder. Pessimists argue that the developing countries should delink from the global capitalist system and rely on subsistent production. Optimists argue that a full inclusion in this global system will bring Western capital and technology to the Third World and hence will increase the living conditions there. Both assumptions are wrong. It is not possible and not desirable to delink from a global system where all aspects of material production are globally interconnected. It also makes sense for Third World countries to use modern technologies in order to increase productivity and wealth, but the main problem is the unequal global distribution of wealth and technological progress. What is needed is not only local change, but also global structural change. Technology doesn't automatically cause poverty in the Third World, the opportunities and risks caused by technology depend on the global usage and 
design of technology. Capital export to the Third World doesn't mean the automatic increase of wealth in these countries because the question is how newly generated wealth is distributed. Frequently the produced surplus is consumed by local elites or is exported to the First World without much benefiting local people. Capital export to the Third World won't automatically increase local wealth, the question is how profits are locally distributed and if capital outflow exceeds capital inflow. The solution to the problem is neither local subsistence nor full integration into the world capitalist system, but the structural transformation and reform of the world system in such a way that all can benefit. First steps towards a more democratic world system could be the complete debt cancellation of developing countries and a basic income for all people in the Third World that guarantees physical survival.

Eurocentrism is based on the racist assumption that Western knowledge and technology is superior to local Third World knowledge and that scientific-technological rationality has to be spread in the developing countries in order to overcome poverty. The basic assumption is that if people in the Third World would act "more like us", they would have no social problems, and that hence social problems in the developing countries are not the result of the long history of colonialism and capitalism, but are self-inflicted. Enrique Dussel (1998) argues that Eurocentrism defines modernity as exclusively European, developing in the Middle Ages in Europe, and expanding from the seventeenth century on throughout all the "backward" cultures. Instead of this "reductivist fallacy" (ibid.: 18) an alternative modernity that considers the worldsystem as planetary in scope and includes a liberation of the excluded and oppressed would have to be established. "The concept of Western technology involves a masked essentialism and immanence that cement the relationship between the European and modern technology and posits that any participation in the technological revolution must necessarily import European culture. The implications of this ideology, which refuses to place science in a historical context and to see the evolution of Europe as a particular moment of that history, have been devastating to cultures in Africa, which are usually viewed in binary opposition to Western culture and technology" (Diawara 1998: 119).

Thus far Western rationality has made things indeed worse for the Third World, but the problem is not science or technology itself, but its racist and imperialistic usage. Third World knowledge and science is not considered as an equal partner, global science and global knowledge can only benefit all when they are universal in the sense that all can equally contribute to them and all groups are considered as equally important partners. Poverty won't be overcome by eliminating science and technology, but by finding another rationality that is participatory, sustainable, and democratic. There is no need to idealize traditional life, but also no need to idealize modern life, one can draw on elements from both in order to produce a new rationality that benefits all. This rationality would have to be based on unity in difference of knowledge. To romanticize local cultures and to see everything that is global in character as bad is as problematic as to fetishize Western cultures, both are an expression of admiring the One as opposed to the Other and hence difference and neglect that global wealth and wisdom can only be gained by Unity in Plurality, not by isolation or homogenization. There is no reason to assume that local capitalists will treat workers better than global capitalists, and that hence localized capitalist production will solve the Third World's problems. What is needed is a universal global technological, ecological, economic, political, and cultural whole where all can participate and that is guided by the spirit of partnership and co-operation. Susantha Goonatilake (1998) argues in this context that globalization opens up the possibility for a global science where the "role of a dominant center over a periphery is eroding as near-instant communication begins to spread information and knowledge creation across a wide network" (ibid.: 258). A global science is only a universal and wise science if it has an open, democratic, and participatory character. The same is true for social realms such as technology, economy, polity, culture, media, etc. Goonatilake (1994) argues that Third world countries should not focus on "fundamentalist searches for doomed cultural purities" (82) that are impossible in a world that is shaped by multiple identities and dynamic interconnected global and local communities that transcend physical and social borders that are supported by ICT, but on incorporating elements from their scientific and cultural traditions into the larger globalizing whole. 
Optimists argue that Western technology will automatically benefit the Third World, it will create jobs and wealth, pessimists argue that Western technology enslaves people in the Third World by lowering working conditions and wages as well as displacing workers and destroying traditional life. Both assumptions are deterministic and don't take into account that technology is socially constructed. Without modern technology there can be no life without hard work and poverty, without changing modern technology into an alternative, appropriate, alliance technology for the people such life will increasingly be possible only for a minority, whereas a sustainable technology could indeed provide these benefits for all.

People in the developing countries are not simply objects of globalization and modernization processes that cause poverty and inequality, they are also active subjects within the world system. There is not just the domination of the periphery by the core as a passive process because the Third World does have the structural power to act as a subject and try to change this situation. The end of direct colonialism, the end of apartheid in South Africa, social movements in the developing countries that question Western dominance, protests against structural adjustment programmes of the IMF and the World Bank, and the rise of the newly industrializing countries (NICs) show that the objects of domination are subjects of resistance to this domination. The images of the Third world that are presented by global media in the West draw a picture of Africa, Asia, and Latin America as corrupt, primitive, backward, and being ruled by infectious diseases, warlords, and ethnic cleansing. There is a lack of recognition of the value of the variety of Third World culture, production, knowledge, science, art, and philosophy.

Capital export to the developing countries can mainly be found in labour-intensive areas of manufacturing like clothing, toys, and textiles industries, or the assembly stage of high-tech production. TNCs have partly relocated production to the NICs of East Asia in order to decrease labour costs. Exportprocessing zones (EPZs) that are locales of so-called world market factories and are characterized by low wages and taxes and minimal regulations have been set up in parts of the Third World in order to attract global capital. The flexibility and nomadic nature of global capital has frequently caused super-exploitation of Third World workers (low wages, bad working conditions), but this is not an automatic process. For many developing countries delinking from global capitalism and hence not attracting Western capital is not a feasible short-term strategy because delinking in a globally interconnected economy means advancing exclusion from the global economy. A feasible short-term strategy hence should focus on regulating Western capital in the Third World in such a way that working conditions are improved, wages increased, social security is implemented, and the taxation of capital is increased. Such a strategy requires global coordination. A feasible long-term strategy is not the establishment of islands of subsistence within a global capitalist system, but the socially and ecologically sustainable transformation of the world system.

Decolonization is considered by many in Africa, Asia, and Latin America not as the end of colonialism, the latter would have transformed its nature and appearance. Transnational capitalism would be a continuation of colonialism with other means, whereas old colonialism relied on direct violence and political control, neocolonialism relies on the violence of economic forces. "Colonialism continues through global capitalism. After the withdrawal of administrative colonialism, the global space created by the empire is filled by TNCs. Thus, even after independence, the bondage of the colonized has remained fixed" (Subramani 1998: 147). Masao Miyoshi argues that transnational capitalism is "the continuation of exploitation and colonialism, domestic and overseas" (1998: 258). "TNCs and MNCs are readily capable of ignoring borders and creating areas of poverty in any place, either in Oregon or Jakarta. And when the Indonesian labor demands become too exorbitant, the Nike operation might move again, this time to China, the Philippines, Vietnam, to the sweatshops in Los Angeles, California, or New York City, [...] or even to the inside of state prisons and penitentiaries, where literal slave labor is being carried on with the approval and support of the taxpayers of the United States" (ibid.: 257f). 
Capital-intensive industries are mainly located in Western countries, Third World countries are confronted with a technological knowledge and skills gap, it takes time and money to establish a work force and science that can keep up with the speed of Western innovation. Hyper-mobility and transnationalism are mainly characteristic of labour intensive production, this is where the exploitation of surplus value in the Third World is of some importance. In the area of capital-intensive production, the main structural mechanism that affects the Third World is not exploitation, but the unequal nature of capitalism that causes skills and knowledge gaps and hence provides the developed areas with major competitive advantages that further the exclusion of the Third World. But the Third World is not the passive object of Western technological dominance, the rise of Toyotism and the Japanese economy since the 1970ies and the fact that the industrialization of the Asian NICs has not been mainly caused by Western TNCs, but by an alliance between local capital and the state, show that also within the capitalist system Third World countries can become important actors in innovation and RTD.

Western capitalism hasn't simply culturally homogenized the Third World through consumer culture, migration and globalization also bring Southern and Eastern cultural elements to the West, not all people and groups in the Third world are sympathetic to Western culture, values, and consumerism, and not all Western popular culture is an expression, but sometimes rather a critique of Western domination and lifestyle (e.g. The Simpsons or rap music). Western consumer culture represents the attempt to commodify the whole planet, but this attempt itself is an antagonistic process that produces unexpected readings, outcomes, and struggles.

Neoliberal policies are based on the assumption that all social problems are caused by state intervention. "The neo-liberal remedy for [...] [the problems of the Third World] was the encouragement of the private sector and the liberalisation of Third World economies. Three key policy proposals were recommended: currency devaluation, rolling back the state and the liberalisation of international trade" (Kiely 1998a: 32). Unhindered market forces and deregulation are proposed as measures for reducing poverty by neoliberalism. The structural adjustment programmes introduced by many Third World governments in order to get credits from the IMF and the World Bank, have been strongly influenced by neoliberalism. But in many cases these policies haven't much improved the living conditions of the masses, rather than causing new problems such as a massive increase of the price of goods such as bread and rice that satisfy basic needs. Trade liberalization frequently doesn't benefit Third World countries because due to the technological gap they are not able to specialize in certain areas of production and hence to achieve a comparative advantage on the world market. Not the state, but the global capitalist system is the cause of poverty in the Third World, the state can to a certain extent improve the situation of the poor in the Third World by regulating prices and capital flows, providing the poor and disadvantaged with subsidies, imposing controls and limitations on capital, and redistributing wealth. "Although states in the Third World may be weaker in their attempts to regulate the control of TNCs, they are not passive“ (Kiely 1998b: 55). Neoliberal development policies have been falsified by the dramatic persisting rise of poverty in the Third World.

Achille Mbembe argues that the assumption that the boundaries that separate African states were arbitrarily drawn by colonialism is wrong. "Far from being simple products of colonialism, current boundaries thus reflect commercial, religious, and military realities, the rivalries, power relationships, and alliances that prevailed among the various imperial powers and between them and Africans through the centuries preceding colonization proper. From this point of view, their constitution depends on a relatively long-term social and cultural process" (Mbembe 2000: 265). Globalization in the sense of fluid, dynamic borders and of of a relative lack of congruence between political territory and areas of exchange, tradition, language, and religion, has always been an aspect of African life. Precolonial and postcolonial African territoriality is itinerant territoriality. Today's African civil wars and armed conflicts are partly due to the fact that decolonization was carried out in such a way that certain groups have been installed as loyal ruling 
elites by the colonial powers and hence a new social and material geography of inequality has been created that continues to set off ethnical conflicts that are based on the distinction of imaginary ethnical identities. Mbembe argues that the colonial structuring of economic spaces was not abolished, but prolonged by the postcolonial regimes. Most of the border disputes in Africa would not have their origin in the desire to create ethnocultural spaces, but in the struggle to control vital resources such as water. The main problem would be borders of states don't coincide with natural borders, "the question is how to reconcile the three requirements constituted by the freedom of use, the right of access for everyone, and sovereignty over the land through which the river flows" (Mbembe 2000: 273). E.g. concerning access to the Nile there are conflicts involving Burundi, Congo, Ethiopia, Egypt, Kenya, Rwanda, Tanzania, and Uganda.

Besides water, oil, diamonds, and forests are central vital African resources that have been subject of conflicts. Since the beginning of the 1980s various Western oil companies such as Agip, Chevron, Exon, and Shell have purchased drilling permits from African governments in countries such as Angloa, Cameroon, Chad, Congo, Guinea, Nigeria. The regions where oil production by Western companies takes place have been torn apart by armed conflicts over the annexation of resources and the destruction of communities and natural environments. Armed struggles between governments supported by Western companies and social movements have emerged.

The neocolonialism of transnational capitalism and the prolongation of the colonial structuring of the access to economic resources by new African regimes have resulted in flexible boundaries and fragmented forms of sovereignty in Africa that make war and armed conflicts a permanent African reality. Slavery and colonialism have been realities of the globalization of modernity that the Africans have long been confronted with, decolonization has not resulted in global participation and global wealth, but in new unequal geographies of wealth, the exclusion of the Third World, and a continuation of colonialism with new means. Hence colonialism has been a continuous experience of people in Africa, Asia, and Latin America.

Harris (1987) has spoken of the "end of the Third World" in the sense that due to the fact that the Asian NICs compete in the global economy and have become important economic actors, the marginalization and exclusion of certain parts of the world comes to an end. I don't share this optimistic account because the reality of post-Foridst capitalism shows that large parts of the world are excluded from wealth and are facing a massive increase of poverty. Parts of the world that can generate economic value are increasingly linked in the global economic and technological networks, whereas every thing, person, group, and area that doesn't have economic value is switched of and disconnected from the networks. The persistence and aggravation of exclusion is an indication of the continuous existence of the Third World. I use the term Third World not in a ideational or ethical sense that indicates that people in these countries and their cultures are less valuable, but in a material sense that indicates that there is a large gap in wealth between parts of the world.

There is no longer a strict geographical separation between the developed and the developing countries, the Third World has not come to an end, but has globalized and diversified. Third World conditions can increasingly be found also within Western countries, the rise neoliberalism has been accompanied by a massive increase in poverty and economic and social polarization in many Western countries. Extreme poverty can be found next to extreme wealth. Manuel Castells (1998) has spoken of the rise of the Fourth World in order to describe the globalization of social exclusion. "A new world, the Fourth World, has emerged, made up of multiple black holes of social exclusion throughout the planet. The Fourth World comprises large areas of the globe, such as much of Sub-Saharan Africa, and impoverished rural areas of Latin America and Asia. But it is also present in literally every country, and every city, in this new geography of social exclusion. It is formed of American inner-city ghettos, Spanish enclaves of mass youth unemployment, French banlieues warehousing North Africans, Japanese Yoseba 
quarters, and Asian mega-cities' shanty towns. And it is populated by millions of homeless, incarcerated, prostituted, criminalized, brutalized, stigmatized, sick, and illiterate persons. They are the majority in some areas, the minority in others, and a tiny minority in a few privileged contexts. But, everywhere, they are growing in number, and increasing in visibility, as the selective triage of informational capitalism, and the political breakdown of the welfare state, intensify social exclusion. In the current historical context, the rise of the Fourth World is inseparable from the rise of informational, global capitalism" (Castells 1998: 164f).

Some observers argue that the current form of globalization hasn't widened the gap between the rich and poor, but "has actually promoted economic equality and reduced poverty" (Dollar/Kraay 2002: 120). This conclusion is derived from an analysis of global income inequality which indicates that from 1820 to 1975 income inequality increased, whereas since 1975 it has decreased and from data that show that the absolute poor (those living on less than $\$ 1$ per day) has declined by 200 million since 1980. Dollar and Kraay argue based on this foundation that decreasing poverty requires trade liberalization and structural reform in Third World countries. They provide a simplistic and reductive analysis of inequality, and concentrate only on single effects and opportunities, not on the dynamics and antagonistic trends of the world society. The reduction in the number of the extreme poor has absolutely decreased due to progress in China and India. But as the data from the United Nations Human Development Report that I mentioned at the beginning of this section show, in many parts of the developing countries, especially in Africa and Central+Eastern Europe, poverty and income inequality and poverty has massively increased during the 1990s. Hence there are two antagonistic trends that affect the Third World: material inclusion and material exclusion. The rise of the knowledge-based society has been characterized by simultaneous economic development and underdevelopment, social inclusion and exclusion. Neoliberal observers tend to see only one side of this antagonism in order to stress that liberalization, privatization, and deregulation decrease poverty. The dynamic of inclusion and exclusion shows that this is not the case.

Globalization hasn't brought an end to poverty, the rise of poverty as a global problem is itself an expression of the globalization of modernity. We are today experiencing the globalization of science, technology, ecology, economy, polity, and culture, but in an uneven and unequal way, there still is a lack of participation, the Third world is systematically excluded and marginalized, globalization is not yet a wise and universal process. The benefits of globalization in its current forms are restricted to fewer and fewer people, there is a need for an alternative globalization within an alternative, new modernity that preserves the best and most advanced elements from modernity and premodernity, but is postmodern in the sense that it establishes universal wealth, participation, co-operation, and happiness for all by going beyond the limits of modernity.

After discussing the antagonistic aspects of the five dimensions of the globalization of modernity, I will now explain the antagonistic relationship of globalization and informatization in the knowledge-based society (KBS). Hence we will further ascends towards a more concrete level of analysis by taking a look at the dynamics of globalization in the KBS. Again the five dimensions of society will be analyzed.

\section{Antagonisms of Globalization and Informatization in the Knowledge-Based Society}

The transition from the Fordist to the Postfordist (that can be better described as global informational capitalism) mode of development took place within the framework of a societal crisis and heavy fluctuations that have especially by the theory of regulation been discussed as crisis of Fordism (cf. Fuchs 2002a, 2003g). In the early 1970s, the Fordist mode of development of capitalism entered crisis (cf. Fuchs 2002a, 2003g). One of the reasons was that the hierarchical Taylorist model of organizing work reached its limits and promoted refusal of work and class struggle because the work force couldn't stand the permanent and extraordinary psychological and physical burdens ${ }^{13}$. Other reasons were the technological

\footnotetext{
${ }^{13}$ Helmut Willke (1995: 81ff) points out that increasing complexity with the help of hierarchy results in a point where efforts and costs
} 
and organizational limits the centralist Taylorist methods had reached. As a result, the growth rate of productivity decreased and wages and constant capital relatively increased. The centralised and hierarchic forms of economic organization increasingly proved to be inflexible and rigid. The costs of wage labour had increased relatively fast during the 1960ies due to the power of the organized interest of the working class. The growth of productivity was relatively slow during the 1960ies, the growth of wages relatively fast. These two factors negatively influenced profit rates. The economic hegemony of the USA was questioned during the 1960ies by the fast economic development of European countries and Japan. This competition along with expenditures of the US state for financing the Vietnam war resulted in a large budget deficit and in deficits of the balance of trade. The role of the US dollar as "world money" was increasingly questioned and finally the system of Bretton Woods broke down in the early 1970ies. Stagflation appeared as a new economic phenomenon. The Keynesian policy of deficit spending was based on the assumption that the crises of capitalism could be overcome, but once the crisis of Fordism began and the profits fell the state also entered crisis because it heavily depends on taxes that stem from the production process (taxation of wages and profits). The increasing international character of production came into conflict with the nationally organized policies of regulation. The anti-war movement, the students protests and the emergence of new social movements questioned the Fordist way of life. Taken together, all these tendencies produced an overall economic, political and ideological crisis of world society. Fordism reached its end during the first half decade of the 1970ies. We can more generally argue that the anatgonisms of Fordist self-organization resulted in a large overall crisis that brought about restructurations of all subsystems of society. These restructurations are due to the search for a solution of the crisis, contemporary globalization is a manifestations of the transition to the informational (or Postfordist) mode of capitalist development. The new mode of development brings about a new structure of social antagonisms that is based on the general antagonisms of modern society. Postfordism is both a new emergent level of capitalist development and of social globalization.

We today live in an information or knowledge-based society in the sense that information and information technologies (IT) have become immediate forces of production that influence and change all subsystems of society. Information or knowledge doesn't simply mean subjective ideas. Information is a relationship of reflection between self-organized units of matter where a reaction in the form of systemic chance takes place that is triggered by perturbations. Knowledge is a manifestation of information in the human-social realm. Knowledge doesn't exist in nature as such, it is a human and cultural product. Knowledge exists both in the human brain and in social structures and artefacts. It has subjective and objective aspects. Objective knowledge is stored in structures and enables time-space distanciation of social relationships. Knowledge has meaning and significance, it involves interpretation of data and is constituted within and part of human experiences. The increased knowledge-based character of society is due to the rising importance of expertise, scientific knowledge and knowledge-based technologies.

Capitalism has since its beginning been based on knowledge in the sense that all technologies and all products are an embodiment of human knowledge. Manuel Castells (1996) has pointed out that the specifity of informational capitalism is that in it the source of productivity lies in the technology of knowledge generation, information processing, and symbol communication/transmission, knowledge acts upon itself as the main source of productivity, it is oriented towards the accumulation of knowledge and towards higher levels of complexity in information processing, knowledge itself becomes the product of the production process, the products of new information technology industries are knowledge-processing devices or knowledge processing itself. Capitalism would have from its beginning been a world economy,

for organizing correct communication becomes counterproductive. Complexity would become unmanageable due to the increase of complexity of things (instruments, machines, technologies), communications and interactions, time, space, time, space and cognition. One can say that at the beginning of the 1970ies Fordism had reached a point where hierarchical steering in economic organizations became impossible due to the increased complexity of production. 
but only in its informational phase its economy would become global in the sense of working as a unit in real time on a planetary scale.

Information is a relationship that exists as a relationship between specific organizational units of matter. In the case of a social system, we speak of knowledge as the social manifestation of information and the units of organized matter are active human (individual or collective) actors. We suggest that information is a general concept that can be found in all self-organizing physical, biological, and social systems. In a human living system, data is a manifestation of information, when it is interpreted and integrated into the cognitive system it is transformed into knowledge, knowledge that is embedded into practical experienced situations is transformed into practical knowledge. Knowledge is neither purely a subjective cognitive attribute nor purely an objective material thing, it is a process and relationship between active human agents that participate in a self-organizing social system and co-ordinate their subjective knowledge in such a way that objective knowledge emerges. Knowledge is a manifestation of information in social systems that involves the interpretation, experience, evaluation, and usage of data and can be found in various subsystems of society. Knowledge is a threefold process of cognition, communication, and cooperation. It is a social relationship between active, knowledgeable, self-conscious human agents.

All societies are based on human activity that produces subjective and objective knowledge. But nonetheless we don't characterize all types of societies as "knowledge-based societies" (KBS). This term is reserved to characterize a social formation that is shaped by a specific type of knowledge, scientific and technological knowledge, in all its realms. The emergence of the knowledge-based society is a multidimensional shift that involves the rise of knowledge as strategic resource in all societal areas. Knowledge has become besides labour, capital, property, and power a defining characteristic and mechanism of modern society. This manifests itself e.g. in a boom of service and knowledge industries, an increasing importance of innovation, universities, expertise, research, knowledge work, knowledge products. The first phase of capitalist development was based on extensive technological development, the quantity of technology, labour, and capital applied in the production process was steadily increased, but technology only changed slowly. In knowledge-based capitalism there is an intensive technological development that is based on a series of qualitative technological innovations.

Like letters, books, television, radio, telephone, fax machines, telegraph, etc. the computer is a knowledge-based technology or medium. The specific feature of the computer is that it enables the convergence of traditional media in one digital medium, knowledge-representation in the computer can combine written text, spoken words, audio, video, and animations in one single medium. This can be achieved by the digitization of the represented knowledge. The computer enables many-to-many communication, it is an interactive medium that allows new forms of co-operation and relationships across spatio-temporal distances. In respect to interactivity the computer differs from traditional media. We today live in knowledge-based society in the sense that knowledge and knowledge-based technologies have become immediate forces of production that influence and change all subsystems of society. The increased knowledge-based character of society is due to the rising importance of expertise, scientific knowledge and knowledge-based technologies.

Globalization and informatization are inherently linked, this relationship again calls forth antagonistic relationships in all subsystems of society (Fuchs/Hofkirchner 2003a, b). The antagonisms are an expression of the fact that with the increased knowledge-based character of society, there is an increase of both fragility and problem-solving capacities. Knowledge is today besides capital and labour a constitutive structuring factor of society. Globalization and informatization increase the number and scope of choices for action as well as the number and scope of social risks. The antagonistic dual forces presented in tab. 8 are both an expression of informatization and globalization. The prefix "k" denotes that 
we are dealing not simply (although also) with the impacts of information-/knowledge-based technology (IT), but with the impact of social knowledge.

\begin{tabular}{|l|l|l|}
\hline subsystem & \multicolumn{2}{|l|}{$\begin{array}{l}\text { the relationship between informatization and globalization } \\
\text { produces antagonisms between.. }\end{array}$} \\
\hline technosphere & global alliance net & global meganet \\
\hline ecosphere & global sustainable k-ecosphere & global risk k-ecosphere \\
\hline economy & global open k-economy & global k-empire \\
\hline polity system & global k-agora & global k-control \\
\hline culture & global k-noosphere & global k-manipulation \\
\hline
\end{tabular}

Table 8: Antagonisms of informatization and globalization

\subsection{Technosphere: Global Alliance Net VS. Global Meganet}

The microelectronic revolution has had both military and economic reasons, the Internet first was a military network (ARPANet) and has gradually been transformed into a global marketplace. Networked computer technology drastically increases the speed of transportation of messages and hence enables communication in real time. New information- and communication technologies (ICT) facilitate the delocalization and disembedding of economic communication in the sense of the generation of spatial and temporal distance. The Postfordist internationalisation of production is facilitated by these technologies. ICT are medium and outcome of the economic globalization of capitalism. On the one hand they make the generation of temporal and spatial distance possible, hence local processes are influenced by global ones and vice versa. ICT simplify global communication and world trade. They push ahead globalization, decentralization and flexibilization of production, they are a medium of the territorial restructuring of capitalism. The generation of networks of production that are typical for transnational corporations has been made much easier by ICT, the latter are also a result of the economic movements of restructuring that are typical for capital. ICT are not only medium of globalization processes, they are also an outcome of them. In order to optimise the accumulation of capital, technologies have to increase their productivity. This results in phases of heavy automation. ICT are a result of this. Historically shipping, railway, telegraph, telephone, radio, TV, automobile, aircraft, computer and nowadays new ICT have been logical results and functional categories of the international dimension of capitalism.

In the academic and political discussions concerning ICT there are generally two positions: modernists who argue that the new technologies will lead to economic prosperity, unlimited wealth and a new Golden Age, and anti-technologists who say that modern technology as such is causing social problems as well as alienation and that hence one should get rid of it. Both positions are short-sighted and don't see that technology and society are mutually related and that hence social antagonisms are reflected within technology. Technology is a social product and contributes to the production (i.e. self-organization) of social relationships. A feasible position is one that assumes that new technologies can both contribute to social risks and social emancipation. It is the task of humankind to design society and hence also technology in a sustainable way that opens up new advantages for all and avoids new risks.

One of the main characteristics of ICT is that they increase the speed of delivery of data massively and hence are a medium of the time-space distanciation of social relationships. They contribute to the disembedding and delocalization of social systems and relationships and hence reshape society. But they also further the reeembedding and localization of disembedded social relationships, e.g. the globally availabe information on the Internet is embedded into local cultural contexts of action by the recipients. Manuel Castells $(1989,1996,1997,1998)$ argues that the result the dissolution of temporal and spatial distances by ICT is a new geography and network logic. The main characteristic of this logic would be the space of flows, a global technological, geographical and social network. The space of flows would be characterized by timeless time and the space of flows. "Timeless time [...] occurs when the characteristics 
of a given context, namely, the informational paradigm and the network society, induce systemic perturbation in the sequential order of phenomena performed in that context" (Castells 1996: 464). "The space of flows [...] dissolves time by disordering the sequence of events and making them simultaneous" (ibid.: 467). Also spatial distances would be dissolved in the space of flows: "The more organizations depend, ultimately, upon flows and networks, the less they are influenced by the social context associated with the places of their location" (Castells 1989: 169). The virtual time characteristic for the space of flows would be characterized by simultaneity, timelessness, unprecedented temporal immediacy, and real time dialogue.

David Harvey speaks of time-space-compression of social relationships that can be achieved by new technologies and new forms of organization. Space would be a source and container of power and class struggle. Capital accumulation would be the major driving force of the further exploration of temporal and spatial displacement. The economic crisis of 1846-47 would have been the first crisis of overaccumulation of capitalism and would have resulted in technological and organizational innovations that allowed more time-space compression and hence an acceleration of the turnover time of capital in production and the speed up of the circulation of capital in mass markets. There would be a "history of successive waves of time-space compression generated out of the pressures of capital accumulation with its perpetual search to annihilate space through time and reduce turnover time" (Harvey 1990: 306f). "I use the word 'compression' because a strong case can be made that the history of capitalism has been characterized by speed-up in the pace of life, while so overcoming spatial barriers that the world sometimes seems to collapse inwards upon us" (ibid.: 240). The capitalist crisis of the early 1970ies would have resulted in a new phase of time-space compression, hence the rise of network technology, and in a flexible regime of capital accumulation. "The transition to flexible accumulation was in part accomplished through the rapid development of new organizational forms and new technologies in production" (ibid.: 284). A new round of time-space compression would indeed have been entailed by the new flexible regime of accumulation: "the time horizons of both private and public decision-making have shrunk, while satellite communication and declining transport costs have made it increasingly possible to spread those decisions immediately over an ever wider and variegated space" (ibid.: 147). "Given the pressures to accelerate turnover time (and to overcome spatial barriers), the commodification of images of the most ephemeral sort would seem to be a godsend from the standpoint of capital accumulation, particularly when other paths to relieve overaccumulation seems blocked. Ephemerality and instantaneous communicability over space then become virtues to be explored and appropriated by capitalists for their own purposes" (ibid.: 288).

The basic idea that underlies Harvey's work is that capitalism is an antagonistic system that results in crises of accumulation. As a strategy for solving these crises, burst of technological innovation emerge that drive forward globalization. The common theme underlying Giddens' concept of disembedding, Castells' concepts of timeless time and the space of flows, and Harvey's concept of time-space compression is that modern capitalistic society requires new technologies and forms of organization that accelerate and flexiblize production in order to function. Hence the history of capitalism is a history of globalization and of the technological acceleration of transportation (of data, capital, commodities, people) that makes the world a smaller place in the sense that it increasingly mediates social relationships more efficiently so that it appears like distances are disappearing. Technological progress has resulted in an increasing separation of the movements of information from those of its carriers, the movement of information gathered speed on a pace much faster than the travel of bodies (Bauman 1998: 14). Bauman is right in emphasizing that this today is a stratifying form of mobility where unprecedented freedom from physical obstacles and ability to act from a distance can only be enjoyed by some.

ICT can make the access to information, the interchange of knowledge, co-operation and communication much easier, it can support cultural dialogue, provide interesting and pretentious new ways of entertainment and education, and can contribute to the abolition of hard work. On the other hand 
ICT are medium of surveillance, control, manipulation, rationalisation that results in technological unemployment and an increase of poverty and the cyberspace is segmented and reproduces social inequalities. This duality is an expression of the antagonism between the Internet as a Global Alliance Net of Co-operation and a Global Meganet of domination. Technological artefacts reflect social relationships of domination and property. This also applies to the Internet. The access to cyberspace demands financial resources for telephone, modem, computer, Internet Service provider etc., but at the same time we are witnessing an increasing social gap. There is no free access to cyberspace, only a small percentage of the world population has access to the new media, the cyberspace is dominated by white, male Americans and Europeans. The cyberspace and new media reproduce segmentations along the lines of class, gender, origin, age and qualification. The distribution of the worldwide Internet users shows that there are major disparities and that the digital divide is a social divide and reflection of social inequalities (tab. 9). "The sharpening inequalities in the distribution of the infrastructure for electronic space, whether private computer networks or the Net, in the conditions for access to high-powered segments and features, are all contributing to new geographies of centrality on the ground and in electronic space" (Sassen 1998: 178).

Manuel Castells (2001) argues that the problem of the digital divide is not only the lack of access for many, but the existence of inequality in a society whose dominant functions and social groups are increasingly organized around the Internet. He says that access barriers could be overcome to a certain extent by the commercial expansion of the Internet, but this wouldn't solve the problem, because the digital divide would not be a technological, but a social problem. Access to computers and the Internet wouldn't dissolve the digital divide because the important aspect would be learning how to manage knowledge, learning how to learn, knowing how to know, "what is really required is the skill to decide what to look for, how to retrieve it, how to process it, and how to use it for the specific task that prompted the search for information" (Castells 2001: 259). Today there would be a large knowledge and skill gap, the school system would be territorially and institutionally differentiated by class and race, schools would be preoccupied with warehousing and disciplining children, not with advancing active participatory learning. Hence the central gap that constitutes the digital divide would be a gap in skills, knowledge, and education.

\begin{tabular}{|l|l|l|l|}
\hline Region & $\begin{array}{l}\text { Percentage } \\
\text { share of world } \\
\text { population }\end{array}$ & $\begin{array}{l}\text { Number of } \\
\text { Internet users } \\
\text { (millions) }\end{array}$ & $\begin{array}{l}\text { Percentage } \\
\text { share of } \\
\text { worldwide } \\
\text { Internet users }\end{array}$ \\
\hline Worldwide & & 605,60 & \\
\hline Africa & $13,5 \%$ & 6,31 & $1,0 \%$ \\
\hline $\begin{array}{l}\text { Asia/Middle } \\
\text { East/Pacific }\end{array}$ & $61,1 \%$ & 192,36 & $31,8 \%$ \\
\hline Europe & $11,7 \%$ & 190,91 & $31,5 \%$ \\
\hline Canada/USA & $5,1 \%$ & 182,67 & $30,2 \%$ \\
\hline Latin America & $8,5 \%$ & 33,35 & $5,5 \%$ \\
\hline
\end{tabular}

Table 9: Distribution of worldwide Internet users (Source: http://www.nua.com/surveys/how many online/index.html, March 2003)

Mark Poster (1996) argues that network technologies are the electronic version of the Panopticon, a "superpanopticon". Zygmunt Bauman (1998) in contrast says that cyberspace is different from the Panopticon, it would be a Synopticon because the Panopticon would make sure that no one can escape beyond a closely guarded space, whereas the Synopticon would make sure that no one who doesn't meet certain closely observed conditions can enter a guarded space. In the Panoptican the suppressed would be the watched, whereas in the Synopticon of the mass media they would be the watchers. The many would watch the few selected who form a mobile elite. "The database is an instrument of selection, separation and exclusion. It keeps the globals in the sieve and washes out the locals. [...] Unlike the 
Panopticon, the database is a vehicle of mobility, not the fetters keeping people in place. [...] In the Synopticon, locals watch the globals" (Bauman 1998: 51+53).

Contemporary patterns of inequality won't be solved by creating access for all because these are social problems that are in need of political solutions, there are no pure technological solutions to social problems. Those who don't have access normally also don't have the skills, cultural and social resources that are necessary for turning data into meaningful knowledge and wisdom. They are denied not only technological access, but access to a whole field of social qualities. "Yet, when one considers in detail the necessary physical infrastructure (such as electricity, phone lines, computer hardware and software, servers) and social infrastructure (such as literacy, political will and economic ability) required for supporting ICTs, it becomes clear that access to computer technology represents only the pinnacle of a whole array of prerequisites - prerequisites which in themselves denote a fairly high degree of economic prosperity" (Burkett 2000: 681).

Mass media like the cyberspace don't constitute a "global village" or "virtual community", these metaphors optimistically imply that all benefit from the emergence of new media. Such metaphors are uncritically optimistic and technologically deterministic. The cyberspace isn't a global village or a virtual community, it is an uneven space segmented along lines of exclusion like income, class, gender, origin, age, education, etc. Whether the new technologies will contribute to global co-operation or global domination will be determined by social practice.

Websites are written in a specific language, the Hypertext Markup Language (HTML). Users make use of tools like Dreamweaver, FrontPage, Homesite, etc. in order to produce HTML-code. A hypertext is a network of informational nodes that contain informational pieces (texts, images, sounds, videos, animations) and are interlinked. The hypertext has a distributed nature, it can consist of texts, images, sounds, videos, animations, etc. (hence one also speaks of hypermedia) that are not necessarily stored on one computer, but all over the WWW, and of links to web pages that are distributed over the WWW. Links from all over the WWW lead to a hypertext, it can be produced jointly and at a distance by making use of co-operative work systems, it can be used and maybe extended or changed by people who are distributed all over the world. The hypertext is essentially dynamic, fluid, transitory, it has no fixed place. A specific hypertext forms a node in the Web that develops dynamically in such a way that links from and to this hypertext frequently appear and disappear.

Besides hypertext, virtual reality (VR) is also an important aspect of knowledge-based technology. Virtual Reality (VR) means a space where information is not stored in the human brain, but in computer networks, that enables human communication and activity at a distance. VR is an extension of human reality in the sense that is based on human beings, their actions and interactions, it is a socially created space that has a technological substratum and is inhabited by human beings. VR is not the opposite of reality and it doesn't abandon reality. The experiences and practices we have through VR are real, hence Castells $(1996,2001)$ speaks of "real virtuality". The culture of real virtuality would be "virtual because it is constructed primarily through electronically based, virtual processes of communication. It is real (and not imaginary) because it is our fundamental reality, the material basis on which we live our existence, construct our systems or representation, practice our work, link up with other people, retrieve information, practice our work, link up with other people, retrieve information, form our opinions, act in politics, and nurture our dreams. This virtuality is our reality" (Castells 2001: 203). VR means a technological multiplication of reality, a simulation that constructs a new level of imagination and reality (Poster 1995). VR is characterized by three Is: immersion, interactivity, information intensity (Heim 1998). Immersion means that virtual reality creates new human experiences, interaction means that the state of an application changes according to changes of the human body that are feed as an input into the technical 
system, information intensity means that a virtual world can offer special qualities like telepresence that show a certain degree of intelligent behaviour.

When we browse the WWW, we are immersed into an artificial space that we navigate by clicking links and entering commands with the help of interaction devices such as the mouse and the keyboard. Certain human senses are observed by the system in order to gather input and change the state of the system, the output that the system produces appeals at least to our eyes and ears, the computer digitally combines data that can appeal to several of our senses and it digitally converts input of multiple senses into data that is used for changing the system's state. Hence the computer is a multi-medium. Digitization allows the convergence of text, sound, images, videos, animations, etc. Human-Computer-Interaction $(\mathrm{HCl})$ involves a potentially endless feedback loop between the human user and the computer where the activity of a human being's sense organs changes the system's output and the output changes sensual human experiences. This process is the basic loop involved in interactivity. The WWW is not a fully immersive medium because our senses are not fully concentrated on interaction with the technology, you can see, hear, feel, smell, and taste stimuli that are not produced by the WWW while you are browsing. The Internet is a partly immersive system.

Full immersion can be achieved in a virtual reality system that makes use of 3D graphics, a data glove or data suit, and a head-mounted display. A fully immersive virtual reality system isolates the human senses totally from the outside environment, they are fully concentrated on interaction with the technology, the only sensual input into the body during the time of virtual experience is produced by the technology. The system exactly measures the user's position and movements and hence allows the user's control of artificial agents that move in a world that is presented to the user via the head-mounted display. The only thing he sees is the virtual world, it is not possible to observe the outside environment as it is when you surf the WWW. Frequently the virtual worlds are not purely artificial, but a simplified representation of reality. Examples are the virtual operating room and the virtual cockpit of a warplane. Midlevel immersion can be provided by the simulation of 3D spaces on a 2D monitor. This is e.g. the case in 3D arcade games like Duke Nukem or Silent and VRML (Virtual Reality Modelling Language) spaces like cybertown.com.

Pierre Lévy $(1998,2001)$ argues that the virtual is not the opposite of the real, philosophically it would mean that which exists potentially rather than actually, a field of forces and problems that is resolved through actualization. Hence one can consider VR systems as objective systems that contain a mass of human knowledge that can be potentially actualized as subjective human knowledge. When one reads a piece of information in the WWW, objective knowledge is transformed into subjective knowledge, potential subjective reality is actualized into actual subjective reality.

\subsection{Ecosphere: Global Sustainable K-Ecosphere vs. Global Risk K-Ecosphere}

Industrialization has massively increased the material and energetic flows to an extent never seen before on earth. These flows threaten to get out of control. With the rise of information and ICT as central principles of modern society, the question arises whether these developments mean a new, more intensive phase of industrialism that multiplies environmental degradation or a post-industrial age where informational flows substitute material and energetic flows and hence contribute to ecological sustainability. Will the informational revolution be used for restoring the balance between human beings and their natural environment? Or will it further environmental degradation by means of computer usage? There is no clear-cut answer to these questions. Environmental problems are social problems, not technological problems, they are neither caused by science or technology as such, nor can they be solved by science or technology as such. Science and technology have due to their unsustainable social design contributed to environmental degradation, they have been turned into destructive forces by social forces. Heavy promotion of computer usage is not an appropriate means of achieving ecological sustainability, 
the latter requires alternative models of economic production. If humankind is interested in a sustainable society, the destructive character of the economy must be reversed, a new social model is needed. Within such an alternative social setting, ICT and biotechnology surely can make a contribution to sustainability. Today this is not the case, environmental performance evaluations of computer technologies show that the latter doesn't heavily reduce material outputs, the production of one PC requires 16-19 tonnes of material resources and more than $5000 \mathrm{kWh}$ energy, the emission of the production of one piece include $60 \mathrm{~kg}$ waste, $1850 \mathrm{~kg}$ carbon dioxide, $2 \mathrm{~kg}$ sulfur dioxide, and $1 \mathrm{~kg}$ nitrogen oxide (Grote 1994). Nonetheless within an alternative model of production, ICT could make a contribution to sustainable development by using them for analysing material and energetic flows, as environmental information systems, making use of IT-based environmental monitoring and documentation systems, and furthering sustainability, possibilities for substituting commercial and private transport by making use of telecommunication, telework, teleconferencing, and online-shopping. Whether ICT contribute mainly to a global sustainable ecosphere or to global environmental risks as is the case today, is not a definitive affair, it is determined by human practice.

Knowledge creates non-knowledge, in the KBS this dynamic is of special importance because scientifictechnological progress results in a number of unpredictable uncertainties of development, i.e. modernization risks. These risks threaten to get out of control, Helmut Willke speaks in this context of a crisis of knowledge (Willke 2002). The increased influence of scientific-technological knowledge on our lives has resulted in an increased fragility of society and nature (Stehr 1994). Risks arise a side-effects of a form of modernization that is "blind and deaf to [...] [its] own effects and threats" (Beck 1994a: 6), the KBS is a high risk society. Ulrich Beck argues that side-effects of modernization like the destructive power of modern technologies and environmental degradation are an expression of non-knowledge. Nonknowledge would be the medium of reflexive modernization (Beck 1994b, 1996). The more modern a society, the more knowledge-based and risk-intensive it would become (Beck 1996). There would be two forms of non-knowledge: something that one doesn't want to know (Nicht-Wissen-Wollen) and something that one can't know (Nicht-Wissen-Können) (ibid.: 300, 302). Further dimensions of non-knowledge would be selective reception and distribution, uncertainty of knowledge, and mistakes/errors. All decisions in late modern society would be confronted with uncertainty, even expert knowledge. But to a certain extent one could try to manage risks by reflecting non-knowledge, learning to know that and what one can't know and avoiding not wanting to know (ibid: 309). Knowledge would be dependent on modernization risks. Many of the new dangers would not be immediately visible (e.g. radioactivity). To become visible the perceptive organs of science would be needed to produce knowledge about risks. "In this way threat situations create social dependencies of information and knowledge" (Beck 1999a: 266). Only through external knowledge one could become aware of the threats one is facing (e.g. that your daily cup of tea contains DDT) (Beck 1999a). Those who are affected of risks lose a significant proportion of control over knowledge and information, they are dependent on the knowledge of others, but thereby also on the non-knowledge and mistakes of experts (ibid.). Beck argues that there is no scientific monopoly of knowledge about risks because science and technology would themselves produce a great deal of risks (ibid.). Risk society would demand a reorganization of power and responsibility towards a participatory democracy that includes public risk awareness and consciousness (ibid.). Indeed the emergence of the KBS as a high risk society has brought about the formation of a certain degree of consciousness about the risks immanent in the KBS. This awareness manifests itself in new social movements that have a democratic potential.

\subsection{Economy: Global Open K-Economy vs. Global K-Empire}

The economic diffusion of ICT is related to the crisis of global Fordism. As a reaction to the relative fall of profit rates, computerisation and automation have been put forward in order to save labour costs and to increase the rates of profit. ICT are medium and result of the economic globalization of capitalism. On the one hand they make the generation of temporal and spatial distance possible, hence local processes are 
influenced by global ones and vice versa. ICT make global communication and world trade easier. They push ahead globalization, decentralisation and flexibilization of production, they are a medium of the territorial restructuring of capitalism. The generation of networks of production that are typical for transnational corporations has been made much easier by ICT, the latter are also a result of the economic movements of restructuring that are typical for capital. So ICT are not only medium of globalization processes, they are also a result of them.

ICT make outsourcing, rationalisation and de-centralisation of production, team work, the flexibilization of jobs and the flattening of organizational hierarchies much easier. They have contributed to the shift of the employment sector from a focus of industrial jobs to service jobs. In most advanced countries the service sector today makes up two thirds of total employment. The Postfordist economy is a flexible regime of accumulation that is enabled by ICT and is based on the on the outsourcing, decentralisation and "flexibilization" of production, lean management, just-in-time production, the flattening of internal hierarchies in corporations, small organizational units in corporations, delegation of decision-making from upper hierarchical levels to lower ones, decentralisation of organizational structures, team work, strategic alliances, innovation networks, semi-autonomous working groups, network-organizations, tertiarization and informatization of the economy, triadization of international trade and of capital-export, team work, semi-autonomous working groups, participatory management, a new phase of economic globalization, diversified quality production, automation and rationalization mediated by computerized information- and communication-technologies (ICT). Speculative ("fictive") capital that is detached from material production and constitutes fast, self-increasing, unstable ("bubble economy"), global flows of capital is gaining importance. It is due to the fact that ICT dissolve temporal and spatial distances that corporations can flexibly manage production and make use of global interconnected flows of capital, technology, labour, and information. Network organization is a characteristic of the Postfordist global economy: networks of firms, networks of suppliers and distributors, financial networks, strategic alliances, joint ventures, financial markets that are based on fast global flows of increasingly "immaterial" speculative capital that are transmitted and manipulated digitally by making use of network technology. "We live in a global economy. This is not the same as a world economy, a reality that has existed since the sixteenth century. A global economy is an economy in which all processes work as a unity on real time throughout the planet; that is, an economy in which capital flows, labour markets, markets, the production process, management, information, and technology operate simultaneously at the world level" (Castells 1999). The global flows of capital, power, humans, information, labour, commodities, images, travellers, etc., Castells argues, are largely uncontrollable, they would segment countries and people and result in an extremely uneven social geography. "The ability to generate new knowledge and to gather strategic information depends on access to the flows of such knowledge or information, be it flows between major research centres or insider knowledge in Wall street trading. It follows that the power of organizations and the fortune of individuals depend on their positioning vis-à-vis such sources of knowledge and on their capacity to understand and process such knowledge. It is in this fundamental sense that we liven in a knowledge-based informational society" (ibid.). Economic globalization today means globe-spanning social relationships of commodity and finance markets, transnational corporations. Large corporations increasingly outsource production to foreign small and medium-sized enterprises (SMEs) and get involved in transnational production and innovation networks between firms in order to lower investment costs and increase profits. Strategic alliances concern especially joint R\&D, there is a sharp rise in such alliances, hence Dunning (1997) speaks of "alliance capitalism". Strategic alliances are a co-operative effort to develop competitive advantages. Geographically dispersed production, strategic alliances, the network enterprise, innovation networks, distribution networks, and participative management are important new qualities of the global economy. The Postfordist enterprise is not a static, hierarchic, centralized unit, but embedded into many dynamic social production networks and webs of strategic alliances. Castells (1996) hence speaks of the network entreprise constitutes the new organizational logic of informational capitalism. 
The new flexible, decentralized global economy is characterized by a systemic form of centralization. The economy is increasingly dominated by a small elite of transnational corporations that can determine consumption, political decisions and living conditions of the world population. Many people feel the effects of this rigid economically dominated type of globalization and feel estranged because decisions that affect their lives are made by anonymous powers that they don't know and whose actors they will never meet and are physically detached from local contexts. This increased economic dominionism could well result in the long persistence of a global informational Empire.

On the other hand the development of the productive forces has reached a level where the high productivity standards would enable a true participatory economy where there is wealth for all without hard work as well as a maximum of free time and the abolition of alienated, estranged labour. Development of the productive forces has reached a stage where capitalism is based on co-operative economic, political and cultural networks. It enables high degrees of productivity and socialisation which are both material preconditions of a fully participatory, democratic and co-operative society where socialisation permeates all areas of public life including ownership of the means of production that are today still treated as private property although with the increased importance of information as a social, collective and historical product the concept of private ownership no longer seems to make sense. We today find the objective, material conditions for a free society, but at the same time the culminating antagonisms produce global problems.

In society, information can only be produced jointly, not individually. Whenever new information emerges, it incorporates the whole societal history of information, i.e. information has a historical character. Hence it seems to be self-evident that information should be a public good, freely available for all. But in global informational capitalism, information has become an important productive force that favours new forms of capital accumulation. Information is today not treated as a public good, rather as a commodity. There is an antagonism between information as a public good and as a commodity. This antagonism stems from the fundamental capitalistic antagonism between products as use values and as exchanges values. Exchange value dominates use value, not the usefulness of a product is its main aspect, but its commodification and valorization.

An information product has a very low value (i.e. very little time is needed for producing or copying one single product), but is sold at a much higher price. The profits in the New Economy and the IT-sector are a result of this gap between value and price of information (Fuchs 2002b). Large corporations try to monopolise the production and distribution of information. The media are dominated by large transnational corporations like AOL Time Warner, Disney, Viacom, Bertelsmann, Murdoch, AT\&T, Sony and Seagram, the largest corporations all operate in the media- or IT-sector. Corporations make use of Intellectual Property Rights (IPRs) in order to extract economic profit from information.

Social movements like the Open Source community oppose the commodification of information and argue that information should be freely available to everyone. Information can be easily copied and distributed over the Internet. This makes it difficult for corporations to prevent the free sharing of information. The MP3-movement and software applications like Napster, KaZaA, Audiogalaxy, LimeWire, Morpheus, EDonkey, WinMX, iMesh, Bearshare, Blubster, SoulSeek, Overnet, Toadnode, Grokster, Blubster that distribute digital music files for free over the Internet pose a threat for large corporations (e.g. Virgin will close down some of its "Megastores" during the next years due to heavy losses that have been caused by the free sharing of music over the Internet). Hence the Recording Industry Association of America (RIAA) sues operators of such network-applications, but whenever one operator has been forced to quit its services, others have emerged. This shows that information and informational networks like the Internet are hard to control and that one should consider whether it is just and fair to monopolise and commodify information and to destroy its public character. All sorts of networked open source activities 
show the power of co-operation and the possibility of enhancing co-operation by making use of digital networks.

In the Internet each consumer of information is also a potential producer and vice versa, with the Internet we see the emergence of the prosumer. Also each receiver is a potential sender and vice versa; and each reader a potential writer and vice versa. The traditional relationship of the author and the reader is broken up. The Internet is closely connected to concepts like Open Source, Open Content, Open Theory, etc. It fosters the networked, co-operative production of information, you can download existing code, data, images etc., reuse and improve it. The open source standards of the Internet software have in fact been one of the factors that have fostered its rapid growth. "The openness of the Internet's architecture was the source of its main strength: its self-evolving development, as users became producers of the technology, and shapers of the whole network" (Castells 2001: 27). Open source software is one of the key features of the Internet's evolution.

This antagonism between information as open source and intellectual private property is characteristic for the situation we are facing today. On the one hand there are progressive aspects of the productive forces that seem to speak in favour of a fully open, co-operative and participatory character of the economy, on the other hand this openness is challenged by closure and centralisation of economic resources. The outcome of the antagonism between the global open informational economy and the global informational empire will be decided by human practice.

\subsection{Polity: Global K-Agora vs. Global K-Control}

The informatization and globalization of the political system puts forward another antagonism that poses the question whether the informatized polity will globally empower the political actors or will extend the interior and external control over them. ICT has both positive and negative political potential. It is shortsighted to say that the new ICTs are solely dangerous or solely advantageous. It depends on how the human beings make use of and design these new media, i.e. participatory new media can only exist in a participatory, co-operative society.

Society is not yet a global village, the new media today don't put forward agoras of the global village. Society is today a global sphere of capital accumulation, not a global noosphere of solidary co-operation. The cyberspace is not a political agora, but a system of commerce and stupidifying amusement. But there is no need to be too pessimistic, because the technological networking of the world pits forward a new principle: all-embracing, participative, networked co-operation.

The new technologies are embedded into an antagonism between political participation and political control/surveillance, they foster both positive opportunities and negative risks. Aspects that could strengthen global democracy include the increase of access to information via the Internet, the provision of a polydirectional medium of interaction, the production of publicity and counter-publicity via new media, new forms of global interactive, many-to-many political communication, the immunisation of political communication against authoritarian structures due to the lack of control of decentralised complex technological networks, making the administrative procedures more transparent by using network technologies, improving information management by fast distribution of political information, pluralizing public opinion by furthering numerous digital sources of political information, producing new patterns of political perception and action by making use of the multimedia dimension of the Internet for presenting political issues. On the other hand the use of ICT also poses a threat to global democracy because they can be used as networked media of surveillance and hence for constructing rigid networks of control and disciplinary power, they maximise the potential of destruction of war technology, there is a marginalization of political issues in the Internet which is dominated by sex and commerce and unambitious entertainment, the Internet also restricts communication (there are no obligations, no binding character of 
communication, no social cohesion, no mimic and gestures, misunderstandings can easily show up), alternative political voices are not efficiently represented in the Internet due to financial and hierarchical restrictions ${ }^{14}$.

The WWW is a system that requires human activity, active human browsing, and active human knowledge creation for its existence and permanent reproduction. Each receiver is a possible transmitter. Nonetheless the Internet today is more a space of commerce and passive information consumption, but it has the potential to become a space of active, mutual, co-operative, inclusive information production. The Web is a space suited for "nomadic co-operation" (Lévy 1997).

The Internet is technologically based on a decentralized network that forms a polydirectional medium of interaction where many-to-many-communication can take place. In comparison to traditional media that were based on one-to-many communication this is a new quality that has a fundamental political potential. Traditional media such as television, radio or printed media have a one-dimensional character, they only work in one direction from the sender to the receiver without possibilities for mutual interaction. The interactivity of the Internet can extenuate the elitist character of traditional media, there is a shift from oneto-many- to many-to-many- and all-to-all-communication. The technological networking of the world pits forward a new principle: all-embracing, participative, networked co-operation (cf. Fuchs 2003a) and direct democracy in all realms of society. It is up to the human beings to change society in such a way that it can make full use of and realize the opportunities the Internet poses. Internet communication can support the emergence of a global public sphere and a global civil society.

Vilém Flusser (1996a, b) has distinguished between dialogic and discursive forms of communication. Dialogue would mean exchanging and sharing information in order to produce new information jointly and co-operatively, discourse would mean the distribution of existing information. Dialogues would be conservative and totalitarian because they would try to conserve and distribute existing information. The traditional media would operate in the form of amphitheatre discourses where there is one sending centre that functions as a channel that transmits information to the mass of passive receivers. Another form of communication would be network discourses that could mainly be found in daily life as gossip and spreading rumours. The existing communication structure would be dominated by a combination and synchronization of the amphitheatre discourses of the mass media and gossiping network dialogue. The amphitheatre discourses would program unambitious, manipulating information in the form of techno images (symbolic patterns that signify linear texts that signify pictures that signify parts of the world, images that signify concepts/texts) that would be realized by the gossiping network dialogues in the life world. The character of network dialogue would be shaped and dominated by discourses.

In the times of the new media, there would not only be a potential for a new totalitarianism, but also one for a new level of human communication (1996b: 50) that means real human communication (ibid.: 157). The TV could easily be transformed into a dialogic medium that functions like a telephone (ibid.: 203) and enables a democratic cosmic village (ibid.: 204). Adding feedback structures to existing mass media wouldn't be a technological problem (ibid.: 226), doing so could open up new possibilities for a cosmic creative dialogue (ibid.: 228). Computer-based technologies would have the potential for transforming society into a new dialogic polis (ibid.: 286-299). Telematics (telecommunication+informatics) would have a democratic potential for helping to realize a fully dialogic society, a "telematic society" (Flusser 1996a) that is not based on intercourse between techno images and human beings, but on intercourse between human beings that is mediated by techno images that enable democratic dialogue (ibid.).

\footnotetext{
${ }^{14}$ If you are e.g. looking for the term "political news" with a search engine such as google.com, you will find CNN, the Washington Post, BBC etc. as top results, but you won't find indymedia.org, alternet.org, z-mag.org etc. given a top priority. You will find plenty of sex sites on the Internet, but only one or two per cent of political contents and only a minor share of these political sites will contain critical and alternative political information.
} 

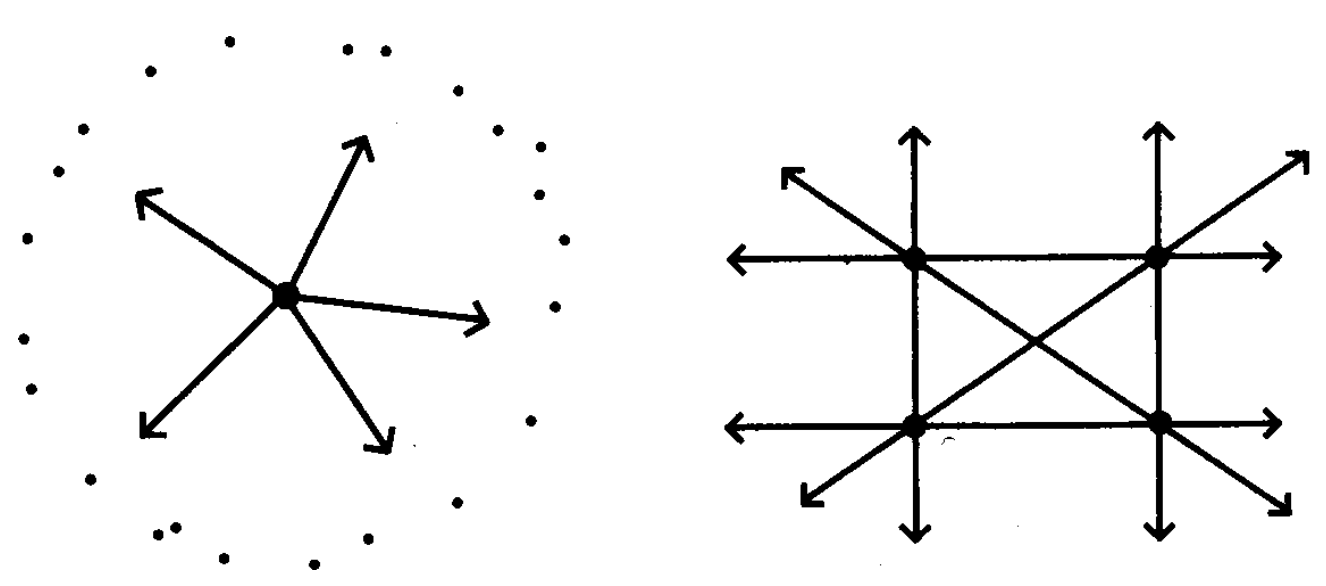

Figure 8: Amphitheatre discourse and network dialogue as two forms of communication (from: Flusser 1996b, pp. 27+32)

Flusser died in 1991, he didn't live long enough to see and describe the emergence of the Internet as a mass phenomenon. But he has clearly seen that computer-based networks pose both new opportunities and risks. The Internet forms on its technological level a system of networked dialogue, but on the social level society doesn't make adequate use of this potential because it is dominated by discourses in all realms of social life. Realizing the democratic potential of the Internet would mean that a technological system of network dialogue is coupled to a social system of network dialogue. The old system of amphitheatre discourse that still dominates society in all of its realms would be replaced by a democratic form of network dialogue. The form of network dialogue that Flusser describes as simplistic gossip and the spreading of "false consciousness" in the life world would be transformed into a form of network dialogue that is participatory, co-operative, inclusive, and direct democratic. Human beings would be enabled to shape their lives and decisions all by themselves, self-determination, permanent dialogical decisions and consensus democracy would become central aspects of the dialogical society. Social network dialogues would no longer be dominated by discourses, but would be fully dialogic and supported in their democratic character by a technological infrastructure that is organized itself as network dialogue.

Whether the political system will turn out to be a global informational agora or a global system of informational control will be determined by political practice, ICT as such has an ambivalent character that both strengthens and weakens the establishment of a truly democratic and global world society.

\subsection{Culture: Global K-Noosphere VS. Global K-Manipulation}

The technological networking of the world pits forward a new principle: all-embracing, participatory, networked co-operation. Overall societal development is lacking behind this new logic, a globally wise society that provides wealth, security, and well-being for all has not yet been established. Based on the principle of participation the sociosphere could develop into a noosphere, a global sphere of reason, cooperation, solidarity and responsibility. The technological and economic globalization of the world anticipates and is a shining forth of a well-rounded solidary interrelation of individuals in an association of humanity. I doubt that the reaching of a noosphere can be achieved by strengthening the dominance of economic processes. New forms of globalization and governance are needed. Globalization is in need of global wisdom and global solidary forms of governance.

ICT can both contribute to the establishment of a global noosphere and a global sphere of manipulation. The Internet does not - as suggested by many observers and the mainstream media frequently - colonise and destroy face-to-face communication as serious studies show. 
It is not the Internet that isolates people, confronts them with violence, sex etc., it is modern society that is violent, racist, sexist etc. and that puts forward isolation. "Even though the net reproduces old forms of sexual and racial privilege more than it unsettles them, cybertechnologies ALSO contain a radical potential for the undoing of racialized and sexualized identities" (Eisenstein 1998: 92). The Internet does not automatically result in social isolation, on the contrary it is a medium of social processes. There are multiple virtual communities on the Internet that make use of modern technologies as a medium of communication. Such a globalization of communication can be very interesting and can have many positive effects. Real and virtual communication co-evolve, quite commonly people who meet virtually also meet in real life, become friends etc. ICT provide new means of polydirectional cultural and political interaction and of linking social movements. The Internet is a field of experiment for new forms of art, politics, entertainment, and publishing, its inherent interactive character makes possible forms of communication that are not based on the principle one-to-many that is employed by traditional mass media, but on the more democratic form of many-to-many-communication. Social movements and alternative publishers can make use of the Internet in order to increase their efficiency and to a certain extent overcome the problems of traditional publishing (low capital, poor access to mainstream distribution, legal constraints, repression, disinformation about alternative thinking in the mass media).

But there are also problematic aspects of ICT in the cultural realm: The Internet is dominated by unambitious mass entertainment that furthers manipulation, there are restrictions for alternative forms of communication, politics, and publishing (restricted access, alternative voices are less heard or read on the Internet than Mainstream ones, web sites that are owned by institutions and persons that do not have a lot of political and economic power are only scarcely visible in the Internet because they can't purchase a lot of attention, given a very low priority). In the information society, people are massively confronted with more or less valuable information. The problem is that most people do not want to hear critical information and that alternative voices must accomplish to be heard and to be selected by those who want (or do not want!) to be informed. The task is not only to reach those who are already interested, but to reach those that are completely disinterested.

Network technology also furthers new forms of manipulation of public opinion. ICT make it hard to distinguish between reality and fiction. Gérard Raulet (1988) speaks of technologically mediated derealisation, Jean Baudrillard (1983) has termed the process of substituting the real by the virtual simulation. More and more symbols, signs and pictures transform reality. Simulacra are omnipresent and hard to distinguish from reality. This, Baudrillard argues, results in hyper-reality as a new space of experience that is constituted by simulacra. Real life is confronted with a mass of self-referential signs, modern media result in the multiplication and copying of reality. Baudrillard claims that the value of the signs replaces economic value. This is not the case, signs, symbols and information today always refer to economic and social processes, materiality and the accumulation of capital. Hyperreality does not result in a post-modern or post-industrial world, but it is a hint on the fact that modern technologies are used in manipulative ways in order to create the impression that something fictive has become reality. All of this takes place in the modern, capitalist world.

The coverage of CNN on the events of September $11^{\text {th }}, 2001$ and the war in Afghanistan is a good example of the manipulative dimension of hyperreality. Warfare has always included deception of the public and the enemy. It makes use of the simulation of images and symbols that represent the enemy in order to steer public opinions and the simulation of a clean war that does not result in civilian deaths. Vietnam was the first virtual warfare because television was included as a machinery of propaganda. Today, modern technologies and global flows of information function in the same manner. After the terrorist attacks of September $11^{\text {th }}$, CNN showed jubilating Palestinians. It is not clear whether these pictures have already been taken in 1991 or not. Nonetheless this shows that global mass media have tremendous influence on the ideological production of consent in military conflicts and that images and 
symbols can very easily be removed from their original context in order to simulate hyperrealities in another context. Modern technologies not only result in de-realisation, they also result in decontextualisation and kaleidoscopic perception where signs are taken from their original contexts and brought together in a new context in order to generate new meanings and on the pragmatic level specific reactions. In the hyperreality of caleidoscopic perception, one can not distinguish between a picture that shows people jubilating due to a terrorist attack or a marriage. Decontextualisation can be used in order to ideologically manipulate public opinion.

After the terrorist attacks on the World Trade Center, CNN presented a kaleidoscope of images an symbols: interviews with mourners, analyses, amateur videos of the attack, archived material, President Bush promising revenge, God Bless America and again and again the pictures of the two planes hitting the WTC - a kaleidoscope that is more than the sum of its parts and that produces new meanings and reactions: revenge and war-cries. Terror and mass-media are interrelated: Terrorists can be sure that the pictures of their attacks will be globally distributed by the media, the mass media profit from the broadcasting of terror and the misery that results from it. Mainstream media do not analyse why such terrible attacks take place, they are only interested in spreading superficial and manipulating information. Symptomatically for this is the permanent intercut of the line "America Under Attack" on CNN that soon changed into "War against the USA". "America's New War", "War against Terror" and "America Strikes Back". All of this is part of war propaganda, the mass media are not interested in spreading reasonable arguments that try to prevent an escalation of violence and to escape the vicious cycle of direct and structural violence in order to establish world peace. It is all about war propaganda and the legitimisation of terror as an answer to terror. The complex situation is not analysed, it is reduced to symbols such as Osama Bin Laden and the Taliban-regime. Other alternatives than war shall not even be considered as a possible solution by the recipients. The hyperreal machinery of war is in need of mass media as an instrument of propaganda in order to legitimise war.

Traditional mass media institutions (especially TV and cinema) make use of network technologies for reaching global audiences and providing globally available stations and programmes. There is a fierce competition between a few global players in the mass media market for global audiences and ratings. $\mathrm{CNN}$ and Hollywood are the main symbols of the globalization of mass media-markets. The digitalisation of TV and radio broadcasting puts forward new forms of entertainment such as pay-per-view and videoon-demand. This can on the one hand enhance leisure time and education, on the other hand it can especially under the influence of monopolisation and competition standardise programmes (unpretentious programmes sell) and undercut the provision of cheap information and entertainment sources.

Contemporary cultural globalization means homogenisation in the sense that culture has increasingly and worldwide a commercial character and is dominated by a few cultural TNCs. However, this process of homogenisation makes use of difference and plurality, e.g. CNN makes use of local reporters and knowledge, the cultural industry appeals to feelings of difference by consuming certain individualised products. Individualisation and difference (micro-marketing) have indeed become marketing strategies for homogenising markets. "Media globalization may have a homogenizing effect, yet this homogenising effect is more limited than previously anticipated, and it often occurs with a particularising effect" (Wang 1997: 317). This form homogenisation doesn't automatically mean the formation of global "false consciousness", there are indeed different readings and interpretations of cultural products that have to a certain extent an unexpected character and can also be oppositional in character (Fiske 1996). But besides oppositional readings/codes there are also what Stuart Hall (1980) calls hegemonic codes that employ dominant values and patterns and have a dominant character, and hybrid forms of codes.

Political coverage in the mass media frequently makes use of principles such as emotionalisation, concentration on selective facts, limitation to the methodical, demonstrative harmlessness and inoffensiveness, classificatory thinking, decontextualisation, emergent meaning, and recoding. This results 
in misrepresentations and manipulation of reality. Monopolisation is an important aspect of the mass media. Media corporations engage in both horizontal and vertical integration, they try to monopolise existing areas of specialisation, but they also try to settle down and expand their influence in other areas of mass media. They aim at both selling content (film, music, videos, books, TV programs etc.) and acting as providers and distributors (media megastores, TV channels, cinemas etc.). Production and distribution of media contents is converging. The system of the mass media is technologically multidimensional (multimedia), but institutionally there is an increasing lack of plurality, it is controlled by a few large global players that engage in such different areas as software, Internet, film, broadcasting, music etc. at the same time. The mass media are dominated by a few, large transnational corporations (AOL Time Warner, Disney, Viacom, Bertelsmann, News Corporation (Murdoch), AT\&T, Sony, Seagram, Polygram, NBC, Phillips, TCl, etc.) (McChesney 1999), the largest one is Time Warner Inc. that has been a result of the fusion of Time and Warner in 1989 and of Time Warner and Turner Broadcasting in 1996. In 2000 AOL, the largest Internet provider, merged with Time Warner, the largest media and entertainment corporation, in order to create AOL Time Warner. The system of the mass media has a capitalistic character and to a certain extent pursues economic goals. The contemporary transformations of the global economy also apply for these media TNCs: transnational corporation structure, market concentration, privatisation, etc. Whereas in premodern and agricultural societies the main actors of cultural globalization were world religions and empires, with the rise of modern society the rationalistic enlightenment ideology that heavily focuses on economic interests became the main medium of cultural globalization. Today we witness an intensification and acceleration of modernisation, the mass media and cultural TNCs have become the main aspects of cultural globalization. The symbolic cultural contents that people are confronted with today (books, films, broadcasts, food, magazines, digital content, etc.) have an increasingly segmented global character in the sense that they reach consumers across the globe, but mainly stem from Western countries (especially the USA). Concentration in the cultural industry moves along a horizontal and a vertical axis, horizontal integration means that cultural TNCs focus on mergers with corporations that offer the same services, whereas in vertical integration they try to acquire both large channels of production and distribution in order to control the consumption process. Hence there is a convergence in ownership of content production and distribution networks.

The Internet as an ambivalent mass medium that both can strengthen global wisdom and global manipulation shapes the cultural relationships, the informatization of culture poses new possibilities and threat. Whether a global noosphere or a global manipulating system will be established, will depend on the outcome of social practices.

Cultural globalization, i.e. the spreading of certain ideas, norms, and values, is not something completely new if one thinks e.g. of world religions, empires, or colonialism. New qualities of cultural globalization are due to the fact that global mass media have increased their reach, volume, and speed of cultural flows massively. There are certain mass cultural events and commodities that are shared, i.e. consumed, by an increasing number of people. An increasing number of people worldwide is confronted with distant cultural traditions, symbols and artefacts without direct presence in these cultures. Contemporary cultural globalization is largely connected to the emergence of global technological networks that allow cheap and fast transmission of digitised information. That increasingly there are comparable life styles in many parts of the world is not due to the spread of new technologies, it is due to "socially shared experiences" (Friedman 2000: 646), it has social, not technological causes.

Digitisation allows the convergence of traditional media that are based on sound, images, video, and text, the Internet is a multi-medium. Fibre-optic cables and satellite transmission allow communication in real time. But these cultural flows are uneven and mainly stem from the most powerful parts of the world, this disparate cultural (and economic and political) geography is increasingly being recognised as unjust and as threatening national and traditional identities. This results in an increase of fragmentation, global conflicts, nationalism, and fundamentalism. But there is also a tendency of the formation of global 
consciousness and global wisdom that can especially be found in progressive social movements. Many people realise that the problems some face are globally connected with the problems others face, the formation of global consciousness means the emergence of - to speak with Raymond Williams - a global "structure of feelings".

\section{Conclusion}

Contemporary globalization is a muli-leveled complex process that results in uneven development and social stratification. The emergence of informational capitalism and the Postfordist mode of capitalist development is due to a phase of crisis and heavy fluctuations that has resulted in new emergent order, a new phase of globalization. The outcome of this development is a number of new tendencies that can be seen as a continuation of general modern antagonisms and pose both great opportunities and great risks. Many theories of globalization argue that there is nothing human beings can do about the contemporary form of globalization and that they have to adapt to the new situation no matter which problems this might pose. In such discourses globalization "is represented as a brand new phenomenon, an almost natural event, inevitable and beyond our control - all we can do is adjust as quickly as possible or we will fall behind" (Ebert 1999). This neoliberal fatalism is deterministic in the sense that it doesn't see that the human being is an active knowledgeable being that can consciously choose between different alternative actions. We can make a difference, human choices are of central importance in order to solve the global problems we are facing today. "The universe, including the human universe, is only one of the possible realisations of the laws of nature - the 'possible' is richer than the actual" (Prigogine 2000: 894). If the possible is richer than the actual, then this means that there must be alternatives to the current development that has resulted in global problems and that an alternative form of globalization is a possibility that can be realised by practice. "The global problems are the harbinger of a reasonable world order that one can struggle for" (Hofkirchner 1994: 29) ${ }^{15}$.

Social development can't be steered because society is a complex, self-organizing system, but this doesn't mean that we are facing all-determining social structures that can't be shaped. Human agency can increase the possibility that certain developments will be realised and that others won't be realised. There won't be any certainty of outcomes, we are indeed confronted with an end of certainties (Wallerstein 1997a), but the facts that the future is only conditioned by the past and not determined in advance and that there is a great deal of uncertainty of social development shows that human agency and intervention are important because they can make a decisive difference. "The future [...] is open to possibility, and therefore to a better world" (Wallerstein 1997b). Hence we should act in order to realise an alternative, democratic, participatory, humane form of globalization that is based on global alliance technology, global ecological sustainability, global wealth, a global participatory agora, and a global noosphere. New forms of globalization and governance are needed, globalization is in need of global wisdom and global cooperation (cf. Fuchs 2003e).

\section{References}

Ackoff, R. L. (1981) Creating the Corporate Future. New York. Wiley.

Ahl, V.IAllen, T.F.H. (1996) Hierarchy Theory. New York. Columbia University Press.

Albers, O. (2001) Zukunftswerkstatt und Szenariotechnik. Schnell und innovative die Unternehmenszukunft gestalten.

Regensburg/Düsseldorf/Berlin. Fit for Business.

Appadurai, Arjun (1990) Disjuncture and Difference in the Global Cultural Economy. In: Theory, Culture \& Society 7(2-3), pp. 295310.

Ayres, Brenda (Ed.) (2003) The emperor's old groove: decolonizing Disney's Magic Kingdom. New York. Peter Lang.

Barber, Benjamin (1995) Jihad VS. McWorld. New York. Times Books.

Baudrillard, Jean (1983) Simulations. New York. Semiotext(e)

Bauman, Zygmunt (1998) Globalization. The Human Consequences. Cambridge/Oxford. Polity.

\footnotetext{
${ }^{15}$ My translation ("Die globalen Probleme sind die Vorausschatten einer erkämpfbaren vernünftigen Weltordnung")
} 
Bauman, Zygmunt (1999) Liquid Modernity. Cambridge. Polity.

Beck, Ulrich (1992) Risk Society. London. Sage.

Beck, Ulrich (1994a) The Reinvention of Politics. Towards a Theory of Reflexive Modernization. In: Beck, Ulrich/Giddens, Anthony/Lash, Scott (1994) Reflexive Modernization. Cambridge. Polity Press. pp. 1-55.

Beck, Ulrich (1994b) Self-Dissolution and Self-Endangerment of Industrial Society: What Does it Mean? In: Beck, Ulrich/Giddens, Anthony/Lash, Scott (1994) Reflexive Modernization. Cambridge. Polity Press. pp. 174-183.

Beck, Ulrich (1996) Wissen oder Nicht-Wissen? Zwei Perspektiven „reflexiver Modernisierung“. In: Beck, Ulrich/Giddens, Anthony/Lash, Scott (1994) Reflexive Modernisierung. Frankfurt/Main. Suhrkamp. pp. 289-315.

Beck, Ulrich (1997) Was ist Globalisierung? Frankfurt/Main. Suhrkamp.

Beck, Ulrich (1999a) Modern Society as a Risk Society. In: Meja, Volker/Stehr, Nico (Eds.) (1999) The Sociology of Knowledge. 2 Volumes. Cheltenham/Northampton. Edgar Elgar. Vol. 2, pp. 262-277.

Beck, Ulrich (1999b) World Risk Society. Cambridge. Polity.

Boli, John/Thomas, George M. (1999) INGOs and the Organization of World Culture. In: Boli, John/Thomas, George M. (Eds.) (1999) Constructing World Culture. International Nongovernmental Organizations Since 1875. pp. 13-49.

Borghesi, Simone/Vercelli, Alessandro (2003) Sustainable Globalization. In: Ecological Economics 44 (2003), pp. 77-89.

Bourdieu, Pierre (1990) The Logic of Practice. Stanford: Stanford University Press.

Burektt, Ingrid (2000) Beyond the "Information Rich and Poor": Futures Understandings of Inequality in Globalizing Informational Economies. In: Futures, 32 (2000), pp. 679-694.

Castells, Manuel (1989) The Informational City. Information Technology, Economic Restructuring and the Urban Regional Process. Cambridge, Mass./Oxford. Blackwell.

Castells, Manuel (1996) The Rise of the Network Society. The Information Age: Economy, Society and Culture, Vol. I. Cambridge, Mass./Oxford. Blackwell

Castells, Manuel (1997) The Power of Identity. The Information Age: Economy, Society and Culture, Vol. II. Cambridge, Mass./Oxford. Blackwell

Castells, Manuel (1998) The End of Millenium. The Information Age: Economy, Society and Culture, Vol. III. Cambridge, Mass./Oxford. Blackwell

Castells, Manuel (1999) Flows, Networks, and Identities. A Critical Theory of the Informational Society. In: Castells, Manuel et al. (Eds.) (1999) Critical Education in the New Information Age. Lanham, MD. Rowman and Littlefield, pp. 37-64.

Castells, Manuel (2001) The Internet Galaxy. Reflections on the Internet, Business, and Society. Oxford. Oxford University Press.

Cerny, Philip G. (1995) Globalization and the Changing Logic of Collective Action. In: International Organization, 49(4).

Cerny, Philip G. (1997) Paradoxes of the Competition State: the Dynamic of Political Globalization. In: Government and Opposition, 32 (2), pp. 251-274.

Chase-Dunn, Christopher (2001) Globalization. A World-Systems Perspective. In: Proto Sociology, 15(2001), pp. $26-50$.

Davis, Mike (1990) City of Quartz. Excavating the Future in Los Angeles. London. Verso.

Deleuze, Gilles/Guattari, Félix (1977) Anti-Ödipus. Kapitalismus und Schizophrenie. Frankfurt/Main. Suhrkamp.

Diawara, Manthia (1998) Toward a Regional Imaginary in Africa. In: Jameson/Miyoshi (1998), pp. 103-124.

Dollar, David/Kraay, Aart (2002) Spreading the Wealth. In: Foreign Affairs, 81(1), pp. 120-133.

Dunning, John H. (1997) Alliance Capitalism and Global Business. London. Routledge.

Dussel, Enrique (1998) Beyond Eurocentrism: The World System and the Limits of Modernity. In: Jameson/Miyoshi (1998), pp. 3-31.

Ebert, Teresa L. (1999) Globalization, Internationalism, and the Class Politics of Cynical Reason. In: Nature, Society, and Thought, Vol. 12, No. 4, 1999, pp. 389-410.

Eisenstein, Zillah (1998) Global Obscenities. Patriarchy, Capitalism and the Lure of Cyberfantasy. New York/London. New York University Press.

Falk, Richard (1999) Predatory Globalization. A Critique. Cambridge. Polity Press.

Fiske, John (1996) Media Matters. Everyday Culture and Political Change. Minneapolis/London. University of Minnesota Press.

Flusser, Vilem (1996a) Ins Universum der technischen Bilder. Göttingen. European Photography.

Flusser, Vilem (1996b) Kommunikologie. Frankfurt/Main. Fischer.

Frank, David John (1997) Science, Nature, and the Globalization of the Environment, 1870-1990. In: Social Forces 76(2) (1997), pp. 409-437.

French, Hilary (2000) Vanishing Borders. Protecting the Planet in the Age of Globalization. New York. W. W. Norton.

Friedman, Jonathan (1990) Being in the World. Globalization and Localization. In: Featherstone, Mike (Ed.) (1990) Nationalism, Globalization and Modernity. London. Sage.

Friedman, Jonathan (2000) Globalization, Class and Culture in Global Systems. In: Journal of World Systems Research, Vol. 6, No. 3, pp. 636-656.

Fuchs, Christian (2002a) Krise und Kritik in der Informationsgesellschaft. Wien/Norderstedt. Libri BOD

Fuchs, Christian (2002b) Software-Engineering and the Production of Surplus Value. In: Cultural Logic, 4/3 (2002), http://www.eserver.org/clogic/2002/fuchs.html 
Fuchs, Christian (2002c) Social Information and Self-Organisation. In: Robert Trappl (Ed.) (2002) Cybernetics and Systems 2002. Proceedings of the 16th European Meeting on Cybernetics and Systems Research. Vienna. Austrian Society for Cybernetic Studies. Vol. 1. pp 225-230

Fuchs, Christian (2003a) Some Implications of Pierre Bourdieu's Works for a Theory of Social Self-Organization. In: European Journal of Social Theory, 6 (4), pp. 387-408.

Fuchs, Christian (2003b) The Self-Organization of Politics, Power and the Nation State. In: Social Science Research Network eLibrary, http://ssrn.com/abstract=385222

Fuchs, Christian (2003c) Dialectical Philosophy and Self-Organization. In: Arshinov, Vladimir/Fuchs, Christian (Eds.) (2003) Emergence, Causality, and Self-Organization. Moscow. Russian Academy of Sciences.

Fuchs, Christian (2003d) The Self-Organization of Matter. In: Nature, Society, and Thought. Vol. 16 (2003) (forthcoming).

Fuchs, Christian (2003e) Co-operation and Self-Organization. In: TripleC (http://triplec.uti.at), 1(1), pp. 1-52.

Fuchs, Christian (2003) Structuration Theory and Self-Organization. In: Systemic Practice and Action Research, Vol. 16 (2003), No. 4. pp. 133-167.

Fuchs, Christian (2003g) The Antagonistic Self-Organization of Modern Society. In: Studies in Political Economy (forthcoming).

Fuchs, Christian/Hofkirchner, Wolfgang (2001) Theorien der Globalizierung. In: Z - Zeitschrift Marxistische Erneuerung, No. 48. pp. 21-34

Fuchs, Christian/Hofkirchner, Wolfgang (2002a) Globalizierung - Ein allgemeiner Prozess der Menschheitsgeschichte. In: Z Zeitschrift Marxistische Erneuerung, No. 49. pp. 89-102.

Fuchs, Christian/Hofkirchner, Wolfgang (2002b) Postfordistische Globalizierung. In: Z - Zeitschrift Marxistische Erneuerung, No. 50. pp. 152-165.

Fuchs, Christian/Hofkirchner, Wolfgang (2003a) Studienbuch Informatik und Gesellschaft. Norderstedt. Libri BOD.

Fuchs, Christian/Hofkirchner, Wolfgang (2003b) The Architecture of the Information Society. In: Wilby, Jennifer/Allen, Janet K. (Eds.) (2003) Proceedings of the $47^{\text {th }}$ Annual Conference of the International Society for the Systems Sciences (ISSS) "Agoras of the Global Village", July 7-11, 2003, Iraklion, Crete. CD-ROM: ISBN 0-9740735-1-2.

Fuchs, Christian/Hofkirchner, Wolfgang/Klauninger, Bert (2002) The Dialectic of Bottom-Up and Top-Down Emergence in Social Systems. Talk at the Congress "Problems of Individual Emergence", Amsterdam, 16.-20.4.2001. In: Proceedings of the Congress "Problems of Individual Emergence" (forthcoming). Download: http://ssrn.com/abstract=385185

Giddens, Anthony (1990) The Consequences of Modernity. Stanford. Stanford University Press.

Giddens, Anthony (1999) Runaway World. How Globalization is Reshaping Our Lives. London. Sage.

Giroux, Henry A. (1995) Animating Youth: The Disneyfication of Children's Culture. In: Socialist Review, 24(3).

Goonatilake, Susantha (1997) The Structure of "Communities" and Communications in the New Millennium. In: World Futures, 1997, Vol. 50. pp. 715-725.

Goonatilake, Susantha (1998) Toward a Global Science. Mining Civilizational Knowledge. Bloomington/Indianapolis. Indiana University Press.

Goonatilake, Susantha (1994) The Futures of Asian Cultures: Between Localization and Globalization. In: UNESCO (1994) pp. 6783.

Goonatilake, Susantha (2002) The Evolution of Merged Culture, Genes, and Computing Artefacts. In: Wheeler, Michael et al. (Eds.) (2002) The Evolution of Cultural Entities. Oxford/New York. Oxford University Press. pp. 201-213.

Grote, Andreas (1994) Grüne Rechnung. Das Produkt Computer in der Ökobilanz. In: CT, 10/1996.

Habermas, Jürgen (1984) The Theory of Communicative Action, Vol. 1 . London. Heinemann.

Habermas, Jürgen (1987) The Theory of Communicative Action, Vol. 2. Boston. Beacon Press.

Habermas, Jürgen (2001) The Postnational Constellation. Cambridge/Oxford. Polity.

Hall, Stuart (1980) Encoding/Decoding. In: Centre for Contemporary Cultural Studies (Ed.) (1980) Culture, Media, Language:

Working Papers in Cultural Studies, 1972-79. London. Hutchinson. pp. 128-38.

Hannerz, Ulf (1987) The World in Creolisation. In: Africa 57(4), pp. 546-559.

Hannerz, Ulf (1989) Notes on the Global Ecumene. In: Public Culture 1(2), pp. 66-75.

Harris, Nigel (1987) The End of the Third World. Harmondsworth. Penguin.

Harvey, David (1990) The Condition of Postmodernity. Oxford. Blackwell.

Hegel, Georg Wilhelm Friedrich (1812) The Science of Logic. translated [from German] by A. V. Miller, foreword by J. N. Findlay. London. Allen \& Unwin.

Hegel, Georg Wilhelm Friedrich (1830I/1986): Enzyklopädie der philosophischen Wissenschaften im Grundrisse. Erster Teil. Frankfurt am Main: Suhrkamp.

Heim, Michael (1998) Virtual Realism. New York/Oxford. Oxford University Press.

Held, David/McGrew, Anthony (Eds.) (2003) The Global Transformations Reader. Cambridge/Oxford/Malden. Polity.

Held, David/McGrew, Anthony/Goldblatt, David/Perraton, Jonathan (1999) Global Transformations. Cambridge/Oxford. Polity.

Hirsch, Joachim (1995) Der nationale Wettbewerbsstaat. Berlin. ID Verlag.

Hirsch, Joachim (2002) Herrschaft, Hegemonie und politische Alternativen. Hamburg. VSA.

Hirst, Paul/Thompson, Grahame (1999) Globalization in Question. Cambridge/Oxford. Polity. 
Hofkirchner, Wolfgang (1994) Ein neues Weltbild für eine neue Weltordnung. Reflexionen über die Selbstorganization der Menschheit. In: Hofkirchner, Wolfgang (Ed.) (1994) Weltbild-Weltordnung. Perspektiven für eine zerbrechliche und endliche Erde. Münster. agenda. pp. 11-30.

Hofkirchner, Wolfgang (2001) The One and the Many. Information Technologies between Modernism, Fundamentalism, and Postmodernism. In: Becker, Jörg/Hashim, R. (Eds.) (2001) Internet in Malaysia. Bangi. UKM. pp. 7-21

Hofkirchner, Wolfgang (2002a) Projekt Eine Welt. Münster. LIT.

Hofkirchner, Wolfgang (2002b) Internet and "Glocalization". In: Becker, Jörg (Ed.) (2002) Internet in Malaysia and Vietnam. Hamburg. Deutsches Überseeinstitut. pp. 165-175.

Hopkins, Terence et al. (1998) The Age of Transition. Trajectory of the World-System, 1945-2025. London/New Jersey. Zed Books. Huntington, Samuel P. (1993) The Clash of Civilizations? In: Lechner/Boli (2000), pp. 27-33 (originally published in: Foreign Affairs, 72(3)).

Jameson, Frederic (1998) Notes on Globalization as a Philosophical Issue. In: Jameson, Frederic/Miyoshi, Masao (Eds.) (1998) The Cultures of Globalization. Durham, NC. Duke University Press. pp. 54-77.

Jameson, Frederic/Miyoshi, Masao (Eds.) (1998) The Cultures of Globalization. Durham/London. Duke University Press. Jessop, Bob (2002) The Future of the Capitalist State. Cambridge. Polity.

Keohane, Robert O./Nye, Joseph S. Jr. (2000) Globalization: What's New= What's Not? (And So What?). In: Held/McGrew (2003), pp. 75-83.

Khondker, Habibul Haque (2000) Globalization: Against Reductionism and Linearity. In: Development and Society, Vol. 29, No. 1, pp. 17-33.

Kiely, Ray (1998a) The Crisis of Global Development. In: Kiely/Marfleet (1998), pp. 23-44.

Kiely, Ray (1998b) Transnational Companies, Global Capital and the Third World. In: Kiely/Marfleet (1998), pp. 45-66.

Kiely, Ray/Marfleet, Phil (Eds.) (1998) Globalisation and the Third World. London/New York. Routledge

Korten, David (1990) Getting to the $21^{\text {st }}$ Century. Voluntary Action and the Global Agenda. West Hartford. Kumarian Press.

Lechner, Frank J. (1989) Cultural Aspects of the World System. In: Robertson/White (2003), Vol. 4.

Lechner, Frank J. (1993) Global Fundamentalism. In: Lechner/Boli (2000), pp. 338-341.

Lechner, Frank J./Boli, John (Eds.) (2000) The Globalization Reader. Oxford. Blackwell.

Lévy, Pierre (1997) Collective Intelligence. New York/London. Plenum.

Lévy, Pierre (1998) Becoming Virtual. Reality in the Digital Age. New York/London. Plenum.

Lévy, Pierre (2001) Cyberculture. Minneapolis/London. University of Minnesota Press.

Luhmann, Niklas (1997a) Globalization or World Society: How to Conceive of Modern Society? In: International Review of Sociology, Vol. 7, No. 1, pp.67-79.

Luhmann, Niklas (1997b) Die Gesellschaft der Gesellschaft. Frankfurt/Main. Suhrkamp.

Marx, Karl (1867) Das Kapital. Kritik der politischen Ökonomie. Band 1: Der Produktionsprozeß des Kapitals. MEW, Vol. 23. Berlin. Dietz

Marx, Karl (1885) Das Kapital. Band 2: Der Zirkulationsprozeß des Kapitals. Berlin. Dietz. MEW, Vol. 24

Marx, Karl (1894) Das Kapital. Band 3: Der Gesamtprozeß der kapitalistischen Produktion. MEW, Vol. 25. Berlin. Dietz

Marx, Karl/Engels, Friedrich (1845/46) Die deutsche Ideologie. MEW, Vol. 3. Berlin. Dietz.

Marx, Karl/Engels, Friedrich (1848) Manifest der Kommunistischen Partei. Berlin. Dietz. MEW, Vol. 4. pp. 459-493.

Masini, Eleonora (1994) The Futures of Cultures: An Overview. In: UNESCO (1994), pp. 9-28.

Mbembe, Achille (2000) At the Edge of the World: Boundaries, Territoriality, and Sovereignty in Africa. In: Public Culture 12(1), pp259-284.

McChesney, Robert W. (1999) The New Global Media. In: Held/McGrew (1999), pp. 260-268.

Miyoshi, Masao (1998) "Globalization", Culture, and the University. In: Jameson/Miyoshi (1998), pp. 247-270.

Modelski, George (1972) Principles of World Politics. New York. Free Press.

Negri, Antonio/Hardt, Michael (2000) Empire. Cambridge/London. Harvard University Press.

Nicholson, Michael (1999) How Novel is Globalization? In: Shaw (1999a), pp. 23-34.

Ohmae, Kenichi (1995) The End of the Nation State. The Rise of Regional Economies. New York. Free Press.

Panitch, Leo (2001) Reflections of Strategy for Labor? In: Panitch, Leo et al. (Eds.) (2001) Socialist Register 2001: Working Classes, Global Realities. London. Merlin Press.

Pieterse, Jan Nederveen (1995) Globalization as Hybridization. In: Featherstone, Mike/Lash, Scott/Robertson, Roland (Eds.) (1995) Global Modernities. London. Sage. pp. 45-68.

Poster, Mark (1995) The Second Media Age. New York. Blackwell.

Poster, Mark (1996) Database as Discourse, or Electronic Interpellations. In: Heelas, Paul/Lash, Scott/Morris, Paul (Eds.) (1996)

Detraditionalization. Oxford. Blackwell. pp. 277-293.

Prigogine, llya (2000) The Networked Society. In: Journal of World Systems Research, Vol. 6, No. 3, pp. 892-898.

Raulet, Gérard (1988) Die neue Utopie. Die soziologische und philosophische Bedeutung der neuen Kommunikationstechnologien.

In: Frank, Manfred et al (Hrsg.) (1988) Die Frage nach dem Subjekt. Frankfurt/Main. Suhrkamp. S. 283-317

Ritzer, George (1993) The McDonaldization of Society. Thousand Oaks, CA. Pine Forge Press. 
Ritzer, George (2002) September 11, 2002. Mass murder and ist Roots in the symbolism of American consumer culture. In: Ritzer, George (Ed.) (2002) McDonaldization: The Reader. Thousand Oaks, CA. Pine Forge Press. pp. 199-212

Robertson, Roland (1992) Globalization: Global Theory and Global Culture. London. Sage.

Robertson, Roland (1994) Globalization or Glocalization? In: Source: The Journal of International Communication 1(1) (1994), pp. 33-52.

Robertson, Roland/White, Kathleen E. (Eds.) (2003) Globalization. Critical Concepts in Sociology. 6 Volumes. London/New York. Routledge.

Robertson, Roland/White, Kathleen E. (Eds.) (2003b) Globalization: An Overview. In: Robertson/White (2003), Vol. 1, pp. 1-44.

Rosenau, James N. (2003) Strategic Links in an Emergent Epoch. From People to Collevtivities and Back Again. In:

Robertson/White (2003), Vol. 1, pp. 191-222.

Rosenberg, Justin (2000) The Follies of Globalization Theory. London. Verso.

Rugman, Alan/Girod, Stéphane (2003) Retail Multinational and Globalization: The Evidence is Regional. In: European Management Journal, Vol. 21., No. 1, pp- 24-37.

Rycroft, Robert (2003) Self-Organizing Innovation Networks. Implications for Globalization. GW Center for the Study of Globalization Occasional Paper Series. CSGOP-03-07.

Sassen, Saskia (1991) The Global City. Princeton/New York. Princeton University Press.

Sassen, Saskia (1995) On Concentration and Centrality in the Global City. In: Know, Paul L-/Taylor, Peter J. (Eds.) (1995) World

Cities in a World-Systen, Cambridge. Cambridge University Press. pp. 63-75.

Sassen, Saskia (1998) Globalization and its Discontents. New York. New Press

Scholte, Jan Aart (1999) Globalization: Prospects for a Paradigm Shift. In: Shaw (1999a), pp. 9-22.

Shaw, Martin (Ed.) (1999a) Politics and Globalization. London. Routledge.

Shaw, Martin (1999b) Globality as a Revolutionary Transformation. In: Shaw (1999a), pp. 159-173.

Stehr, Nico (1994) Knowledge Societies. The Transformation of Labour, Property and Knowledge in Contemporary Society. London. Sage.

Subramani (1998) The End of Free States: On Transnationalization of Culture. In: Jameson/Miyoshi (1998), pp. 146-163.

Tabb, William K. (1997) Globalization Is An Issue, The Power of Capital Is The Issue. In: Monthly Review, Vol. 49, No. 2, pp. 20-30.

Therborn, Göran (2000) Globalizations: Dimensions, Historical Waves, Regional Effects, Normative Governance. In: International Sociology, Vol. 15, No. 2. pp. 151-179.

Therborn, Göran (2001) Globalization and Inequality. Issues of Conceptualization and Explanation. In: Soziale Welt, 52 (2001), pp. 449-476.

Thompson, John B. (1995) The Globalization of Communication. In: Held/McGrew (2003), pp. 246-259.

Tomlinson, John B. (1991) Cultural Imperialism. Baltimore. Johns Hopkins University Press.

UNESCO (Ed.) (1994) The Futures of Cultures. Paris. UNESCO Publishing.

United Nations Conference on Trade and Development (2002) (UNCTAD) World Investment Report 2002. New York. United Nations.

United Nations Development Programme (UNDP) (1999) Human Development Report 1999. New York/Oxford. Oxford University Press.

United Nations Development Programme (UNDP) (2002) Human Development Report 2002. New York/Oxford. Oxford University Press.

United Nations Development Programme (UNDP) (2003) Human Development Report 2003. New York/Oxford. Oxford University Press.

Urry, John (2003) Global Complexity. Cambridge/Oxford/Malden. Polity.

Venter, Dawid/Swart, Ignatius (2003) Anti-Globalization Organization as a Fourth Generation People's Movement. In:

Robertson/White (2003), Vol. 6, pp. 378-411

Voets, Henk J. L./Biggiero, Lugio (2000) Globalization and Self-Organization: the Consequences of Decentralization for Industrial Organization. In: International Review of Sociology. Vol. 10. No. 1, pp. 73-82.

Wagnleitner, Reinhold (1994) Coca-Colonization and the Cold War. Chapel Hill, NC. University of North Carolina Press.

Wallerstein, Immanuel (1974a) The modern world-system. Capitalist agriculture and the origins of the European world-economy in the sixteenth century. New York. Academic Press

Wallerstein, Immanuel (1974b) The Rise and Future Demise of the World Capitalist System. Concepts for Comparative Analysis. In: Comparative Studies in Society and History, 16(1974), pp. 387-415.

Wallerstein, Immanuel (1997a) The End of Certainties in the Social Sciences. Talk at the Seminar "Conceptos en Ciencias y Humanidades. Mexico City, Oct. 16, 1998. http://fbc.binghamton.edu/iwendcrt.htm

Wallerstein, Immanuel (1997b) Uncertainty and Creativity. Talk at Forum 2000: Concerns and Hopes on the Threshold of the New Millennium. Prague, Sept. 3-6, 1997. http://fbc.binghamton.edu/iwuncer.htm

Wang, Georgette (1997) Beyond Media Globalization: A Look at Cultural Integrity from a Policy Perspective. In: Telematics and Informatics, Vol. 14, No. 4, pp. 309-321.

Willke, Helmut (1995) Systemtheorie III: Steuerungstheorie. Stuttgart/Jena. Fischer.

Willke, Helmut (2002) Dystopia. Frankfurt/Main. Suhrkamp.

World Trade Organization (WTO) International Trade Statistics. Lausanne. WTO Publications.

Yeaoh, Brenda S.A. (1999) Global/Globalizing Cities. In: Progress in Human Geography, 23(4), pp. 607-616. 
Zeitlin, Morris (2001) Globalization: Part 2 - Its Radical and Marxist Critics. In: Nature, Society, and Thought, Vol. 14, No. 4, pp. 455488. 